\title{
Drowned Landscape: \\ An Architectural Reflection upon Indigenous Sensibilities in Curve Lake First Nation
}

\author{
By: \\ Chelsea Jacobs \\ A thesis submitted to the Faculty of Graduate and Postdoctoral Affairs in \\ partial fulfillment of the requirements for the Degree of \\ Master of Architecture \\ Carleton University \\ Ottawa, Ontario \\ (C)2019 \\ Chelsea Jacobs
}


"Water helped to remind us of our spirituality and it is still doing that. We are reminded that a lot of our very being, and our soul is water."

-Doug Williams of Curve Lake First Nation'

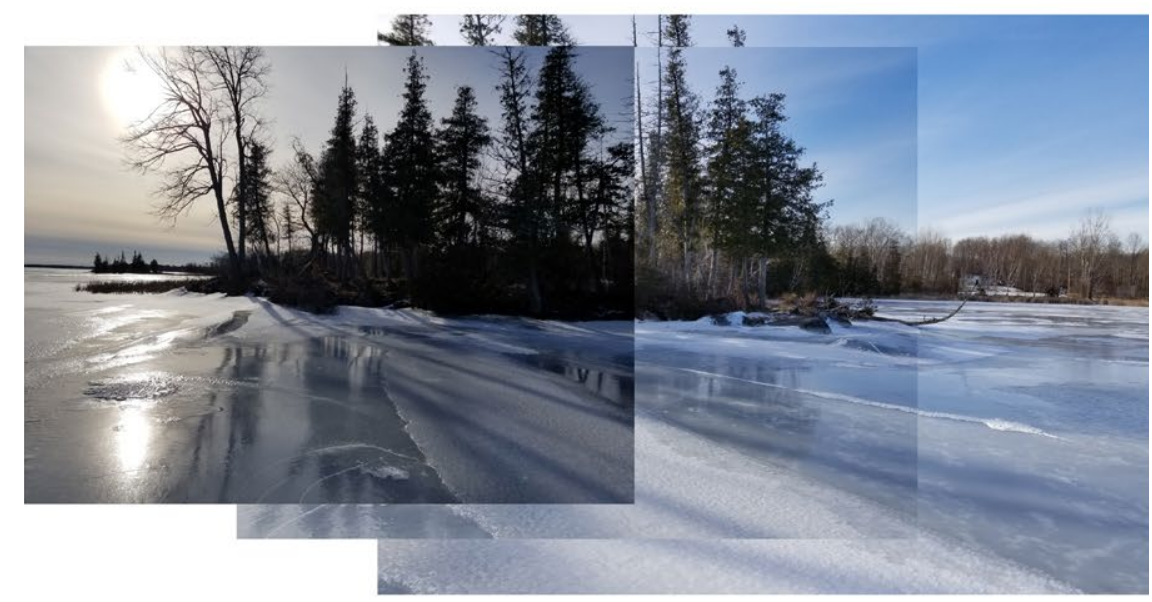

Figure 1: Photograph of Curve Lake Shoreline

1 Williams, Doug. Michi Saagiig Nishnaabeg: This Is Our Territory. ARP Books, 2018, pp. $109-110$ 


\section{Abstract}

Indigenous communities are a source of strength and resiliency for their members, who are collectively striving to overcome generations of hardships inflicted on their culture, languages, and ways of life. This thesis aims to develop an architectural design for the Curve Lake First Nation, which articulates the Anishnaabe sensibilities and encourages the longevity and strengthening of traditional cultural values.

Curve Lake First Nation, a peninsula located in Southern Ontario, is home to the Mississauga of the Anishnaabeg nation. After the Federal Government's flooding of Curve Lake for the Trent-Severn Waterway in 1844 and 1908 the community faced devastating impacts to the local ecosystem and the loss of another 700 acres of their land. This proposal aims to make use of the drowned land through water treatment, education, and storytelling with the emphasis upon landscape experience, providing the opportunity to facilitate landbased learning practices, encouraging the resurgence of cultural traditions, and outlooks.

There is a strong belief that there is a growing disconnect between our children and the land, a connection that is critical to the stewardship of the environment. This thesis asks, how does one create an architectural connection with the land and place whilst respecting the inherent indigenous sensibilities of the people of the place? 


\section{Acknowledgements}

I would like to sincerely thank my thesis advisor, Paul Kariouk, for his unwavering encouragement and guidance throughout this experience.

Additionally, thank you to my family and friends for their constant support throughout not only this thesis, but also my entire architectural education.

Finally I would like to thank the Community of Curve Lake First Nation for the inspiration behind this thesis - Miigwetch. 


\section{Table of Contents}

$\begin{array}{ll}\text { Abstract } & 3 \\ \text { Acknowledgements } & 4 \\ \text { Table of Contents } & 5 \\ \text { List of Figures } & 7 \\ \text { Definitions } & 9\end{array}$

Introduction 11

Chapter 1: Context

1.1 History 15

1.2 Population Demographics 24

1.3 CLFN Master Plan 24

Chapter 2: Indigenous Culture

2.1 Truth and Reconciliation Commission 31

2.2 Land-Based and Indigenous Pedagogy 33

2.3 Culture and Well-being of Indigenous Youth $\quad 37$

2.4 Significance of Study 39

\section{Chapter 3: Indigenous Architecture}

3.1 Indigenous Principals of Architecture 41

3.2 Approaches/Precedents 43

Approach 1: Community Engagement $\quad 44$

Approach 2: Indigenous Sensibilities 46

Approach 3: Contemporary/Traditional 48

Approach 4: Iconography $\quad 50$ 
Chapter 4: Design Proposal- Core Building

$\begin{array}{lll}4.1 & \text { Objectives } & 52 \\ 4.2 & \text { Parameters } & 56 \\ 4.3 & \text { Site } & 58 \\ 4.4 & \text { The Architecture } & 60 \\ 4.5 & \text { Spatial Organization } & 67 \\ 4.6 & \text { Environmental Regeneration / Respect } & 67\end{array}$

Chapter 5: Proposed Design- Land Markers

$\begin{array}{lll}5.1 & \text { Wild Rice Harvesting } & 76 \\ 5.2 & \text { Maple Syrup Harvesting } & 80 \\ 5.3 & \text { Fishing / Ice Fishing } & 83 \\ 5.4 & \text { Hunting } & 85 \\ 5.5 & \text { Crafts } & 87 \\ 5.6 & \text { Medicine Garden } & 89\end{array}$

$\begin{array}{ll}\text { Conclusion } & 92\end{array}$

References $\quad 95$

$\begin{array}{ll}\text { Appendix A: Population } & 101\end{array}$ 


\section{List of Figures}

Figure 1: Photograph of Curve Lake Shoreline

Figure 2: Preliminary Concept Sketch

Figure 3: Location of Curve Lake First Nation within Ontario, in relation to Ottawa and Toronto

Figure 4: Context Map of Curve Lake Showing nearby towns and cities

Figure 5: Pre-Confederation and Post-Confederation Treaties

"Canada's Historic Treaties, Contemporary Agreements (Made after 1973) and Locations of Canada's Existing First Nations Communities." Canada by Treaty: Negotiating Histories, University Of Toronto, 2017

Figure 6: Timeline of the Michi Saagiig and Curve Lake First Nation

Figure 7: Maps showing the negative effects of the Trent Severn Waterway flooding on the Wild Rice Beds

Figure 8: Van Paassen, Kevin. James Whetung Collects Wild Rice on Upper Chemong Lake in Ontario. Curve Lake First Nation, 2015.

Figure 9: Map of Curve Lake First Nation representing current conditions Figure 10: Curve Lake Elementary School

Figure 11: Community Centre

Figure 12: Church/Day Care

Figure 13: Band Office and Day Care

Figure 14: Mshkiigag Wetlands

Figure 15: Pow Wow Grounds

Figure 16: Henry's Gamiing

Figure 17: Pathway Between Henry's Gamiing and the Pow Wow Grounds Figure 18: Porcupine Day School, Encompass Architects. http://www. encompassarch.com

Figure 19: Indian Community School of Milwaukee. Antoine Predock Architect Projectshttp://www.predock.com/ICS/ics.html

Figure 20: Main Entrance to First Peoples House at the University of Victoria. Lehoux, Nick. "First Peoples House/Formline Architecture + Urbanism". Archdaily. https://www.archdaily.com/403556/first-peoples-house-formline-architecture-urbanism

Figure 21: Fond du Lac Tribal and Community College, aerial photograph, Google Earth

Figure 22: Photograph of Proposed Site - Lance Wood Park/Pow Wow 
Grounds

Figure 23: Site Plan

Figure 24: Physical Model of Site Plan

Figure 25: Site Plan of Proposed Sites and Interventions

Figure 26:"Curve Lake First Nation Land Tenure 2009." The Curve Lake

Comprehensive Plan, Curve Lake First Nation, 2009, p. 19.

Figure 27: Roadways and Pathways connected to Main Proposed Site

Figure 28: Conceptual Physical Model

Figure 29: Connection to Community Space/Pow Wow Grounds

Figure 30: Watercraft Access to Building

Figure 31: Orientation allows for natural ventilation

Figure 32: Orientation of the building takes advantage of natural daylighting strategies

Figure 33: Views of surrounding landscape and community features

Figure 34: Floor Plans of Core Building

Figure 35: Floor Plans of Core Building without Landscape

Representation

Figure 36: Detail of First Floor Plan

Figure 37: Section/Elevation (S-A) through Opening of the Core Building

Figure 38: Section (S-B) through Library and Elder Housing of Core

Building

Figure 39: Detail Section showing the minoomin interact with the building

Figure 40: Traditional Activities Calendar in Relation to Annual Water

Levels

Figure 41: Representation of Wild Rice Land-Marker

Figure 42: Representation of Maple Syrup Harvesting Land Marker

"The Boiling Off - Maple Syrup." History of the Ojibwa of the Curve Lake

Reserve and Surrounding Area: Volume 1, p. 102.

Figure 43: Representation of Fishing Land-Marker

"Canoes Returning" History of the Ojibwa of the Curve Lake Reserve and

Surrounding Area: Volume 1, p. 105

Figure 44: Representation of Hunting Land-Marker

"Hunting/Trapping" Curve Lake First Nation, Curve Lake First Nation,

Feb. 2015, www.facebook.com/curvelakefirstnation/photos.

Figure 45: Representation of Craft Land-Marker

"Crafting" Curve Lake First Nation, Curve Lake First Nation, Apr. 2015.

www.facebook.com/curvelakefirstnation/photos.

Figure 46: Representation of Medicine Garden Land-Marker 


\section{Definitions}

Anishnaabe: the autonym for a culturally and linguistically related group of Indigenous peoples within Canada and the United States. The translation of this name is "spontaneous man", and includes the Ojibwe, Algonquin, Ottawa, Potawatomi, Saulteaux, Nipissing, and Mississauga. ${ }^{1}$

Elders: Members of an Indigenous community who have a strong understanding of the history, traditional teachings, ceremonies, and healing practices of their culture. They have been chosen to be teachers to the young people, and give advice and guidance on issues that are personal or affect the whole community. ${ }^{2}$

Indian Band: a governing unit of Indians in Canada instituted by the Indian Act. ${ }^{3}$

Indian Status: a specific legal identity of an indigenous person in Canada based on the criteria determined in the Indian Act. ${ }^{4}$

Indigenous: Within Canada, the term refers to the First Nations, Métis, and Inuit peoples.

\footnotetext{
1"Native American Facts for Kids." Anishinabe Indian Fact Sheet, 2015, www.bigorrin.org/ anishinabe_kids.htm.

2“Elders." Deepening of Knowledge, University of Toronto, Apr. 26AD, 2018, www.oise.utoronto.ca/deepeningknowledge/Teacher_Resources/Curriculum_Resources_(by_subjects)/ Social_Sciences_and_Humanities/Elders.html.

3 "Bands." Indigenous Foundations, The University of British Columbia, 2009, indigenousfoundations.arts.ubc.ca/bands/.

4 "Indian Status." Indigenous Foundations, The University of British Columbia, 2009, indigenousfoundations.arts.ubc.ca/bands/.
} 
Reservation: A tract of land set aside under the Indian Act for the exclusive use of an Indian Band. ${ }^{5}$

Status Members: Members of the band with Indian Status.

5 "Reserves." Indigenous Foundations, The University of British Columbia, 2009, indigenousfoundations.arts.ubc.ca/bands/. 


\section{Introduction}

This thesis is a very personal project for myself as Curve Lake First Nation is my home, I grew up within the community and my passion for architecture, and the effect it has environmentally and socially, stems from my personal connection to the Anishnaabe culture. Growing up within my community, I was taught to have respect for the natural environment. This is something that has fundamentally defined how I perceive, and how I want to participate within the built landscape. My interest in architectural design has always emanated from the possibility to produce architecture that is symbolically and spatially significant to the Indigenous cultures. I desire to manipulate architectural design so as to work with the landscape and have a stronger sense of place and connection to the land. This sense of connection and respect has led me to choose Curve Lake First Nation as my site to explore how Indigenous cultures and worldviews can be represented within architectural design.

Indigenous architecture should represent the identity of its respective communities through the expression of their cultural and traditional values. It's about responding to the place, and resonating within the community through shared knowledge. Designing with Indigenous communities is about the voice of the people in the community, recognizing the inherent knowledge they hold of the land and how their culture informs their relationship with place.

It is important to recognize and respect the knowledge that is held within each particular community, and translate this knowledge into the architectural design. It is the stories and knowledge of the people 
that instill a project with significance for the entire community. In the past, those that designed architecture for Indigenous communities disregarded the knowledge of the people of the place, and instead the emphasis was on assimilation. Through the production of generic substandard housing and public buildings, the architecture designed for these culturally-rich communities impeded cultural values and life.

It is now time to listen and learn from our indigenous communities on how they would like to be represented, for the architecture of a community is a physical embodiment of the culture it represents and will have an effect on future generations. Thus, it is crucial to embolden architecture to play a role in the cultural preservation and development of the Indigenous community by facilitating and embodying cultural relevance.

This thesis aims to consider what Indigenous architecture is and apply it to a series of programs that are necessary within the community of Curve Lake First Nation. Current conditions within the reserve demonstrate a need for the development of a larger school program, water treatment facility, and elder housing. Each program is about the longevity of the community, providing the necessities of education, clean water, and housing in a sustainable and culturally significant way.

"Even as a cultural centre... we have a cultural centre and a library in Curve Lake and to me they are dead places. I think what is it that would make it alive ... really alive? Not a tourist attraction or a place for rich people to come and see Indian stuff, or read about Indians. We don't want to read books about Indians, we want to live it. People make a place alive. You don't see Nishnaabeg going to libraries or museums or galleries. Dead places, full of dead things. Certainly books and art are exciting, but they don't have the same life as people do. And the thing about water, water holds so much life."

- Alice Williams of Curve Lake First Nation ${ }^{6}$

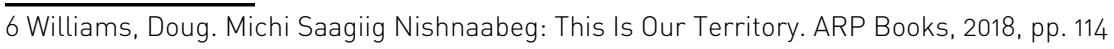


To reiterate, I believe what is being addressed in the above quote by Alice Williams is not necessarily about not inhabiting spaces such as museums and galleries, but that the core Anishinaabe values and traditions are based outside of such institutes, which are more about housing artifacts. It is about knowledge being passed on through experience and communication with our communities, and what is truly required within the community of Curve Lake is not a gallery or museum but a program that encourages connection and experience.

The proposed design, which is in response to the Master Plan outlined in Curve Lake First Nation's Capital Investment Requirements, will attempt to encourage a more culturally rich educational program for the school and community to embolden resilience in Indigenous youth and cultural sustainability within the community. Housing designed for elders, will aim to support the development of greater relations between the community and our indigenous teachers through strong ties to the school. The development of these programs will also address the issue of the limited availability of land within Curve Lake by building within the drowned landscape of the community, thus water will become the central feature that brings the various programs together.

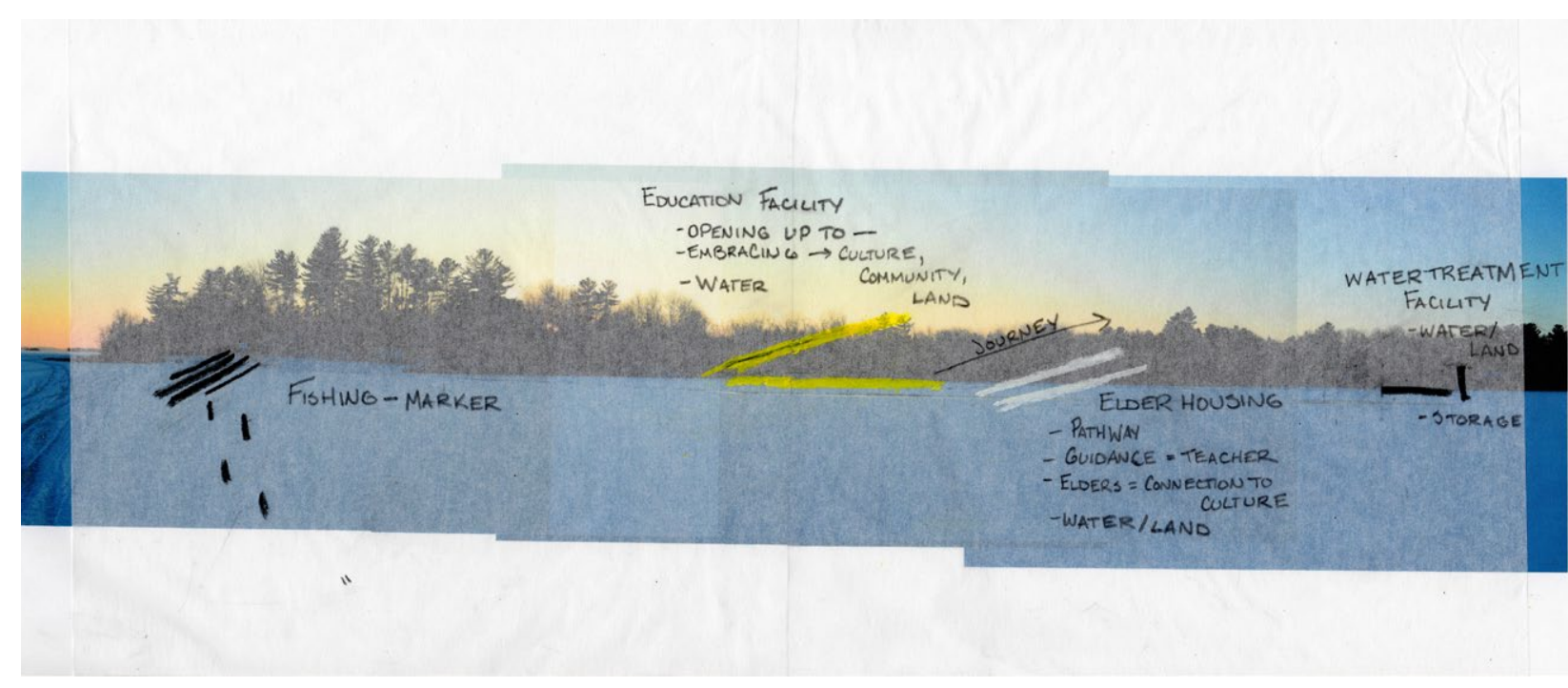

Figure 2: Preliminary concept sketch 


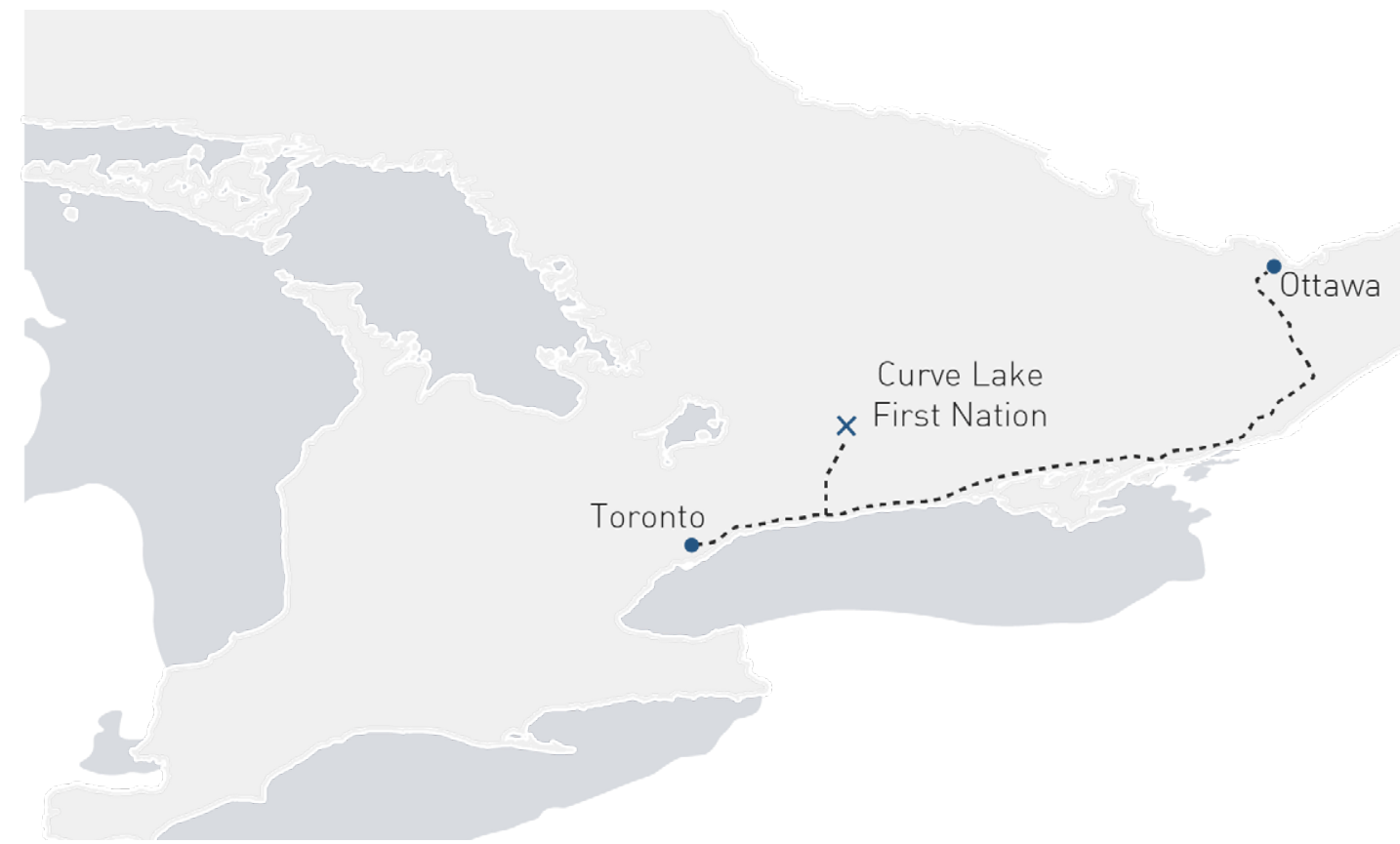

Figure 3: Location of Curve Lake First Nation in Ontario, in relation to Toronto and Ottawa 


\section{Chapter 1: Context}

Located in Central Ontario, Curve Lake First Nation is home to the Mississaugas of the Anishnaabeg Nation. The First Nation community consists of a mainland peninsula and a large island (Fox Island) situated on Buckhorn and Chemong Lake, making the total land base approximately 900 hectares $^{7}$. The community is located just $35 \mathrm{Km}$ North of Peterborough and $175 \mathrm{Km}$ Northeast of Toronto, it is centrally located between the major cities of Ottawa and Toronto.

\subsection{History of Curve Lake First nation}

The Mississaugas (Michi Saagiig) of the Anishnaabeg Nation are known as the "people who live at the mouths of rivers"; they are the people who fished the Atlantic salmon that swam up the St. Lawrence River and spawned in the rivers that flowed into Lake Ontario ${ }^{8}$. They are the people who harvested the wild rice (Minoomin) that grew in the lakes of their traditional territory. They were a people who travelled, moving depending on the season, within their territory. The Michi Saagiig Nishnaabeg's oral traditions state that their territory is the north shore of Lake Ontario and includes all the streams and rivers that run into it?. More specifically, it is the territory that spans from approximately Niagara Falls to the St. Lawrence River at the Eastern end of Lake Ontario ${ }^{10}$. Oral traditions say that the Michi Saagiig Nishnaabeg have lived in this territory since the Ice Age ${ }^{11}$, and the Anishnaabeg creation stories say they

7 "About Us." Curve Lake First Nation School, www.curvelakefirstnation.ca/about-us/. 8 Williams, Doug. Michi Saagiig Nishnaabeg: This Is Our Territory. ARP Books, 2018, pp. 29 $9 \mathrm{lbid}$. 10 Ibid..

$11 \mathrm{lbid}$. 


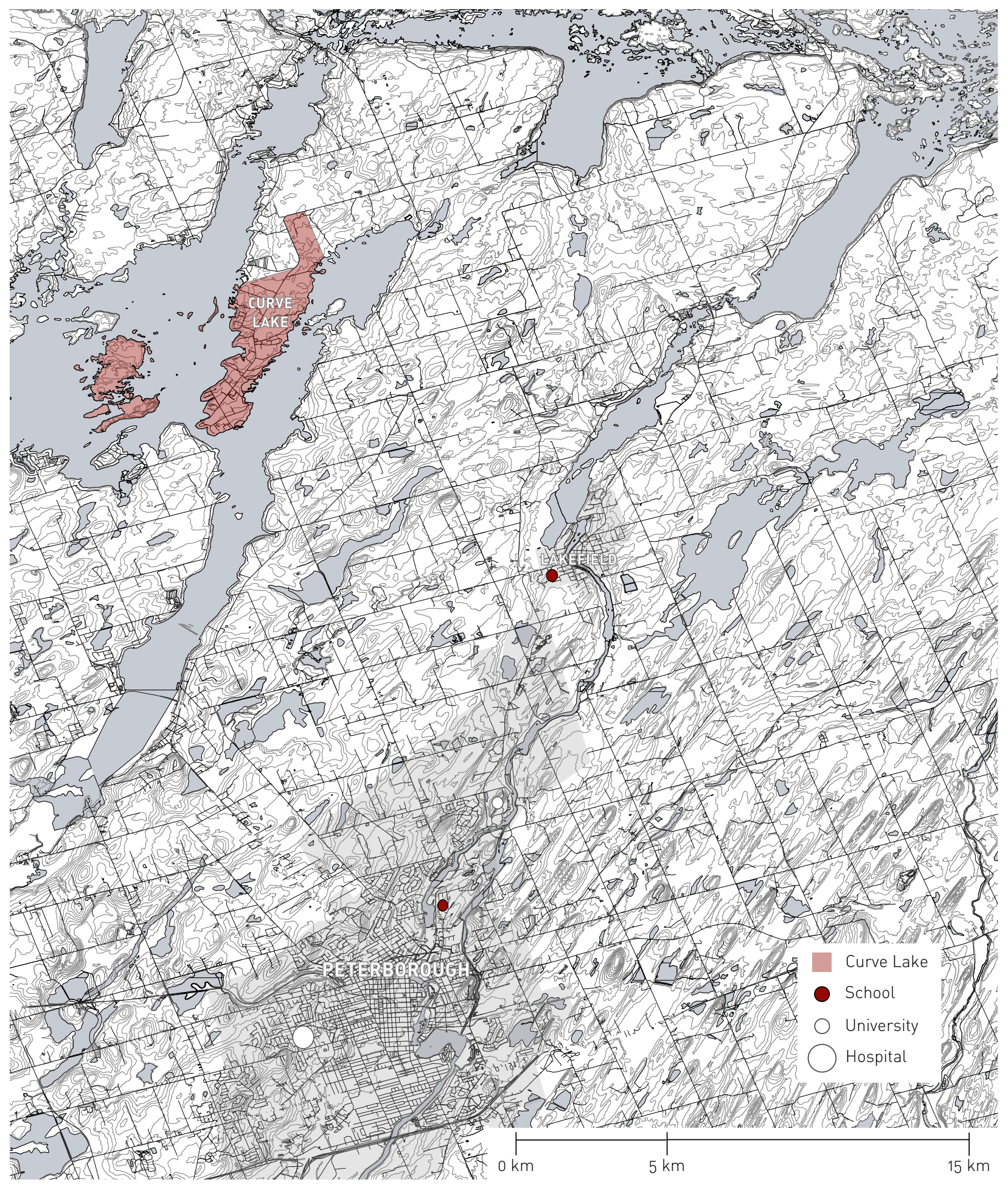

Figure 4: Context Map of Curve Lake First Nation showing connection to Peterborough and Lakefield 
have been on Turtle Island (North America) since time immemorial.

The formation of what is known as Curve Lake First Nation started in 1829, when a peninsula along Mud Lake was chosen by the Crown to establish the Mud Lake Settlement. It wasn't until 1889 that Mud Lake Settlement became an official reserve, and in 1964 the community officially changed its name to Curve Lake First Nation $\# 35 .^{12}$

Between 1781 and 1923, the Michi Saagiig Nishnaabeg were involved in eighteen treaties. The treaties that took place pre-confederation had maintained all First Nations' rights to hunting and harvesting within their surrendered traditional territory. However, in 1910 there were concerns with some of the treaties entered into during preconfederation, and it was discovered that not all the lands in Central Ontario were covered by treaties, which included the central lands of the province and lands on the north shore of Lake Ontario and below Lake Simcoe. ${ }^{13}$ Upon realizing this, the Federal and Provincial governments quickly progressed to terminate any land claim held by the Indigenous peoples of the territory, which included the Michi Saagiig Nishnaabeg. ${ }^{14}$

In 1923 Curve Lake First Nation and six other nations ${ }^{15}$ signed agreements with the Crown in the Williams Treaties, a treaty, which took away all hunting and harvesting rights of the seven First Nation communities involved. The Government forced the First Nations involved in the Williams Treaties to surrender all title to the land in question and any rights to harvesting (hunting, fishing, trapping, and gatheringl that had existed during the pre-confederation treaties. ${ }^{16}$ However, the First Nations involved in the treaties had not agreed to the surrendering of any hunting or harvesting rights on their traditional territory. The Williams Treaties are believed to be the only treaties in Ontario to have removed all rights to harvesting

12 "About Us." Curve Lake First Nation School, www.curvelakefirstnation.ca/about-us/. 13 "Upper Canada Land Surrenders and the Williams Treaties (1764-1862/1923)." Government of Canada; Indigenous and Northern Affairs Canada, 15 Feb. 2013, www.rcaanc-cirnac.gc.ca/ eng/1360941656761/1544619778887\#uc.

$14 \mathrm{lbid}$.

15 The other 6 Nations involved with the Williams Treaty include the Chippewas of Beausoleil, Georgina Island, and Rama, and the Mississaugas of Alderville, Hiawatha, and Scugog Island.

16 "Upper Canada Land Surrenders and the Williams Treaties (1764-1862/1923)." Government of Canada; Indigenous and Northern Affairs Canada, 15 Feb. 2013, www.rcaanc-cirnac.gc.ca/ eng/1360941656761/1544619778887\#uc. 
and hunting ${ }_{1}^{17}$ and for nearly a century the Williams Treaties First Nations were persecuted and prosecuted for any harvesting within their traditional territory. The 1923 Williams Treaty marked the cessation of nearly all the remaining Indigenous land in Ontario to the Crown, as the land in question was the last substantial portion of land in Southern Ontario unceded. ${ }^{18}$

In 1992 the seven Williams Treaties First Nations filed the Alderville Litigation against the Federal and Provincial Government. ${ }^{19}$ The litigation dealt with the disagreement of the making, terms, interpretation and implementation of the 1923 Treaties, and in 2018 a negotiated settlement was reached between the Williams Treaties First Nations and the Provincial and Federal Government. ${ }^{20}$ The settlement included financial compensation, recognition of treaty harvesting rights and an entitlement for each First Nation to add 11,000 acres to their reserve land-base.

17 Switzer, Maurice. "Williams Treaty Crown Concedes Some Hunting Rights." Anishinabek News, Dec. 2012, anishinabeknews.ca/wp-content/uploads/2013/04/2012-12.pdf.

18 "Upper Canada Land Surrenders and the Williams Treaties (1764-1862/1923)." Government of Canada; Indigenous and Northern Affairs Canada, 15 Feb. 2013, www.rcaanc-cirnac.gc.ca/ eng/1360941656761/1544619778887\#uc.

19 "Canada, Ontario and Williams Treaties First Nations Reach Negotiated Settlement Agreement for Alderville Litigation." Government of Canada, Canadian Environmental Assessment Agency, Northern Affairs Canada, 14 Sept. 2018, www.canada.ca/en/crown-indigenous-relations-northern-affairs/news/2018/09/canada-ontario-and-williams-treaties-first-nations-reach-negotiated-settlement-agreement-for-alderville-litigation.html. 20 lbid. 


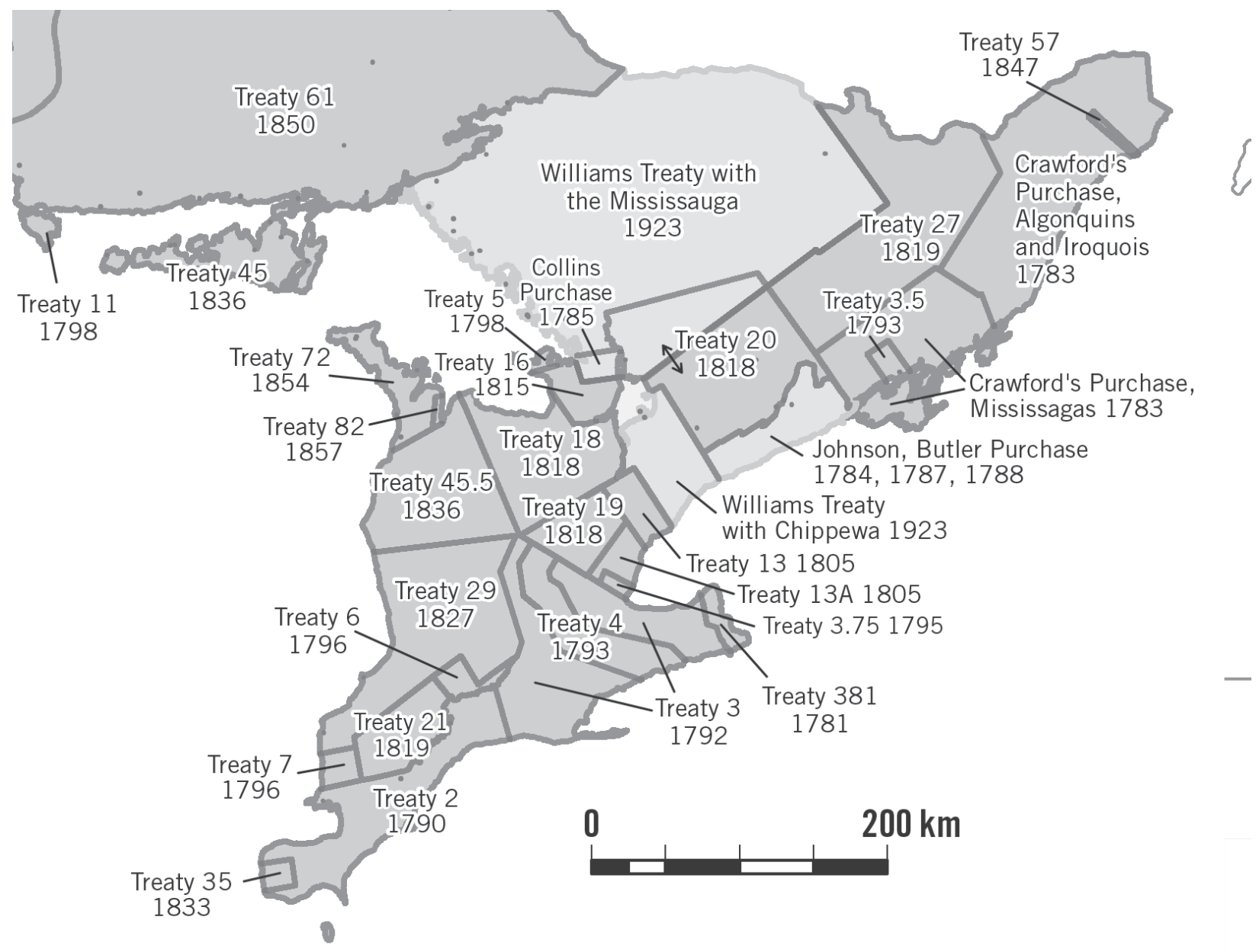

Figure 5: Pre-Confederation and Post-Confederation Treaties

“Canada's Historic Treaties, Contemporary Agreements (Made after 1973) and Locations of Canada's Existing First Nations Communities." Canada by Treaty: Negotiating Histories, University Of Toronto, 2017 


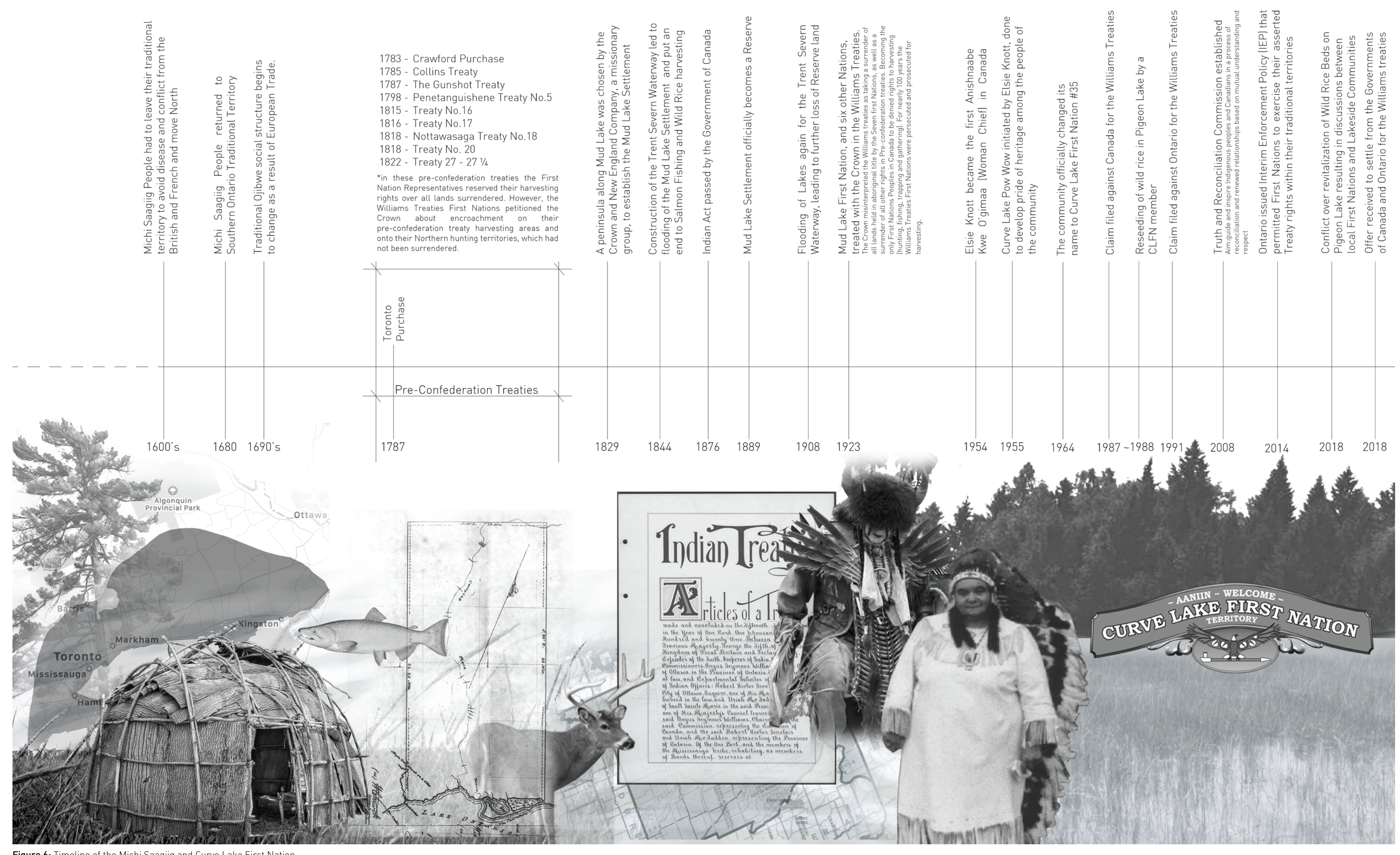


Shortly after the establishment of the Mud Lake Settlement in 1829, the community faced devastating impacts from the construction of the Trent Severn Waterway, a system that linked Lake Ontario with Lake Huron. ${ }^{21}$ Construction took place between 1833 and 1920 and involved the flooding of the lakes surrounding the First Nation reserve, both Chemong and Buckhorn Lake. ${ }^{22}$ Major flooding occurred within the reserve in 1844 and $1908,{ }^{23}$ which resulted in the loss of approximately 700 acres of the landmass. The construction of the waterway was undertaken to facilitate logging, milling, steam boating, grain handling and recreation. ${ }^{24}$ The flooding of the waterway and construction of locks and dams had damaging impacts on the local ecosystem as well, ending the migration of the Salmon and nearly wiping out the wild rice beds. ${ }^{25}$ Both of these were primary sources of food for the Michi Saagiig Nishnaabeg of Curve Lake First Nation. The impacts of the flooding continued to resonate negatively on the local ecosystem and lives of the First Nation community, as the flooding encouraged an increase in settlers and farmers in the area. Cottages built by the settler population were built with sewage systems that emptied into the lakes, farmers would use nutrients and chemicals on their fields that would run-off, and chemicals were sprayed in the lakes to kill weeds for swimming areas. ${ }^{26}$ These actions further disturbed the rice beds that once grew so thickly throughout the lakes and the fish and animal populations that resided there. ${ }^{27}$

\footnotetext{
21 Angus, J. A Respectable Ditch: a History of the Trent-Severn Waterway 1833-1920. McGill-Queens University Press, 1988, pp.xi

22 "Trent-Severn Waterway." The Canadian Encyclopedia, www.thecanadianencyclopedia.ca/ en/article/trent-severn-waterway.

23 Williams, Doug. Michi Saagiig Nishnaabeg: This Is Our Territory. ARP Books, 2018, pp. 82

24 "Trent-Severn Waterway." The Canadian Encyclopedia, www.thecanadianencyclopedia.ca/ en/article/trent-severn-waterway.

25 Williams, Doug. Michi Saagiig Nishnaabeg: This Is Our Territory. ARP Books, 2018, pp. 82. 26 Ibid.pp.83

27 lbid.
} 

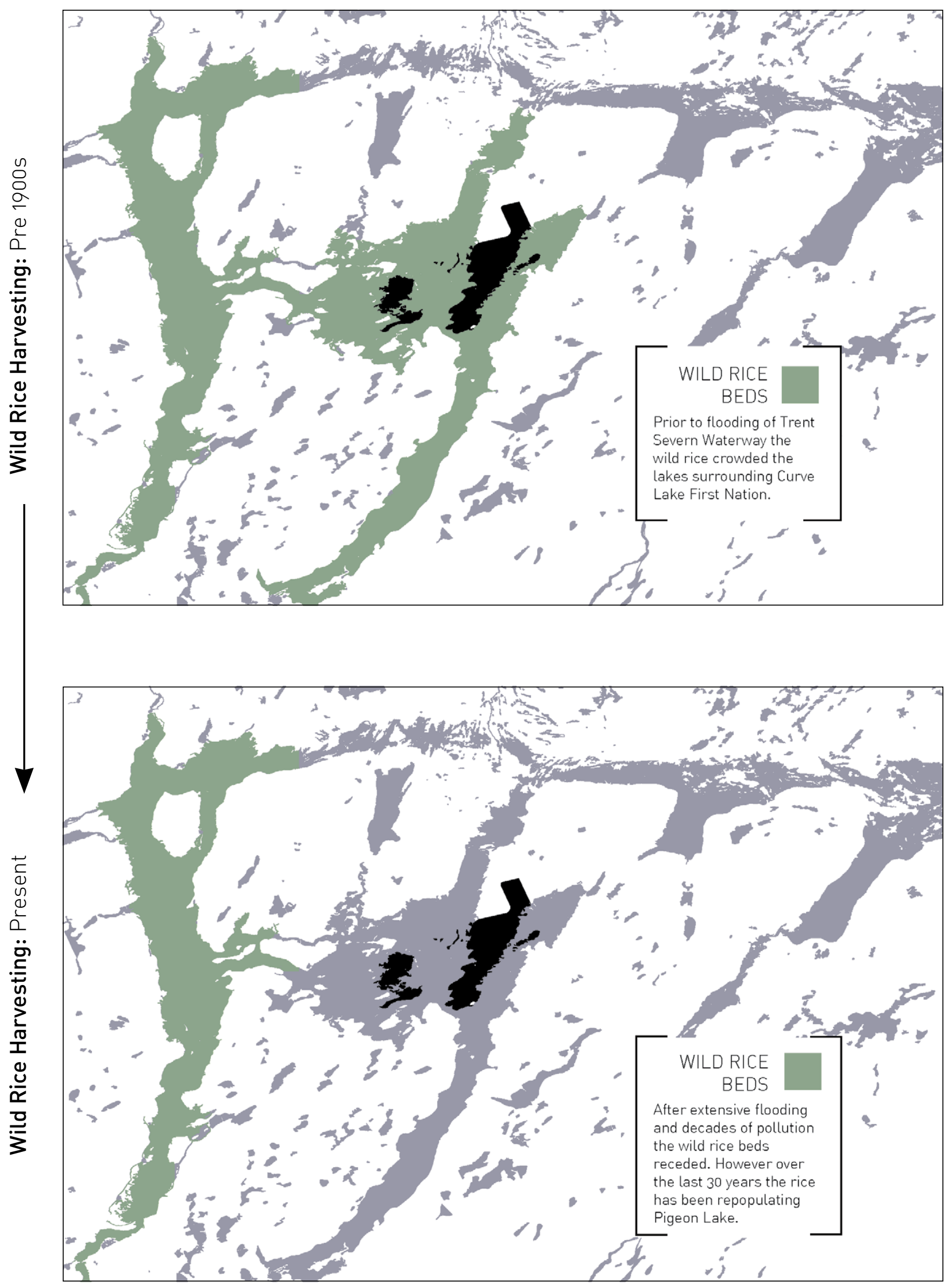

Figure 7: Maps showing the negative effects of the

Trent Severn Waterway flooding on the Wild Rice Beds 


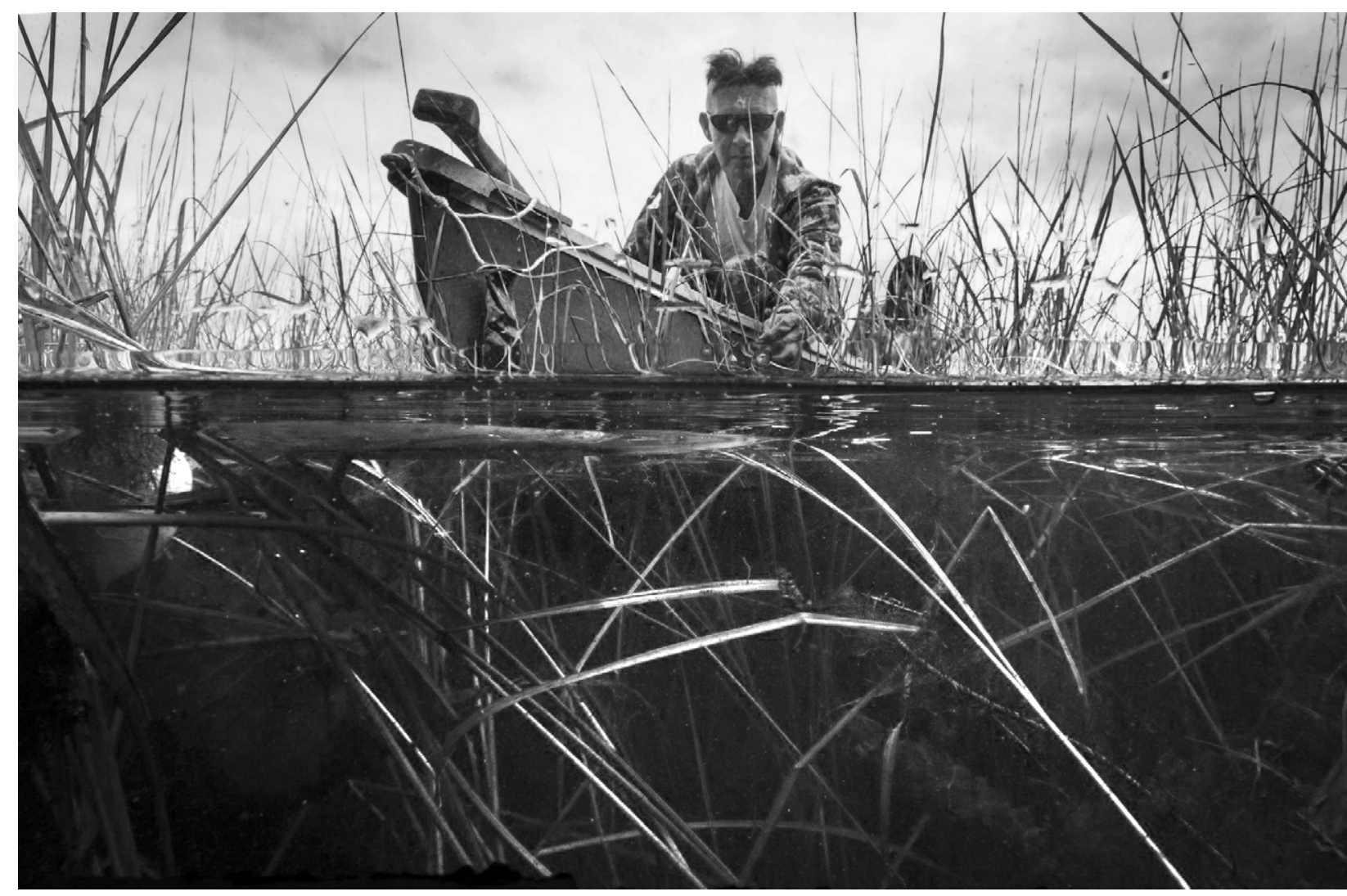

Figure 8: James Whetung Collects Wild Rice on Upper Chemong Lake

Van Paassen, Kevin. James Whetung Collects Wild Rice on Upper Chemong Lake in Ontario. Curve Lake First Nation, 2015. 


\subsection{Demographics of Curve Lake First Nation}

Over 1.6 million people in Canada identified as Indigenous in 2016, which is $4.9 \%$ of the national population. ${ }^{28}$ Since 2006 the Indigenous population of Canada has more than quadrupled, with a projection that the population will continue to grow to include 2.5 million people within the next 20 years. ${ }^{29}$ This continued growth has been recorded both on and off reserve, with a growth of $12.8 \%$ in onreserve populations and a $49.1 \%$ growth in off-reserve populations. ${ }^{30}$

These population trends are concurrent with that of Curve Lake First Nation, ${ }^{31}$ as the population shows an expected growth within the community corresponding to the nationwide population of indigenous peoples. These future population projections within Curve Lake are based on standard and historic trends and show an expected increase in all age categories. ${ }^{32}$ Future plans within the CLFN Capital Investment Requirements outline the need for future housing development, including the addition of a 115-unit subdivision, which would also greatly impact the population. Community needs were grounded on the population demographics of the First Nation community given that this expected increase in population would result in a rise on the demand of public service providers.

\subsection{Curve Lake First Nation Master Plan}

In 2011, Curve Lake First Nation released a document outlining the capital investment requirements, listing all potential projects within the community's development. Through community planning exercises during the 2000s, Curve Lake First Nation was able to determine which projects needed priority over the next 20 years. The projects listed in the document received particular attention due to health and safety concerns, service deficiencies, general maintenance or the useful life expectancy ending. ${ }^{33}$

28 Parrott, Zach. "Indigenous Peoples in Canada". The Canadian Encyclopedia, 07 September 2018, Historica Canada. https://www.thecanadianencyclopedia.ca/en/article/aboriginal-people. Accessed 28 December 2018.

29 lbid.

$30 \mathrm{lbid}$.

31 See Appendix A

32 Banks, Tammy. "Curve Lake First Nation Capital Investment Requirements." 19 Dec. 2011, pp.6

33 Ibid. pp. 3 
These projects include:

- Curve Lake Water Treatment Facility

- Parkland Development

- Senior Citizen Residence

- Daycare

- School Building Upgrades

-115 Unit Subdivision

- Health Centre Renovation and Expansion

- Road Repairs and Upgrades

Community needs were grounded on the expected population demographics of the First Nation community; the expected increase in population will result in a rise on the demand of public service buildings. The CLFN Capital Investment Requirements summarizes multiple projects important for the community to continue to function. A majority of the projects outlined in the document require maintenance to mend service deficiencies and increase life expectancy. Projects that require maintenance include roadways, the Health Centre, the Health and Family Services Building, and the Food Bank building. The Senior Citizen Residence has closed down since the release of the CLFN Capital Investment Requirements, the building remains and is in the process of being repurposed for a new program. A set of 2 new residential buildings have been built to accommodate the senior population instead, the requirement for seniors to be eligible for the homes include a medical need and limited income ${ }^{34}$. However, the new senior housing is insufficient for providing for the community's possible future needs for its increasing elderly population.

The day care program is another project that would require new construction, as the current buildings being used hinder the operation of the program and do not meet the needs of the children or staff. The current difficulties of the daycare program are that the students are spread across 3 separate buildings, with the kitchen and offices located in the main building. This requires a lot of travelling between buildings, and this is not efficient especially during poor weather. As well, there is no common area to allow the different age groups to come together ${ }^{35}$. The projected population

34 "Rental Applications - Housing Department." Curve Lake First Nation, www.curvelakefirstnation.ca/2018/07/03/rental-applications-housing-department/.

35 Banks, Tammy. "Curve Lake First Nation Capital Investment Requirements." 19 Dec. 2011, pp.20 


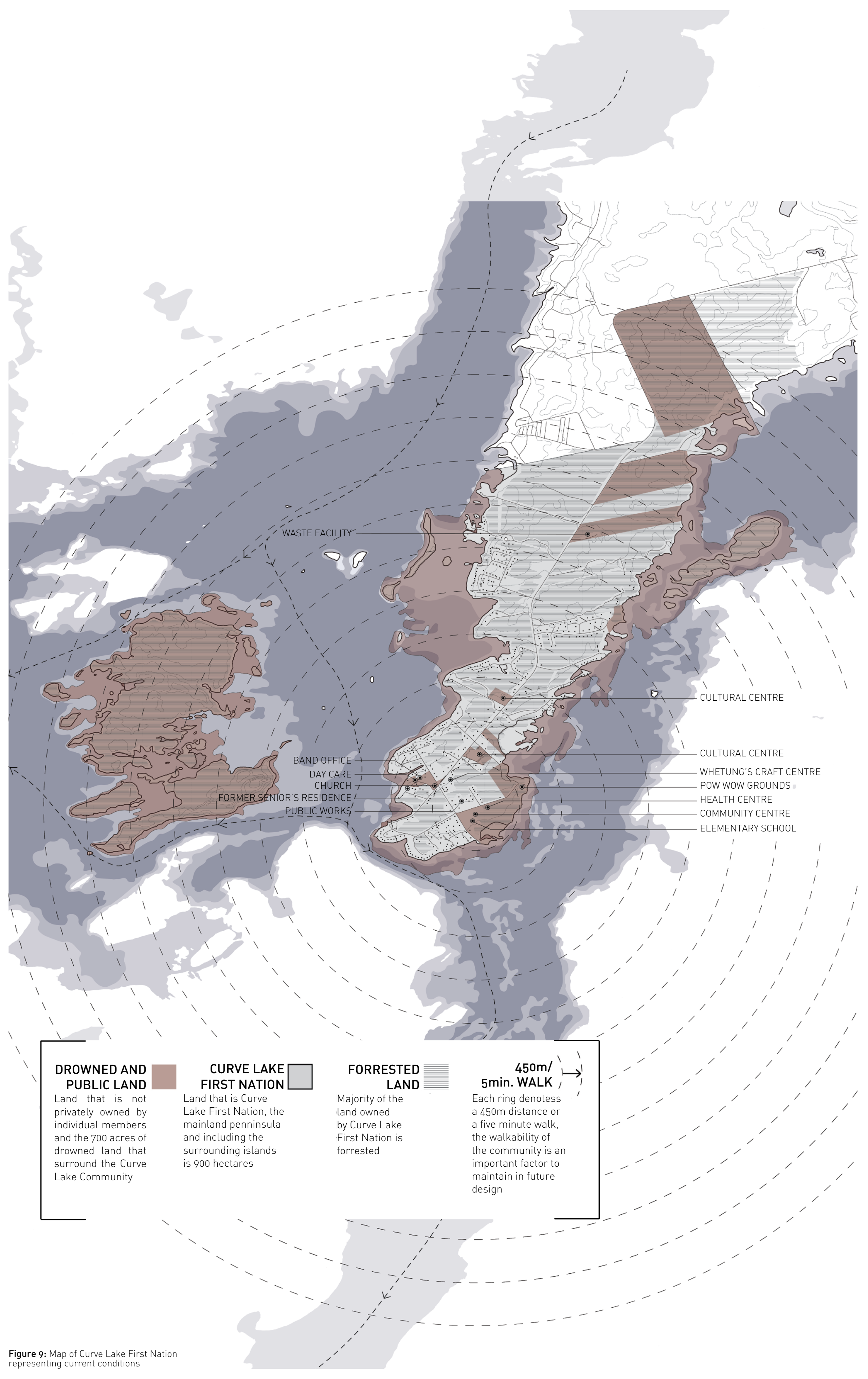


increase will also impact the daycare centre, as the facility will need to continue to grow to meet the population demographics. Although there is a decline in the national birthrates for non-indigenous communities, First Nation communities are the reverse. Curve Lake has an expected $32 \%$ increase in the $0-14$ age group over the next twenty years. ${ }^{36}$ The expected population growth of this particular age group will also have a significant impact on the Elementary school.

The Curve Lake First Nation Elementary School was built in 1981 and is $782 \mathrm{~m}^{2}$ and holds classes for kindergarten up to Grade 3. The building consists of 2 offices, 4 classrooms, a Library, gymnasium, student and staff washrooms, and a teacher's lounge and prep room. ${ }^{37}$ Based on the Master Plan, there is a needed expansion of the school, to not only accommodate a growing population but also to expand the school from Grade 3 to Grade 8 . There are numerous factors that encourage an expansion of the Curve Lake school program, one of the most important being the desire to increase the student's time in a curriculum that is related to their Anishnaabe culture and heritage. As well, the expansion will decrease the number of transitions the Curve Lake students face moving from school to school. Currently, the students move from Curve Lake Elementary School to the Lakefield District Public School for grades 4 to 8 and then to Thomas A. Stewart Secondary School in Peterborough for High School. The current capacity of the school is 104, which is based on 26 students per room. The enrolment of the school at the time of the master plan was 56 , but based on the projected population increase there is likely to be approximately a $24 \%$ increase in the primary age population. ${ }^{38}$ This will cause an increase in enrolment to 71 students, however with the proposed addition of a 115-unit subdivision there is a possibility of a further enrolment of 27 students putting the total at 98 , which is 6 students from full capacity. ${ }^{39}$

Another major concern within the community is that Curve Lake First Nation has had a long-term status of boil water advisories, an issue that has been occurring since well before $2005.4^{40}$ Boil water

36 Ibid. pp.19

37 Ibid pp.22

38 lbid. pp. 23

39 Ibid

40 Kovach, Joelle. “Cleaner Water Getting Closer for Curve Lake First Nation after Making Federal List." The Peterborough Examiner, 27 Jan. 2018, www.thepeterboroughexaminer. $\mathrm{com} /$ news-story/8175152-cleaner-water-getting-closer-for-curve-lake-first-nation-after- 
advisories are released weekly within the community and sometimes even daily, however the advisories are not always widespread, effecting different areas within the community at different times. ${ }^{41}$ The boil water advisory issues within Curve Lake First Nation are a result of the lack of a water treatment facility to supply clean drinking water to the entire community. Currently, a majority of the residents within the community are serviced by personal wells, and a portion of homes are serviced by a communal water system. It is estimated that the required treatment facility to service the entire community would cost roughly $\$ 25$ million, and this is just not feasible for the small community without federal funds..$^{42}$ In 2016, the Government set aside $\$ 1.8$ billion for water treatment facilities in reserves across Canada to be dispersed over a five-year period. ${ }^{43}$ Since this money has been designated for clean water on reserves, there have been 40 reserves that have been able to eliminate their water advisories. 44 Unfortunately, within the same time period that those 40 advisories were eliminated, 26 new reserves have received new long-term water advisory designations as they have had advisories in effect for more than a year. 45

Although a number of projects are critical to the sustainability of the community, projects that this thesis will focus on are the development and growth of the school program, as well as the construction of a water treatment facility and elder housing. All projects would involve new construction, and affect the population as a whole. However, this thesis will propose the projects incorporate cultural values within the design development, as opposed to the proposed developments in the Capital Investments Document that have not integrated this aspect into their designs.

making-federal-list/.

$41 \mathrm{lbid}$.

$42 \mathrm{lbid}$.

$43 \mathrm{lbid}$

$44 \mathrm{lbid}$.

$45 \mathrm{lbid}$. 

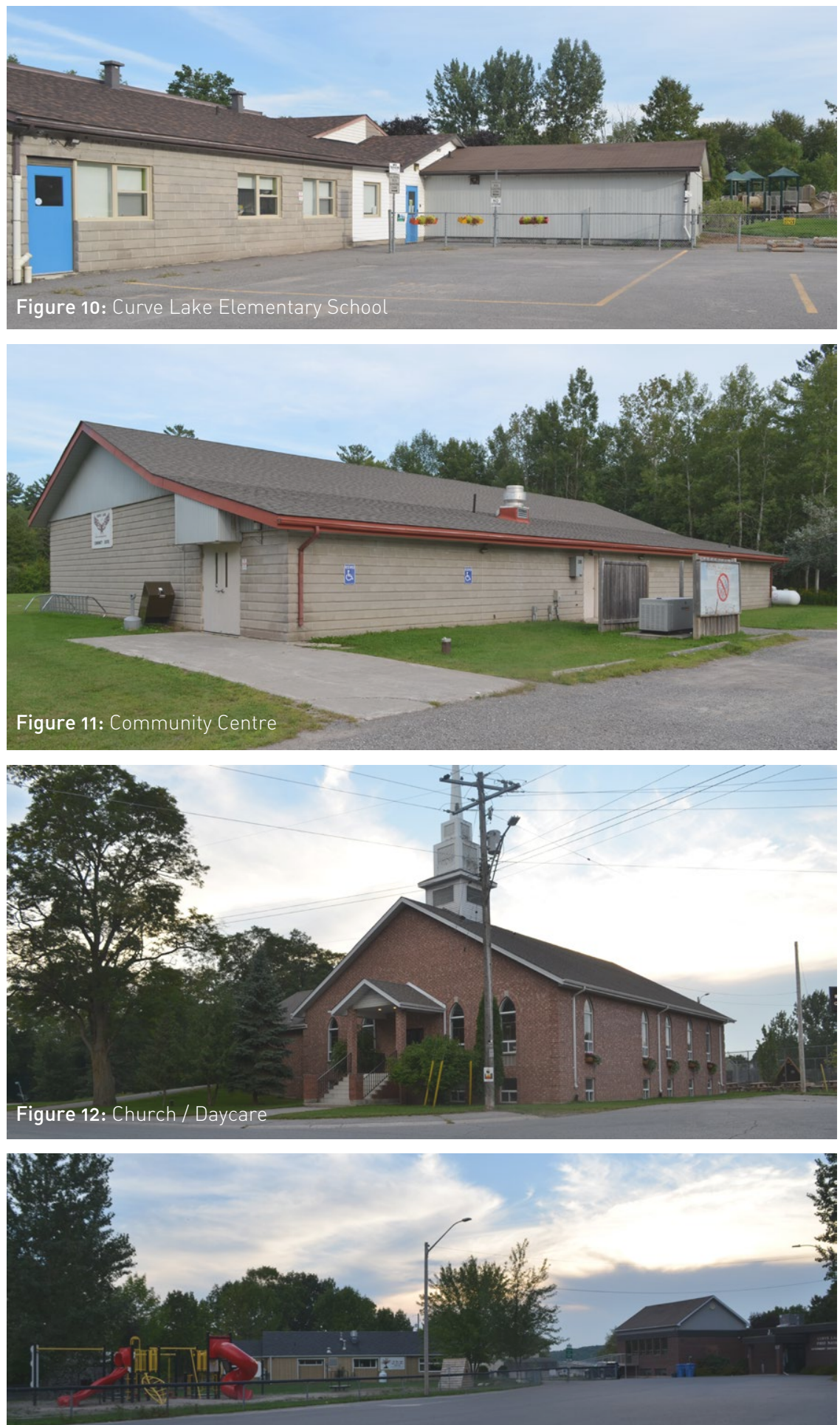

Figure 13: Band Office and Day Care 

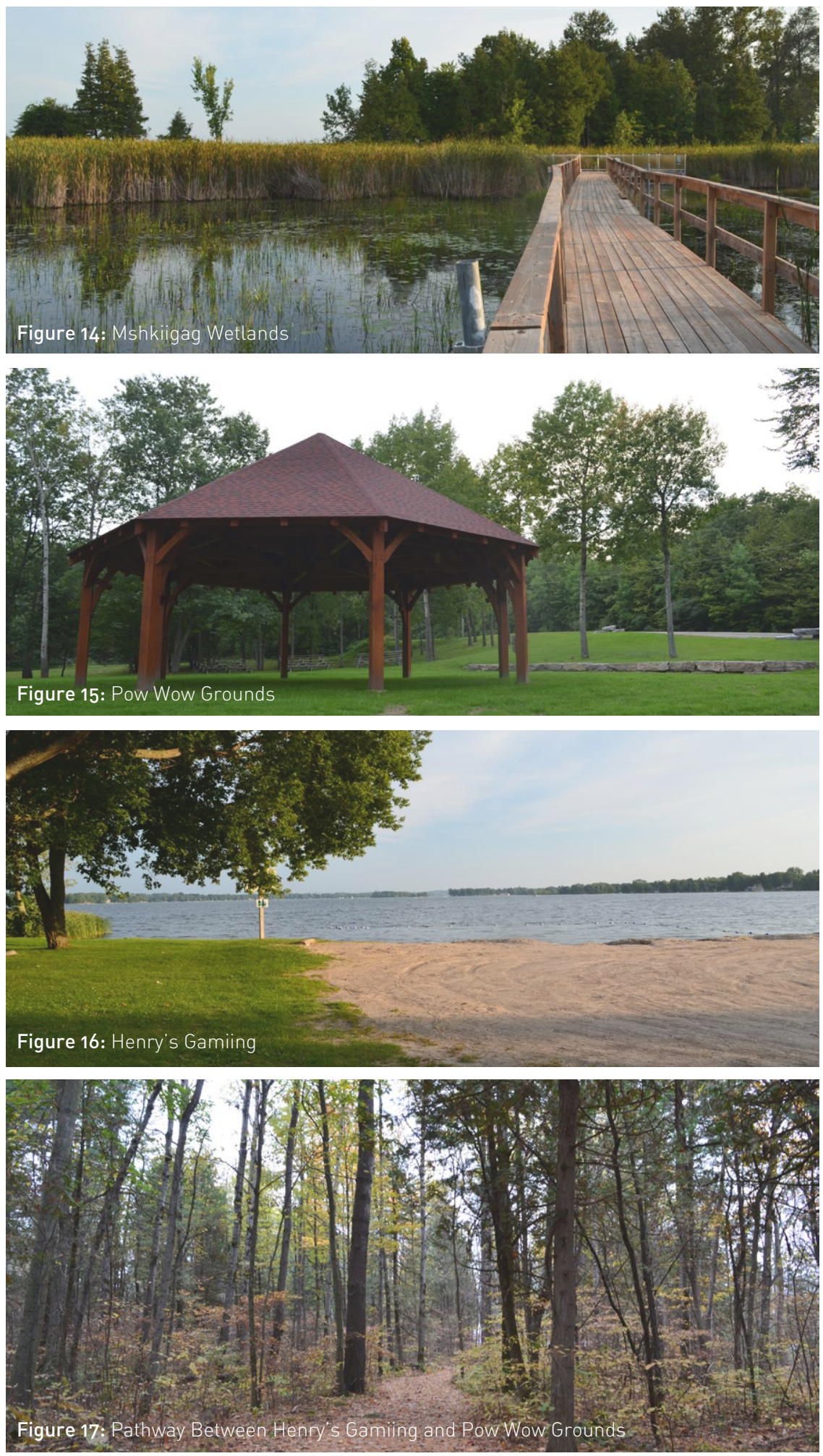


\section{Chapter 2: Indigenous Culture, Education, and Reconciliation}

\subsection{Truth and Reconciliation}

The Truth and Reconciliation Commission (TRC) was implemented as part of the Indian Residential Schools Settlement that began in 2007; it was the largest class action settlement in Canadian history. ${ }^{46}$ The purpose of the TRC was to aid in the reconciliation with former Residential School survivors, their families, their communities and all Canadians, to provide an opportunity for those affected directly and indirectly by Residential Schools to share their stories and experiences, and begin the process of healing. ${ }^{47}$ As part of the TRC's final report in 2015 there were 94 Calls to Action that are integral to the process of Reconciliation within Canada and they include issues such as Child Welfare, Education, Health, Language and Culture, Justice, and Education and Reconciliation. ${ }^{48}$

"Education is what got us into this mess - the use of education at least in terms of residential schools - but education is the key to reconciliation."

- Justice Murray Sinclair, the Chair of the Indian Residential Schools Truth and Reconciliation Commission ${ }^{49}$

46. "Truth and Reconciliation Commission of Canada." Government of Canada; Indigenous and Northern Affairs Canada, Northern Affairs Canada, 19 Feb. 2019, www.rcaanc-cirnac. gc.ca/eng/1450124405592/1529106060525.

47 Restoule, Jean-Paul and Chaw-win-is. "Old ways are the new way forward: How Indigenous pedagogy can benefit everyone", the Canadian Commission for UNESCO's IdeaLab, Oct. 2017, pp.7

48 "Delivering on Truth and Reconciliation Commission Calls to Action." Government of Canada; Indigenous and Northern Affairs Canada, Government of Canada, 25 Oct. 2018, www. aadnc-aandc.gc.ca/eng/1524494530110/1524494579700.

49 Restoule, Jean-Paul and Chaw-win-is. "Old ways are the new way forward: How Indig- 
The TRC and the Calls to Action speak to all Canadians, and are providing the inspiration to institutions and individuals to commit to the contribution of Reconciliation with Indigenous peoples. ${ }^{50}$ Educational institutions in particular are looking for ways to contribute to Reconciliation efforts, helping empower Indigenous communities. ${ }^{51}$ The Calls to Action outlined in the Truth and Reconciliation Commission's final report in 2015 include numerous recommendations for Canadian Public Schools to include Indigenous histories within the curriculum and encourage a better understanding of Indigenous cultures, peoples, worldviews and knowledge..$^{22}$ There is optimism that the restoration of Indigenous pedagogies can play a vital role in the reconciliation process.

enous pedagogy can benefit everyone", the Canadian Commission for UNESCO's IdeaLab, Oct. 2017, pp.8

50 Restoule, Jean-Paul and Chaw-win-is. "Old ways are the new way forward: How Indigenous pedagogy can benefit everyone", the Canadian Commission for UNESCO's IdeaLab, Oct. 2017, pp.8

$51 \mathrm{lbid}$.

52 lbid. 


\subsection{Indigenous Pedagogy}

Indigenous pedagogy is grounded in place-based connections, which have fundamentally formed Indigenous spiritual, communal, and economic traditions. ${ }^{53}$ Land based teachings are the root of Indigenous knowledge; through interaction with the landscape one is able to form an understanding and connection with the local land and ecosystems, as well as an understanding of one's place within that network. The local ecologies within which we live, have collectively taught Indigenous peoples how to live relative to the land, thus developing a much broader form of literacy and comprehension that is intrinsically distinct from that of conventional Western literacy. ${ }^{54}$ Place and community define indigenous pedagogy and literacy - both embody a web of relationships that are tied to a specific ecological context ${ }^{55}$ and are based on the accumulation of teachings that have been handed down through generations consisting of shared experiences and knowledge. ${ }^{56}$ The knowledge handed down is specific to communities and nations, pulling from the land, ceremonies, language, elders, families, and community members. ${ }^{57}$ Passing on knowledge through experience that informs one, "where, when, and how to live on the land, with the benefits both immediate and long term, both personal and communal". ${ }^{8}$

"The long-term ecological history of the land is a cloth woven from the threads of stories and ceremonies provided by many different members of the community." - Dr. Marie Battiste 59

53 Hare, Jan. "To 'Know Papers': Aboriginal Perspectives on Literacy." Portraits of Literacy Across Families, Communities, and Schools: Intersections and Tensions, Routledge, 2005. pp. 246.

54 lbid. pp. 244

55 Battiste, Marie. Indigenous Knowledge and Pedagogy in First Nations Education: a Literature Review with Recommendations. Indian and Northern Affairs, 2002, p. 14

56 Battiste, Marie. "The Struggle and Renaissance of Indigenous Knowledge in Eurocentric Education." Indigenous Knowledge and Education: Site of Struggle, Strength, and Survivance, Harvard Education Review, 2008, p. 87.

57 Hare, Jan. "'They Tell a Story and Theres Meaning behind That Story': Indigenous Knowledge and Young Indigenous Childrens Literacy Learning." Journal of Early Childhood Literacy, vol. 12, no. 4, 2011, doi:10.1177/1468798411417378, pp.408.

58 Hare, Jan. "To 'Know Papers': Aboriginal Perspectives on Literacy." Portraits of Literacy Across Families, Communities, and Schools : Intersections and Tensions, Routledge, 2005. pp. 246.

59 Ibid. pp.19 
Indigenous pedagogy is present in ways of knowing and learning expressed through dialogue and sharing circles, in participant observation, experiential learning, ceremony, and storytelling ${ }^{60}$. Central to imparting Indigenous knowledge are the oral traditions prevalent within the culture. Storytelling, a vital component of Indigenous pedagogy, is not only a form of entertainment, but when listened to carefully it can provide maps, genealogy, history, science, politics, and philosophy ${ }^{61}$.

"Storying is a crucial component of understanding one's place in the past in order to be in the present...land informs pedagogy through storied relationships that are etched into the essence of every rock, tree, seed, animal, pathway and waterway in relation to the Aboriginal people who have existed on the land since time immemorial" -Sandra Styres ${ }^{62}$

Listeners understand stories individually; depending at what point an individual is within their life and which experiences they have had, the stories are interpreted differently. Each story has multiple ways of being told and thereafter understood, having different effects during each iteration. There is knowledge gained in each telling, by both the listener and the teller. Traditional stories are rich, and help in the development of oral, written and listening skills, as well as also encouraging compassion and personal affirmations. ${ }^{63}$ Indigenous knowledge is structured by the symbolic, verbal, and unconscious orders of the indigenous language, meaning language and culture are interconnected, ${ }^{64}$ with language informing indigenous knowledge and worldviews.

\section{"Aboriginal people make sense of their world through}

60 lbid. pp. 18

61 Restoule, Jean-Paul and Chaw-win-is. "Old ways are the new way forward: How Indigenous pedagogy can benefit everyone", the Canadian Commission for UNESCO's IdeaLab, Oct. 2017, pp.15

62 Styres, Sandra D. "Land as First Teacher: a Philosophical Journeying." Reflective Practice, vol. 12, no. 6, 2011, pp. 717-731., doi:10.1080/14623943.2011.601083. pp. 721 63 Restoule, Jean-Paul and Chaw-win-is. "Old ways are the new way forward: How Indigenous pedagogy can benefit everyone", the Canadian Commission for UNESCO's IdeaLab, Oct. 2017, pp. 15

64 Battiste, Marie. Indigenous Knowledge and Pedagogy in First Nations Education: a Literature Review with Recommendations. Indian and Northern Affairs, 2002, pp. 17 
their relationships with living things, with animals, plants, and people, and the natural environment. Instead of written protocols, literacy, for the Anishinaabe and other Aboriginal people across Canada, is located in symbolic systems that are deeply encoded across many dimensions of their environment. They knew where to hunt by land markers, and when to harvest crops by weather and time indicators. It is helpful to think of this rich knowledge as a form of literacy because it is imbued with a sense of reading what is written over the land. " 65

Indigenous pedagogy is community oriented - the whole community is a place of learning, which in turn garners social responsibility, and respect and awareness for others. ${ }^{66}$ The focus on community has to do with relations, the foundation of all indigenous teachings - how we relate to our environment and to the web of connections that form our surroundings. This outlook has informed the core values of Indigenous culture, to have respect for the land through environmental stewardship, a responsibility highly regarded by Indigenous communities. It is important to have a mutual relationship with the land, one which is about respect and knowledge, for the land is our teacher and provider.

"It means breaking out of the walls of schools in order to learn from the community and from the land. In traditional Indigenous education, we learned from our environment. The plants, the animals, the land, the sky are all potential teachers and careful observation of phenomena and relationships within the whole system is a vital source of knowledge. We also learn from community. "67

The 'Calls to Action' outlined within the Truth and Reconciliation Commission's Final Report of 2015 include several recommendations

65 Hare, Jan. "To 'Know Papers': Aboriginal Perspectives on Literacy." Portraits of Literacy Across Families, Communities, and Schools : Intersections and Tensions, Routledge, 2005. pp. 247

66 Restoule, Jean-Paul and Chaw-win-is. "Old ways are the new way forward: How Indigenous pedagogy can benefit everyone", the Canadian Commission for UNESCO's IdeaLab, Oct. 2017, pp.13

67 Ibid. pp.12 
for the inclusion of Indigenous histories, cultures and knowledge within the Canadian Public School curriculum. ${ }^{68}$ The inclusion of such recommendations, would not only have a positive impact on both indigenous and non-indigenous students, but it would also encourage learning from the land in deep and respectful ways, fostering a connection to the environment that recognizes our mutual reliance - a connection which is currently impaired.

"Approaches to education today need to include Aboriginal people's connection to the natural world as a legitimate text from which to learn alongside the print traditions learned in school, particularly as we attempt to define new traditions of living with the land. "69

Indigenous populations within Canada continue to grow significantly faster than the rest of the country's population. Almost half of the total Canadian Indigenous population was under the age of 24 in $2011^{70}$. Because of this statistic it is critical that Indigenous pedagogies and knowledge are incorporated into the modern education system. As a way to not only increase the sustainability of the Indigenous culture but to also provide Indigenous youth a chance to embrace their culture within an educational institution in a valuable way that encourages one to recognize their personal and cultural value, the incorporation of Indigenous pedagogy could largely benefit the whole of the Indigenous community in terms of resiliency and wellbeing.

68 Restoule, Jean-Paul and Chaw-win-is. "Old ways are the new way forward: How Indigenous pedagogy can benefit everyone", the Canadian Commission for UNESCO's IdeaLab, Oct. 2017, pp.8

69 Hare, Jan. "To 'Know Papers': Aboriginal Perspectives on Literacy." Portraits of Literacy Across Families, Communities, and Schools : Intersections and Tensions, Routledge, 2005. pp. 256

70 "Aboriginal Peoples in Canada: First Nations People, Métis and Inuit." Statistics Canada: Canada's National Statistical Agency, 25 July 2018, www12.statcan.gc.ca/nhs-enm/2011/assa/99-011-x/99-011-x2011001-eng.cfm. 


\subsection{Culture and the Wellbeing of Indigenous Youth}

The culture of indigenous peoples in Canada has been repetitively disrupted and diminished, resulting in trauma as a consequence to health epidemics, forced relocation, cultural colonization, and genocide. ${ }^{71}$ From these events, there are continued and palpable impacts. Although the memories of these events will never fade, an increase in wellbeing and resiliency among indigenous communities, and especially indigenous youth, has been attributed to positive affiliation and engagement with one's culture. $^{72}$ Identifying with one's culture allows for the answering of crucial questions such as "who am I?" "Who are we as a people?" and "where am I going?". ${ }^{73}$

"Collective/cultural memory helps individuals find their place in larger temporal and social contexts and situates them as actors in their community and in the world"74

Personal cultural affiliation and a sense of belonging factors into how one relates to the world around them. For Indigenous youth, this translates to their ability to locate themselves in a larger shared context and history. ${ }^{75}$ It ensures that they are able to see and appreciate cultural values which are beyond themselves or their family, and which embody historical traditions. ${ }^{76}$ There is a sense of grounding, self-worth, social connectedness, belonging, and purpose tied to cultural awareness - all of which are critical aspects to one's wellbeing. ${ }^{77}$ Developing a strong cultural identity is an imperative undertaking for Indigenous youth, as well as other ethnic minority young people, who face obstacles such as discrimination, racism, and prejudice. ${ }^{78}$

"Having a strong cultural identity can provide Indigenous

71 Wexler, Lisa. "The Importance of Identity, History, and Culture in the Wellbeing of Indigenous Youth." The Journal of the History of Childhood and Youth, vol. 2, no. 2, 2009, pp. 267-276., doi:10.1353/hcy.0.0055. pp. 267 72 lbid.

73 lbid pp.268

74 lbid. pp.270

$75 \mathrm{lbid}$.

76 Ibid.

$77 \mathrm{lbid}$.

78 lbid. pp.269 
young people with a historically grounded, stabilizing way to understand their people's and their own past and the present. By developing a strong cultural identity, Indigenous youth can craft renditions of themselves that have shared and personal continuity and which can then contribute to a shared and individual future" 79

The integration of Indigenous knowledge into the Canadian Public School curriculum would result in communities feeling authentic, connected, and prepared as a result of having the opportunity to learn about Indigenous knowledge and culture. ${ }^{80}$ Having an affiliation and connection to culture has proven to contribute to the restoration of healthy communities, combatting racism, and improving social relations. ${ }^{81}$ Positive cultural affiliation within educational institutions goes beyond cultural sustainability; it's about cultivating identity and encouraging a sense of well-being within Indigenous communities, connecting to the land, and honouring language and recognizing the right to autonomy. ${ }^{82}$

"The racism inherent in the system drains students of their capacity for achievement in all aspects of their lives. It is time to change the educational outcomes for Aboriginal youth by fully integrating their knowledge and heritage into an educational system that values and respects Indigenous ways of knowing and allows Aboriginal students to embrace and celebrate who they are instead of making them doubt themselves." 83

79 Ibid. pp.273

80 Battiste, Marie. Indigenous Knowledge and Pedagogy in First Nations Education: a Literature Review with Recommendations. Indian and Northern Affairs, 2002, pp. 29

81 Restoule, Jean-Paul and Chaw-win-is. "Old ways are the new way forward: How Indigenous pedagogy can benefit everyone", the Canadian Commission for UNESCO's IdeaLab, Oct. 2017, pp.7

82 Toulouse, Pamela. "What Matters in Indigenous Education: Implementing a Vision Committed to Holism, Diversity and Engagement." What Matters in Indigenous Education: Implementing a Vision Committed to Holism, Diversity and Engagement, People for Education, Mar. 2016, peopleforeducation.ca/report/what-matters-in-indigenous-education/. 83 Battiste, Marie. Indigenous Knowledge and Pedagogy in First Nations Education: a Literature Review with Recommendations. Indian and Northern Affairs, 2002, pp. 28 


\subsection{Significance of Study}

The development of the Truth and Reconciliation Committee and the Calls to Action that were introduced have led to the inclusion and awareness of the importance of Indigenous pedagogies, knowledge, and histories within the Canadian Public School system. As this awareness rises, how to include Indigenous knowledge, experience, and knowing within mainstream curriculum becomes a more sought after approach as we move towards Reconciliation.

"Indigenous people have always adopted and adapted to new ways of doing things, new materials, new technologies, new knowledge, if it encouraged people to live well. But these new ways are incorporated within ethics and values that come from long-term relationship to land and community." 84

The quote above recognizes that this inclusion of Indigenous knowledge is not about completely returning to traditional ways of knowing and living, but about recognizing the value in the Indigenous approach to education. While it is stated that there is a knowledge to be gained from performing traditional indigenous activities, the idea is not to turn away from "Western" technology - the focus is upon acknowledging the Indigenous worldview and embracing it. Indigenous knowledge includes an understanding of the network that defines our environment, the honouring of languages and community values, and the development of resiliency and well being among Indigenous peoples living within a broader Global community.

There is importance in creating a space for Indigenous peoples that honours the Indigenous culture and the land it belongs to, connecting to community values. A space that facilitates Indigenous pedagogy within the traditional western educational institutions, allowing students to proudly walk within both worlds, honouring their Indigenous culture while also persisting within the westernized

84 Restoule, Jean-Paul and Chaw-win-is. "Old ways are the new way forward: How Indigenous pedagogy can benefit everyone", the Canadian Commission for UNESCO's IdeaLab, Oct. 2017, pp.10 
society that dominates. The incorporation of aspects such as the facilitation of cultural affiliation into architectural design can have a significantly beneficial impact upon Indigenous communities like Curve Lake First Nation. Through an empowerment of cultural values, this architectural gesture - implemented into institutions such as educational facilities and community spaces - could have a profound influence for the Indigenous communities of Canada. Instead of disregarding Indigenous worldviews and teachings, by not recognizing their value to their respective communities and not including Indigenous communities within the design process, these elements could become defining values of design development. Consequently, we should be encouraging the decolonization of our education system when these design solutions are applied to educational institutes, which is what has been proposed within this thesis. Thus, empowering Indigenous youth, while simultaneously effecting non-indigenous peoples' worldview on issues such as environmental stewardship, is an issue crucial to all people. 


\section{Chapter 3: Indigenous Architecture}

\subsection{Indigenous Principles of Architecture}

There are multiple Indigenous cultures within Canada and some, including the Anishinaabeg, have traditional philosophies behind Indigenous design that are deeply rooted in the Seven Generations methodology. Designing for seven generations is a planning concept that involves accounting for the future and the past in design development. "The knowledge of the past informs the present and, together, it builds a vision towards the future." ${ }^{85}$ It is not only about designing for the future of Indigenous people but all living entities, those who are regarded as "life-bringers": water, trees, wetlands, all plants and animals, everything that allows for our survival. ${ }^{86}$ The indigenous worldview is steeped in respect, respect for each other and for the environment. It's about recognizing that we are all connected and to be thankful for our mother the earth. The Indigenous communities are stewards of the land, and these values and beliefs should be expressed in all design development.

Designing with Indigenous communities is about the voice of the people in the community, recognizing the inherent knowledge they hold of the land and how their culture informs their relationship with place. An essential outlook one must have when designing for Indigenous communities is collaboration between community members and professionals. It is important to recognize and respect

85 Jojola, Ted. "Indigenous Planning: Towards a Seven Generation Model." Reclaiming Indigenous Planning, McGill-Queens University Press, 2013, pp.452

86 Cardinal, Douglas. "Chapter 9: Cultural Identity and Architecture." Our Voices: Indigeneity and Architecture, ORO Editions, 2018, pp. 96 
the knowledge that is held within each particular community, and translate this knowledge into the architectural design. It is the stories and knowledge of the people that instill a project with significance for the entire community. In the past, those that designed architecture for Indigenous communities disregarded the knowledge of the people of the place, the focus was on assimilation. It is now time to listen and learn from our Indigenous communities on how they would like to be represented, for the architecture of a community has the potential to be a physical embodiment of the culture it represents and will have an effect on future generations. Allowing for architecture to play a role in the cultural preservation and development of the indigenous community is critical.

"Architects have a responsibility to ensure that their architectural statements truly reflect the culture of each community. It is through the bringing together of different architectural voices of Indigeneity that we are able to affect global change for our communities. It is time that colonial nations acknowledge that it is no longer acceptable for design to be done without us or for us, but by us."

- Douglas Cardinal ${ }^{87}$

Giving voice to Indigenous peoples in the development of spatial planning and design within their communities allows the reassertion of autonomy and the development of contemporary architectural languages that speaks to the people of the place. The use of architecture within Indigenous communities should play a role in the community's aim to maintain cultural values and traditions, speaking to the history and knowledge of the past and towards the future members of the community and the environment.

For the architecture to speak to Indigenous values, there are design features that represent the communities' connection to place and land. Environmental respect should be represented within architectural design through sustainable features, aspects that would work towards the regeneration of the land. Passive features

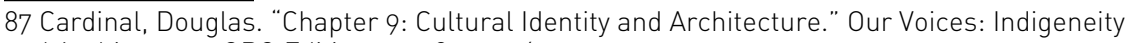
and Architecture, ORO Editions, 2018, pp. 96 
such as natural ventilation, heating, and cooling, solar power, rainwater harvesting, wind power, etc. show respect for the land through thoughtful interventions. This connection and respect to the land so prevalent in the culture should also be represented through site specificity, a feature that facilitates the inclusion of sustainable

features, as well as honours the distinct landscape that defines the design process.

\subsection{Approaches/Precedents}

As Indigenous architecture becomes more prevalent within the Architecture community, there have been multiple approaches by both Indigenous and non-Indigenous architects on how to design an architecture that speaks to its respective community. It is important to reflect on how culturally significant architecture is produced through various approaches, as will be explored in the following four precedents. Each precedent stands as an example of a potential solution or technique through which to approach the design process for Indigenous communities. Although each of the 4 precedents represent multiple architectural methodologies, each project embodies a singular primary design approach, which is summarized below. 


\section{Approach 1: Community Engagement}

\section{Porcupine Day school}

Location: Pine Ridge Reservation, South Dakota

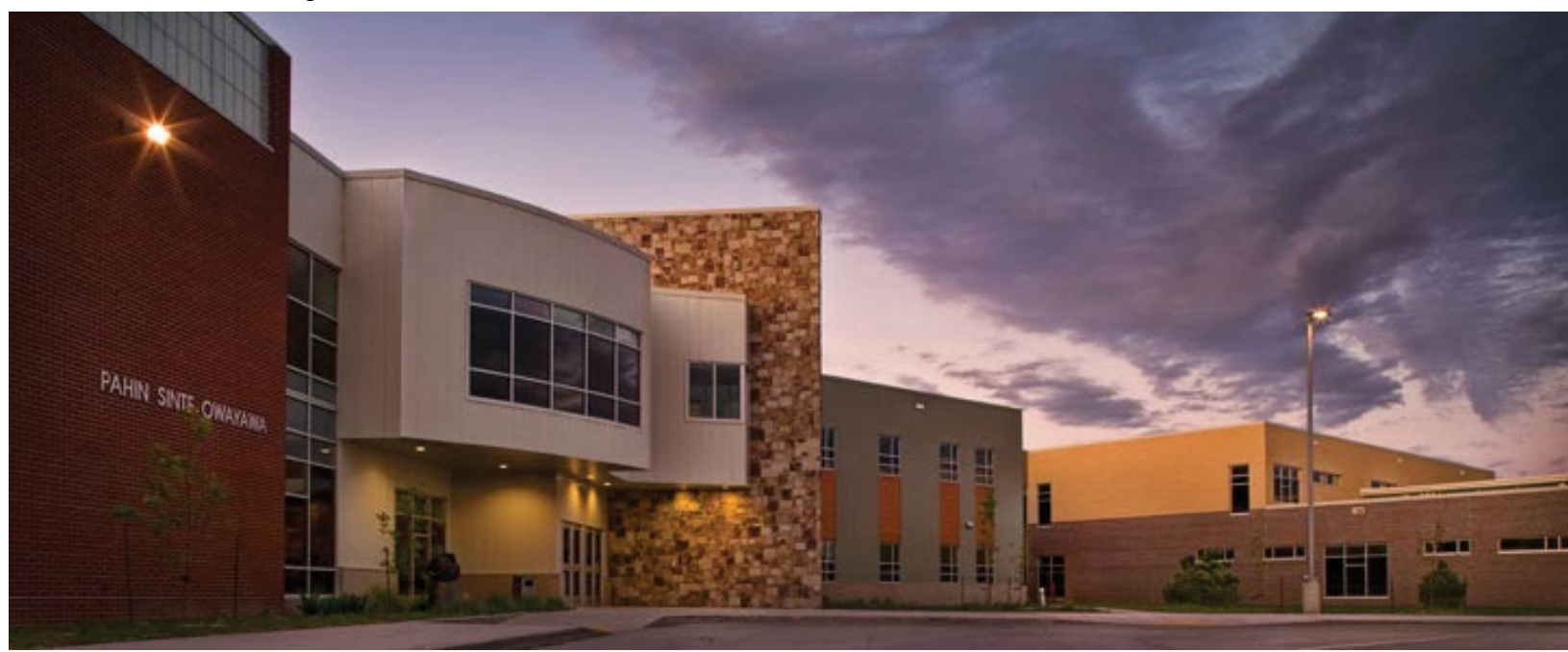

Figure 18: Main Entrance of the Porcupine Day School

Porcupine Day School, Encompass Architects. http://www.encompassarch.com

\section{Program:}

- School for Kindergarten to Grade 8 (serves 300 students)

- 72,000 Sq. Ft.

\section{Design Features:}

- Strong Community involvement in design process

- Designed classrooms in "learning pod" organization to avoid the overwhelming feel of the new size of the school for the students ${ }^{88}$

- Each "pod" has 3 classrooms organized around a central multifunctional classroom space

\section{Positives:}

- Community:

88 Eagle Bull, Tammy. "Chapter 19: Designing to Express Community Values: A Community School in South Dakota." Our Voices: Indigeneity and Architecture, ORO Editions, 2018, pp.187 
- Community involvement was a crucial step within the design process; workshops were held with the school administration, staff, parents, community members, and the children ${ }^{89}$

- Culture:

- References to culture are found in material details, such as in floor and brickwork pattern

- Colour Palette was chosen to pay homage to the surrounding landscape ${ }^{90}$

- Sustainability:

- LEED Silver designation

- Site:

- Building was situated within the hillside, as a sign of respect to the land by not trying to overcome it but instead work with it ${ }^{91}$

Negatives:

- Site:

- From the perspective of the site plan, the School appears disconnected from the community, with no clear visual connection to its other parts.

\section{Analysis:}

The design of the Porcupine Day School is successful because of its strong connection with the community. Encompass Architects ensured the community was an integral part of the initial design phase, understanding the cultural and programmatic needs of the community. Cultural aspects were then embedded within the design, with the architect avoiding the use of overt symbolism.

The layout of the program creates a comforting environment that doesn't overwhelm the students by the size of the new school. Dividing the building into learning pods allows smaller "communities" to develop within the overall population of the school. 


\section{Approach 2: Indigenous Sensibilities and Experiential Approach}

\section{Indian Community School of Milwaukee}

Location: Milwaukee, Wisconsin

Architect: Antoine Predock Architect and Chris Cornelius (Indigenous

Architect), 2007

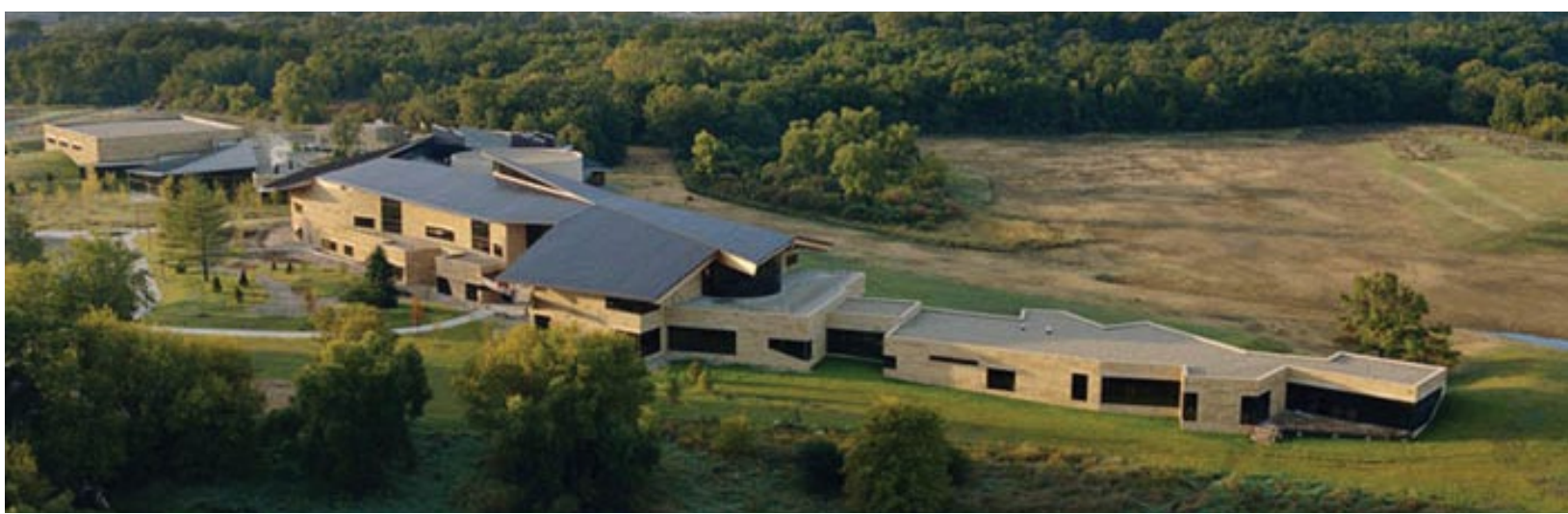

Figure 19: Indian School of Milwaukee

Indian Community School of Milwaukee. Antoine Predock Architect Projects http://www. predock.com/ICS/ics.html

\section{Program:}

- School for Kindergarten to Grade 8

- Community Centre

- 50,000 Sq. Ft.

\section{Design Features:}

- Strong visuals to exterior, bringing the outside to the interior

- Program based around features of the site, responding to landscape features, snaking throughout the site ${ }^{92}$

- Cultural symbols integrated into the details of the building, rather than just murals, to highlight that they are integral

- Architect Chris Cornelius chose to design a building that highlighted Indigenous sensibilities, rather than using iconography 93

- Respect to place and culture visible in the details, such as the

92 Malnar, Joy Monice., and Frank Vodvarka. New Architecture on Indigenous Lands. University of Minnesota Press, 2013.pp.95 93 lbid. pp. 98 
beams in the main entrance which represents the migrating patterns of local animals ${ }^{94}$

\section{Positives:}

- Culture:

- The design embraces the students' connection to the land both symbolically and physically

- Community:

- Multiple site visits were conducted with students, board members, and community members, which helped the designers understand the cultural connection the land has to the Indigenous communities ${ }^{95}$

- Site

- Programs respond to the landscape conditions to define programmatic layout, and ensure the preservation of existing landscape features

\section{Negatives:}

- Site

- From a Site plan perspective the School and community centre appears separated from the community, with no strong visual connection back to other community areas.

\section{Analysis:}

The design of the Indian School of Milwaukee is successful because it is related to the site, responding to local conditions and the culture that is embedded in the area. As the program is designed to provide schooling to children from various Indigenous groups, the strongest cultural factor is how the building and program are able to strengthen the connection between the student and the land.

Impressively, the architecture is able to appear recognizably immersed in Indigenous culture and principles without resorting to stereotypical symbolism and imagery. The connection to the culture is much more experiential and follows Indigenous sensibilities of connecting to the land.

$94 \mathrm{lbid}$. pp.95

95 Indian Community School, Antoine Predock Architects, www.predock.com/ICS/ics.html. 


\section{Approach 3: Contemporary Approach to Traditional Architecture}

\section{First Peoples House, University of Victoria}

Location: Victoria, British Columbia

Architect: Alfred Waugh (Indigenous Architect), 2009

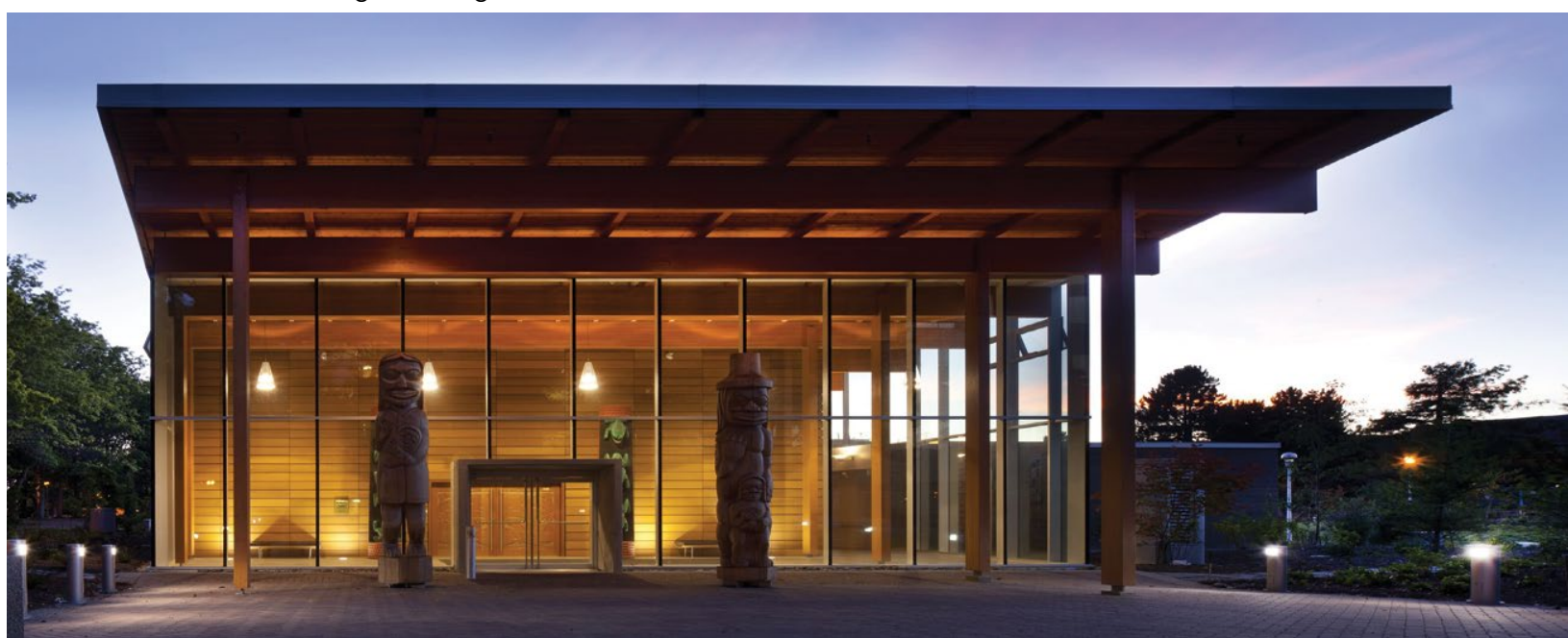

Figure 20: Main Entrance to First Peoples House at the University of Victoria

Lehoux, Nick. "First Peoples House/Formline Architecture + Urbanism". Archdaily. https://

www.archdaily.com/403556/first-peoples-house-formline-architecture-urbanism

\section{Program:}

- Houses the Indigenous Graduate Student Union

- Includes: classrooms, offices, study spaces, ceremonial space and lounges for elders and students

- 12,500 Sq. Ft.

\section{Design Features:}

- "Place of culture, honour, and spirit"96

- Place to learn about First Nations' Culture

\section{Positives:}

- Culture:

- Design draws on traditions of the Coast Salish, as well as being influenced by other surrounding coastal First

96 Malnar, Joy Monice., and Frank Vodvarka. New Architecture on Indigenous Lands. University of Minnesota Press, 2013.pp. 74 
Nations 97

- Spaces For Elders And Ceremonial Space

- Sustainability:

- LEED Gold Certification

- Waterfall and storm-water retention pond

- Reintroduction of indigenous plants, that are low maintenance, into the landscape design

- Passive cooling, fresh-air earth loop, regionally sourced materials

- Inspired by the Coast Salish Longhouse, whose traditional building techniques allow for maximum sunlight, ventilation, natural resources and local materials ${ }^{98}$

- Site:

- Site design works with the existing features of the landscape

- Integrates with surrounding site well

\section{Analysis:}

The design of the First Peoples House at Victoria University is successful because of its use of a traditional structural design in a contemporary fashion to define the form of the building allowing the building to become apart of the learning process of First Nations culture. The building and landscape are also respectful of existing conditions on the site, allowing the building to be seamlessly included within the campus community.

Importantly, the building design is environmentally conscious, an important factor in Indigenous culture, with many sustainable features incorporated that align with Indigenous principles. These sustainable features were easily integrated as they already aligned with traditional Salish building techniques.

"Really our goal is to say we have one foot in the past and have taken one foot into the twenty-first century. We are a living culture, not a dead culture. So we do look at ideas, but we are not literally grafting them on from the past." Alfred Waughig

97 Ibid. pp. 74 


\section{Approach 4: Iconography}

\section{Fond du Lac Tribal And Community College}

Location: Cloquet, Minnesota

Architect: Thomas A. Hodne Jr. (Non-Indigenous Architect), 1992

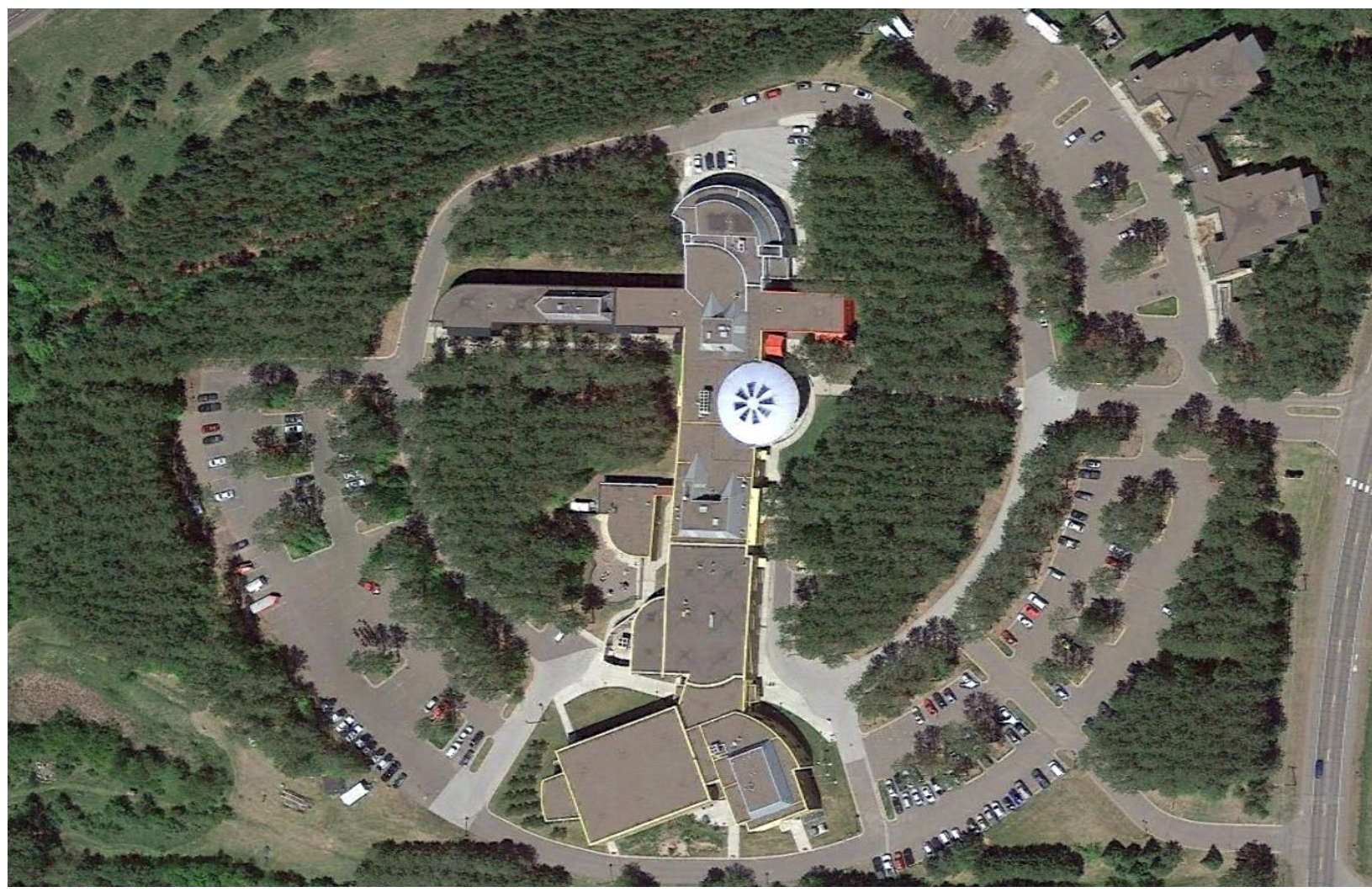

Figure 21: Fond du Lac Tribal and Community College, aerial photograph, Google Earth

\section{Program:}

- Community College

\section{Design Features:}

- Symbolic elements were integrated into the design and are visible in plan, they include the bear paw used in the plantings on the northern slope of the site, the thunderbird is the form of the main building with each arm of the structure pointing towards the cardinal directions and represented by the four 
colours of the medicine wheel, and a circular amphitheatre with a blue dome to represent the sky ${ }^{100}$.

\section{Positives:}

- Site:

- The site chosen for the College overlooks the town of Cloquet, providing a strong visual connection, and is set amongst an old stand of sixty-foot red pines

- Views to the exterior were highlighted to "blur" the distinction between indoors and outdoors providing an environmental connection to the site ${ }^{101}$

- Community:

- Community involvement was a crucial step within the design process; Hodne involved his clients through group discussion and visual workshops to help visualize and develop ideas ${ }^{102}$

\section{Negatives:}

- Culture:

- The use of iconographic fixed forms to develop the plan of the structure make the ability to expand the building to facilitate growing requirements and programs difficult, and to maintain the original formal design restricts opportunities for growth

\section{Analysis:}

The design of the Fond du Lac Tribal and Community College was successful in the eyes of Thomas Hodne's clients, who were involved throughout the design development to identify important imagery and symbolism to aid in defining the form of the structure. Resulting in a symbolic form that held significant importance to the Fond du Lac Tribal and Community College.

However, the use of culturally symbolic forms leave the building feeling cliché in its connection to the culture, especially as the symbolic form is not apparent to the user of the building until viewed in plan.

100 Malnar, Joy Monice., and Frank Vodvarka. New Architecture on Indigenous Lands. University of Minnesota Press, 2013. pp.84-85

$101 \mathrm{lbid}$.

102 Ibid. 


\section{Chapter 4: Design Proposal}

The proposed project's main objective is to support cultural sustainability within the community of Curve Lake First Nation by facilitating activities and programs that incite connection to culture, community, and place. Simultaneously, the project seeks to improve the quality of life of the residents and conserving the limited land available within the community, which will be accomplished through the strategic use of the 700 acres of drowned land surrounding the peninsula of Curve Lake. The proposed programs include:

- New Education Facility for 250 students in Kindergarten through to Grade 8, which will facilitate an Indigenous outlook within an educational institute encouraging resiliency among the youth and ultimately, the community

- Housing for Elders which will inspire a stronger connection to community, specifically with the youth through the education facility, which will help further facilitate an Indigenous outlook on the methods of teaching through the inclusion of elders. Housing will consist of 8 units, which will house 8-16 elders.

- A Water Treatment Facility, to better improve the quality of life of all residents by providing clean potable water through the process of slow sand filtration, a sustainable and low maintenance process

- A route with land guides that moves throughout Curve Lake First Nation as a way of storytelling through landscape immersion and the facilitation of traditional teachings, the program is about community engagement and will have a strong connection to the school program 
The genesis of the project lies within the context of a drowned landscape. The 1844 and 1908 floodings of the Trent Severn Waterway, an initiative of early 20th century colonization tactics discussed in chapter 1, resulted in significant ecological distress and the destabilising of local traditions. Emerging from this loss, and the losses surrounding colonization tactics nationwide, arose recognition of the importance of education and of connection to the land, which is found within Indigenous pedagogy and knowledge. Education has become a significant focus of the reconciliation process within Canada. This connection and therefore the drowned landscape has acted as the bond between all programs proposed within this thesis.

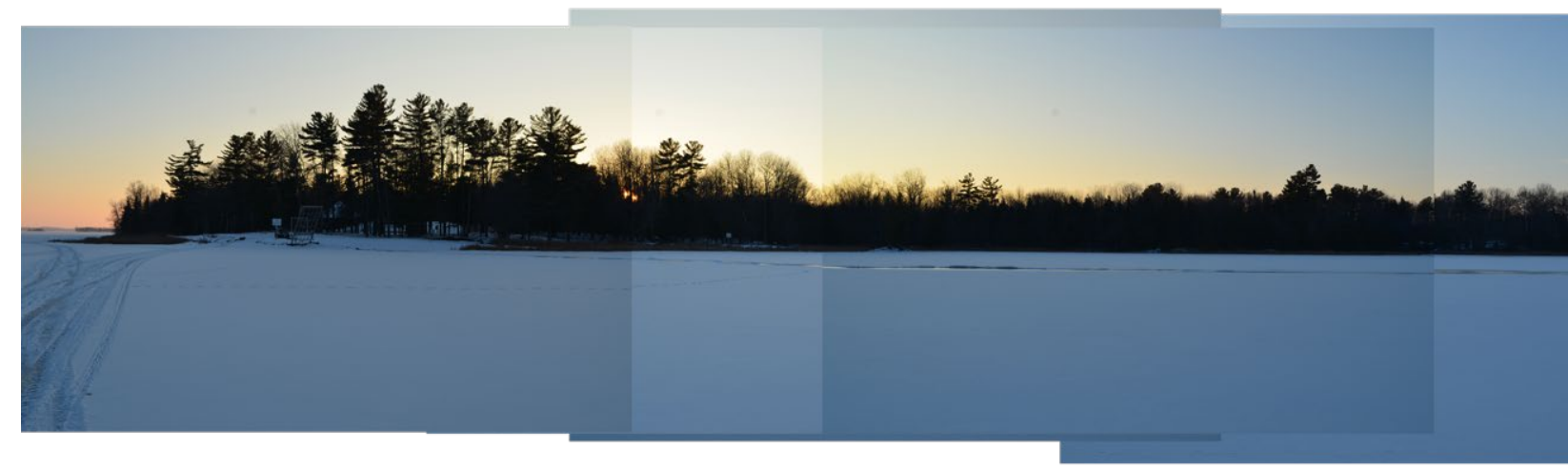

Figure 22: Proposed Site - Lance Wood Park/Pow Wow Grounds 

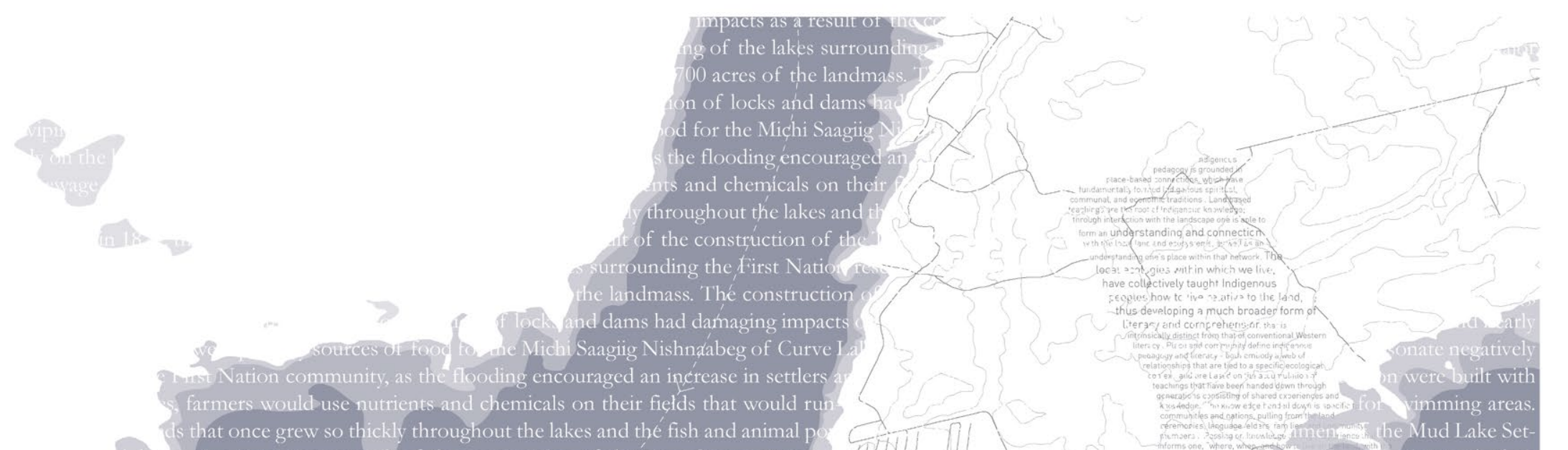

as that once grew so thickly throughout the lakes and the fish and animal ps

(devastating impacts as a result of the construction of the Trent Severn Water

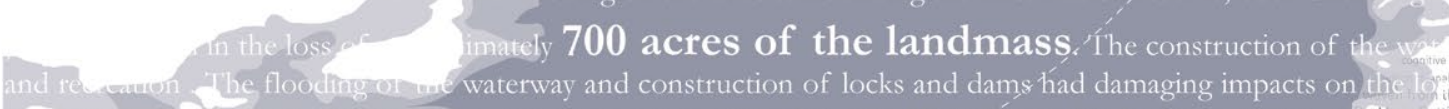

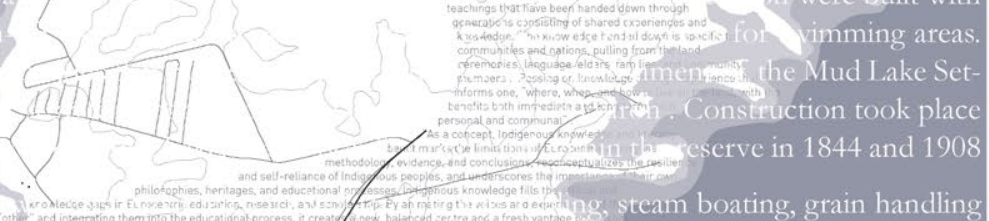
stem and lifestyle of the First Nation community, as the flooding encouraged an increase in settle ystems that emptied into the lakes, farmers would use nutrients-and chemicals on their fields that would ctions further disturbed the rice beds that once grew so thickly throught

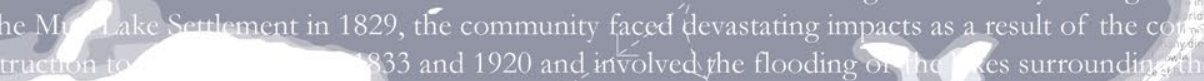

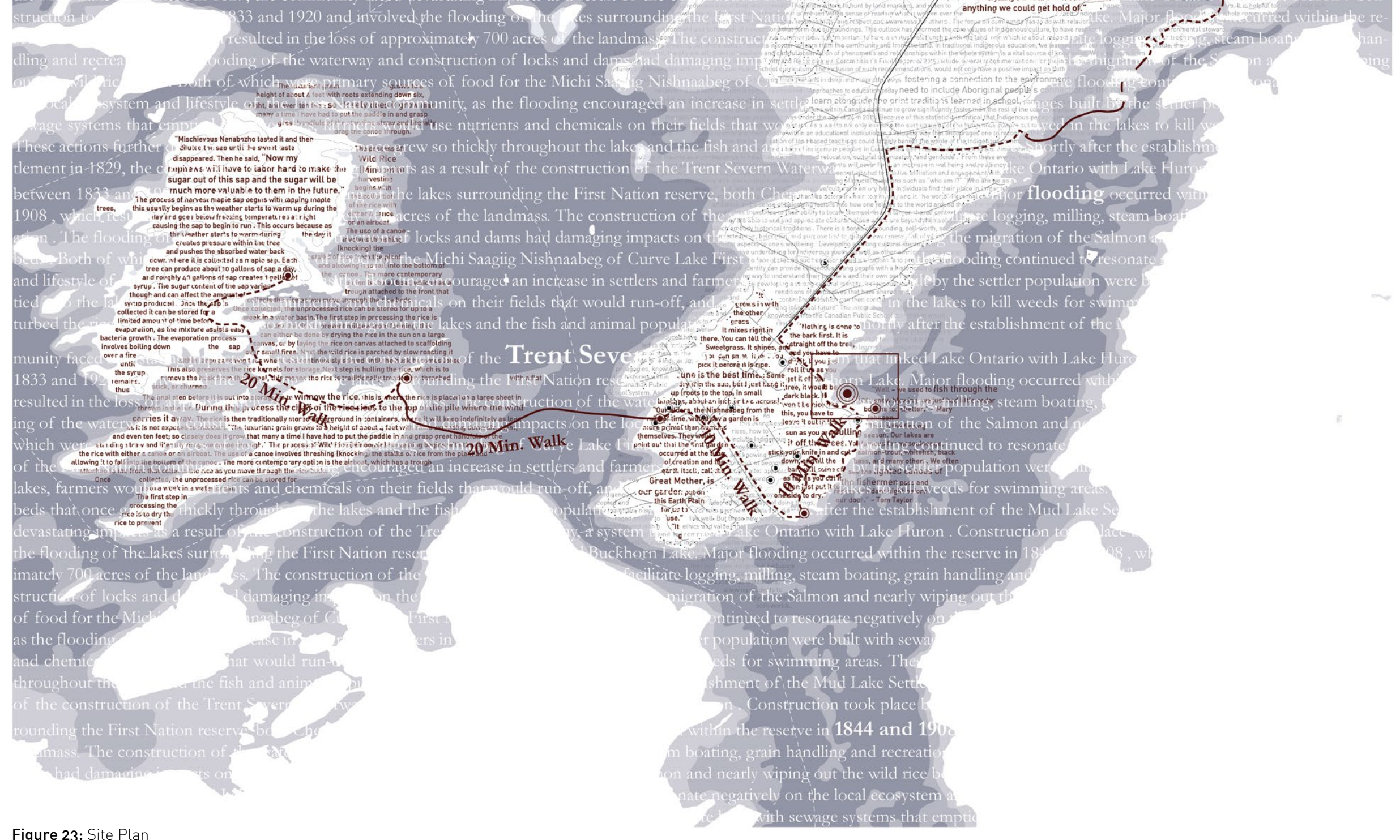

Figure 23: Site Plan 


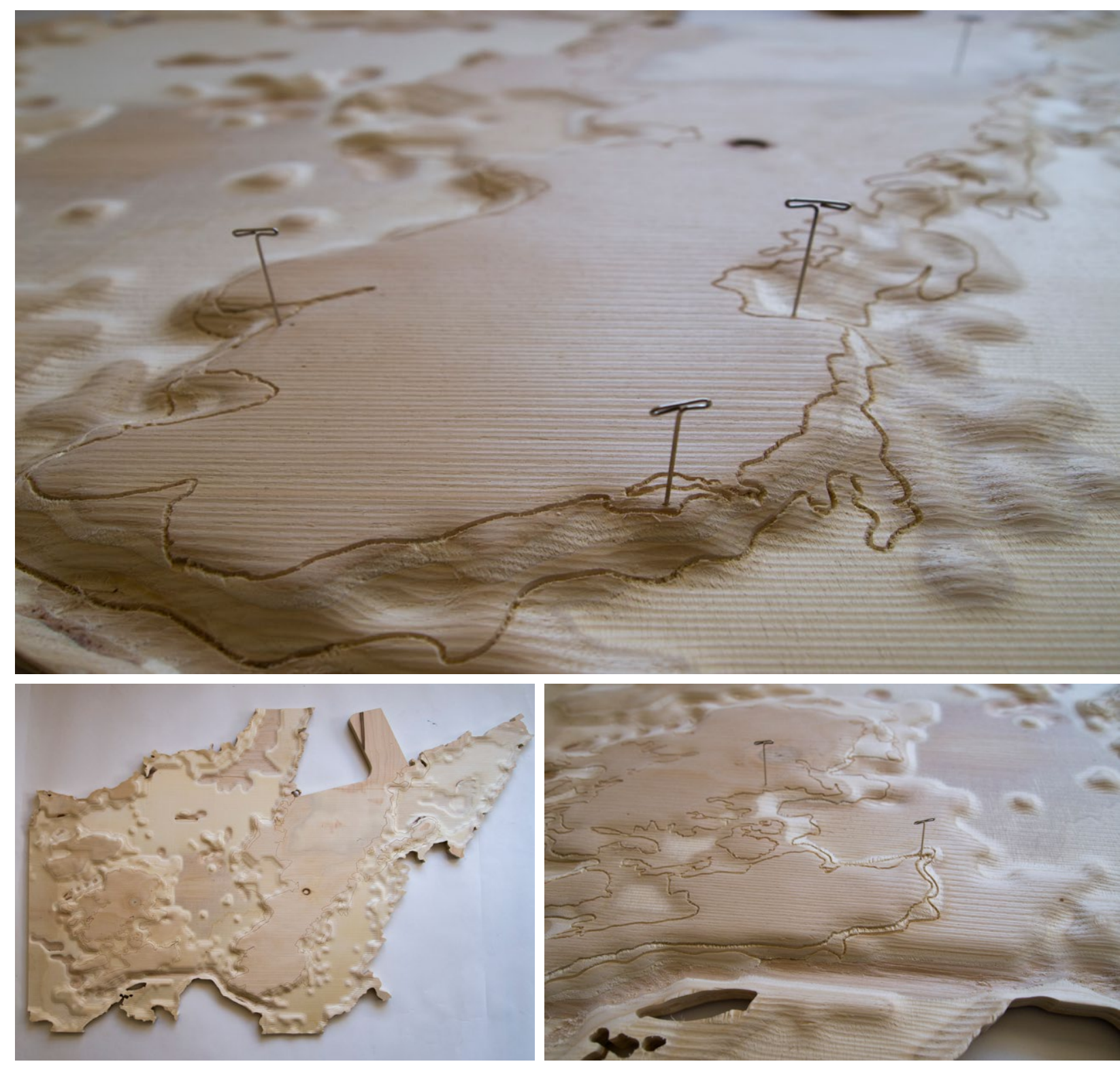

Figure 24: Physical Model of Site Plan 


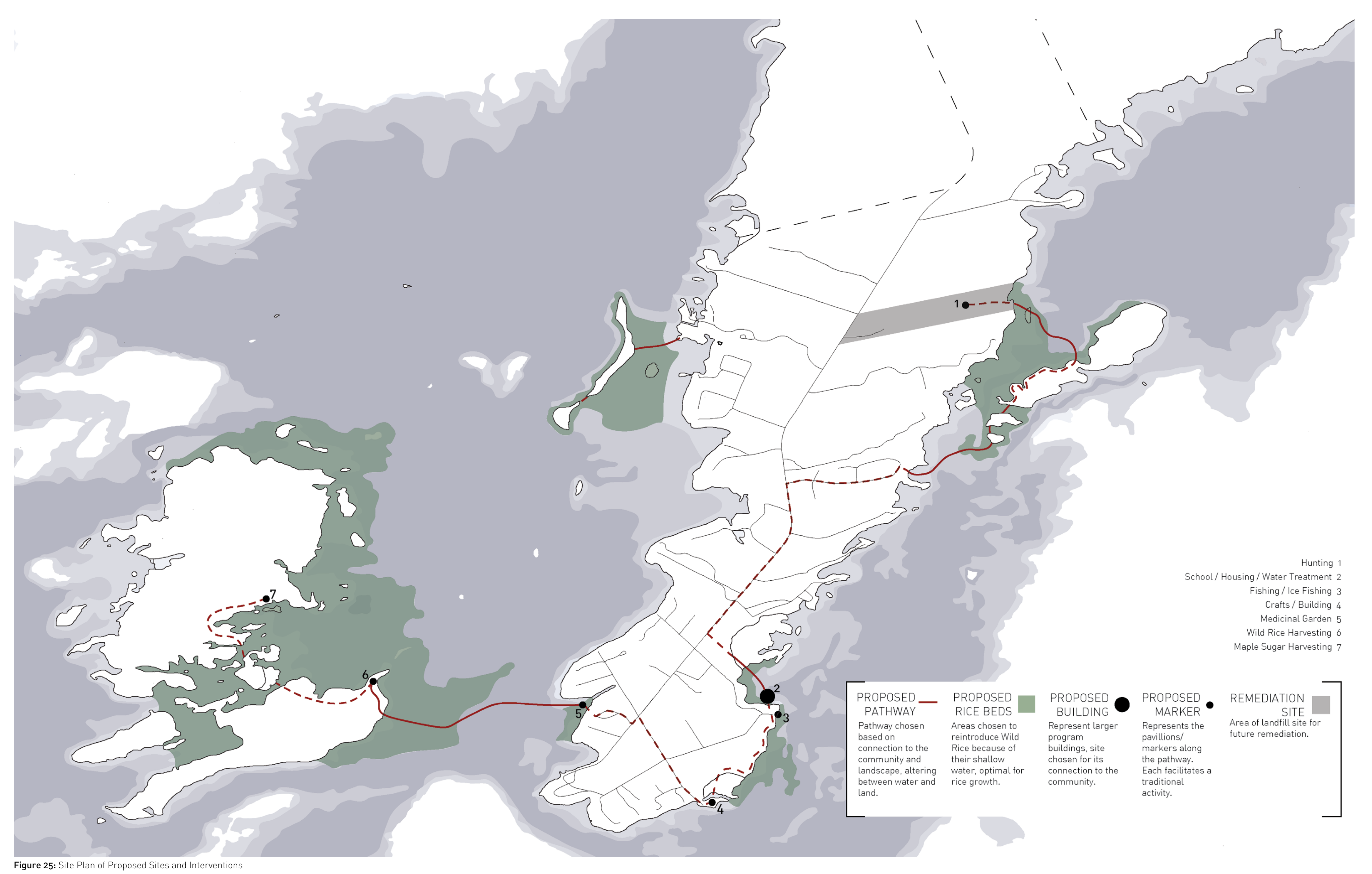




\subsection{Parameters}

\section{Education Facility: Kindergarten to Grade $\mathbf{8}$ for $\mathbf{2 5 0}$ students}

- 9 classrooms - 1000 sq. ft./90 sq. m. per classroom minimum

- Library / computer lab

- Public Washrooms

- Story Room

- Lobby

- Staff room - 50 Sq. m.

- Principal's office - $15 \mathrm{Sq}$. m.

- Reception - 30 Sq. m.

- Conference room - 40 Sq. m.

- Kitchen/Feast Area - 440 Sq. m.

- Community/Ceremonial Space - 350 Sq. m.

- Boat Docking Area

- Mechanical room - 35 Sq. m.

- Storage - 50 Sq. m. x2

Elder Housing (645 Sq. m. / 6950 Sq. Ft.)

- 5 - 1 Bedroom units (75 Sq. m. each)

- 3- 2 Bedroom Units (9o Sq. m. each)

- Garden Area

- Outdoor Public Space

Water Treatment Facility: Slow Sand Filtration with Pre-treatment and Water Storage Tank (600 Sq. m. + 100 Sq. m. + $1000 \mathrm{~m}^{3}$ )

- Sand Beds for slow filtration

- Effective flow rate is 0.1-0.3 m/h, which equates to 100 $300 \mathrm{~L} / \mathrm{h}$ per $\mathrm{m} 2$ of filter area ${ }^{103}$

- Pre-Treatment area

- Required in the chance that lake water impacts the ground water supply ${ }^{104}$

- Roughing filter and sedimentation tank to remove turbidity that could affect the slow sand filtration process $^{105}$

103 "An Introduction to Slow Sand Filtration." Solutions for Water, Dec. 2005, www.solutionsforwater.org/wp-content/uploads/2011/12/Slow-Sand-Filtration-Introduction-7-MB-16Dec-2011.pdf. $104 \mathrm{lbid}$.

105 Faithful + Gould. “Curve Lake First Nation New Water Treatment Plant and Water Supply 
- Weir

- To control the flow of water from the sand beds to the storage tank, preventing the top of the sand bed from running dry ${ }^{106}$

- Water Storage

- Minimum of $1050 \mathrm{~m}^{3}$ is based on future population projections $^{107}$

- Glass Fused storage facility

\section{Land-Based Markers / Route}

- Wild Rice Harvesting

- Maple Syrup Harvesting

- Crafting

- Medicine Garden

- Fishing/lce Fishing

- Hunting

Project." 20 Jan. 2017.

106 "An Introduction to Slow Sand Filtration." Solutions for Water, Dec. 2005, www.solutionsforwater.org/wp-content/uploads/2011/12/Slow-Sand-Filtration-Introduction-7-MB-16Dec-2011.pdf.

107 Faithful + Gould. "Curve Lake First Nation New Water Treatment Plant and Water Supply Project." 20 Jan. 2017. 


\subsection{Site}

The proposed site for the school, water treatment facility, and elder housing is located near the Pow Wow grounds, known as Lance Wood Park. The site was chosen because of its centrality to the community, central both socially and culturally. The Pow Wow grounds are a site of ceremonial importance to the members of Curve Lake First Nation, and are the site of many recreational community activities. As well, the site remains within the core area of Curve Lake First Nation close to a majority of the homes, thus maintaining the walkability of the community.

The core site proposed for the construction of the school, water treatment facility, and elder housing are located within a bay surrounded by a forested area to the South and West, and wetlands to the North, making it the ideal choice based on contact with diverse land features. Lance Wood Park is also within the land deemed public, as it is not privately owned by members of the community (fig. 19). The site is easily accessible by road and has two trails intersecting with the site that connect from the main road, which run through the community, and the second trail comes from the other main recreation site.

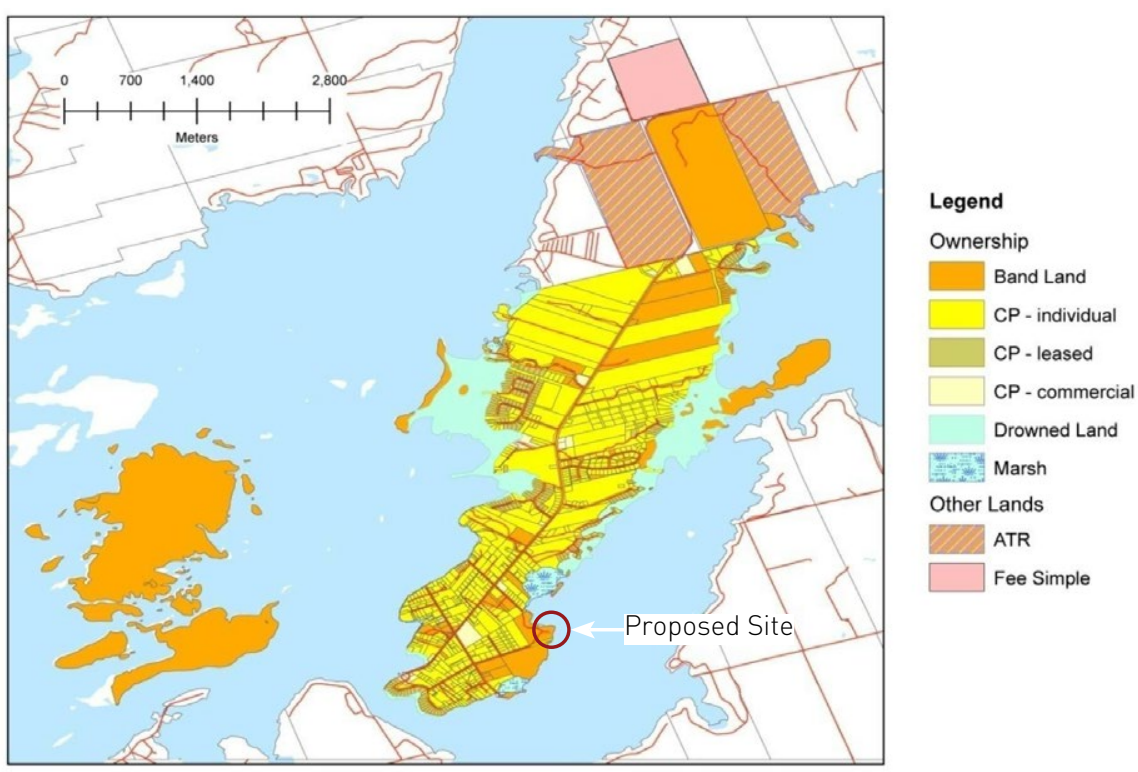

Figure 26: "Curve Lake First Nation Land Tenure 2009." The Curve Lake Comprehensive Plan, Curve Lake First Nation, 2009, p. 19 


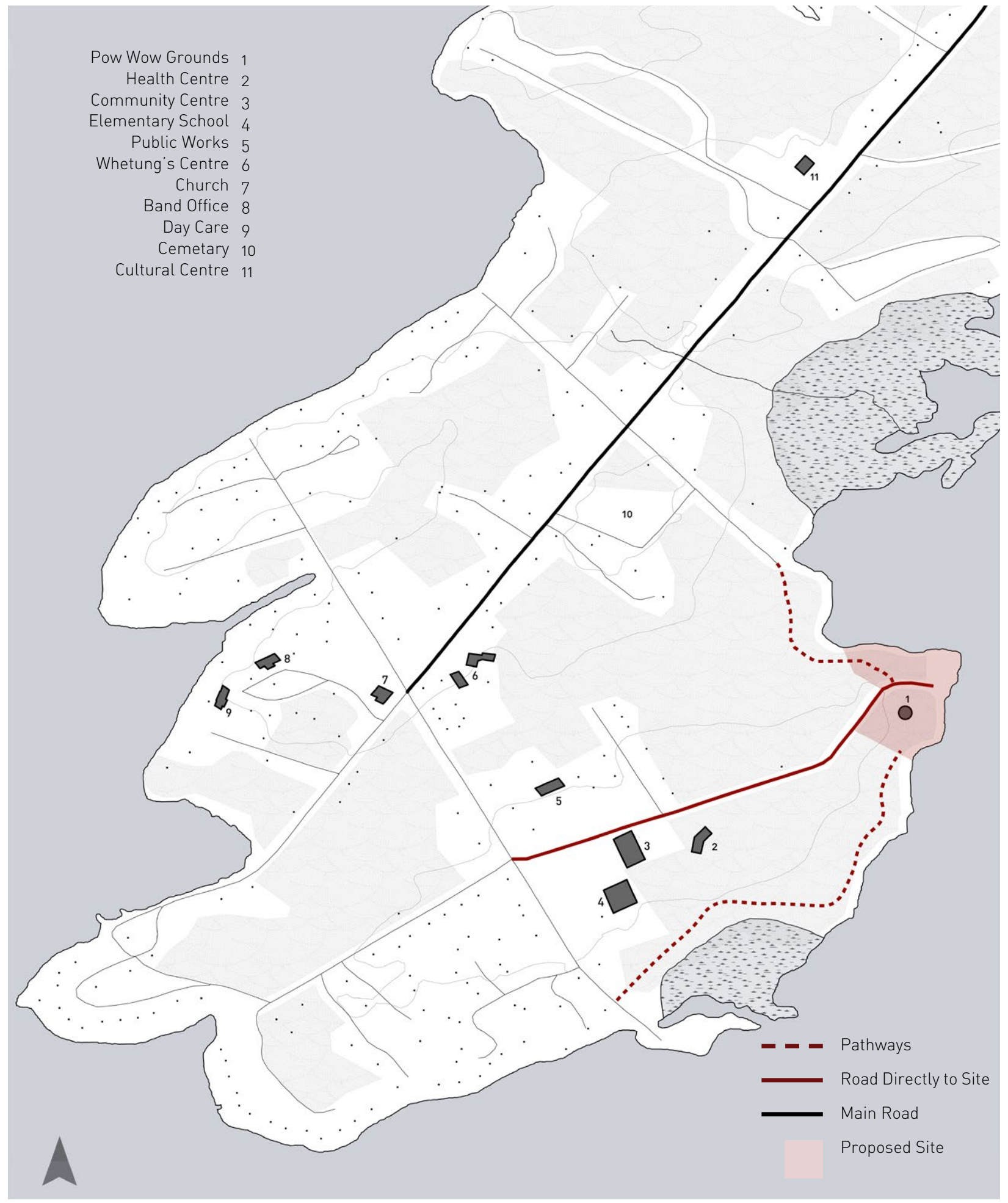

Figure 27: Roadways and Pathways connected to Main Proposed Site 


\subsection{The Architecture}

After exploring various approaches to architectural design within Indigenous communities, the decided methodology for the project's development was to implement a relationship that creates a connection to culture stemming from an experiential approach to the site. By harnessing Indigenous sensibilities in architectural design, the aim was to create connections to place and environmental elements that would impact how the inhabitant interacts with the landscape. Acting as a barometer, the building will be in synch with the environment and accentuate the changing ecological conditions occurring in the surrounding landscape. This will function as an educational tool to facilitate the inclusion of Indigenous pedagogy and knowledge, which includes an understanding of the land that allows one to read the land.

The building's orientation is aligned based on facilitating both social activities and the harnessing of natural elements. The building is oriented to face towards the community space adjacent to the proposed site, facilitating a community connection. This will offer the opportunity for the building to act as an extension of the ceremonial space during community events, such as the Pow Wow. The feast area of the program was situated in the forefront of the building for this reason.

This orientation also acknowledges the natural elements such as wind and daylighting, as well as visual connections to surrounding landscape features. With wetlands to the north, forest to the west and south, and water to the east, the building is able to react differently to each condition. Such as the dock extending into the water and decks projecting out into the surrounding trees. Classrooms will be aligned and views directed to specific environmental conditions, using rooflines as directional tools.

Important within the design development was the symbolic reclamation of the drowned land, accomplished through a pile structure allowing the building to project out from the land and over the water. Using piles to support the structure above the water, the 
building is able to rest lightly on the land and remain as minimally invasive as possible. This allows the lake flora and fauna to remain below the structure, and at times interacting with the building and its inhabitants. Through the use of a strategic porous decking system, the wild rice growing amongst the structural piles will grow through the decking and into the outdoor circulation spaces.

The water filtration system acts as the anchor to the land with the education and housing programs projecting outwards over the water. Both programs act as two masses branching off from the water treatment facility and opening up towards the water and offering the opportunity for access from watercraft.

Verticality is used to celebrate programs of importance within the organizational layout, principally the water storage component, which rises above the rest of the architecture and marks the entrance to the building. As one approaches the building they will be greeted by the towering structure, which emphasizes the importance of water to the culture, community, and design development. This sense of verticality will be mirrored in a smaller scale in the communal ceremony space aligned with the Pow Wow grounds, and the library/storying area above the elder housing. Each programmatic space represents a focal point within the design development as it facilitates Indigenous values and pedagogy. 

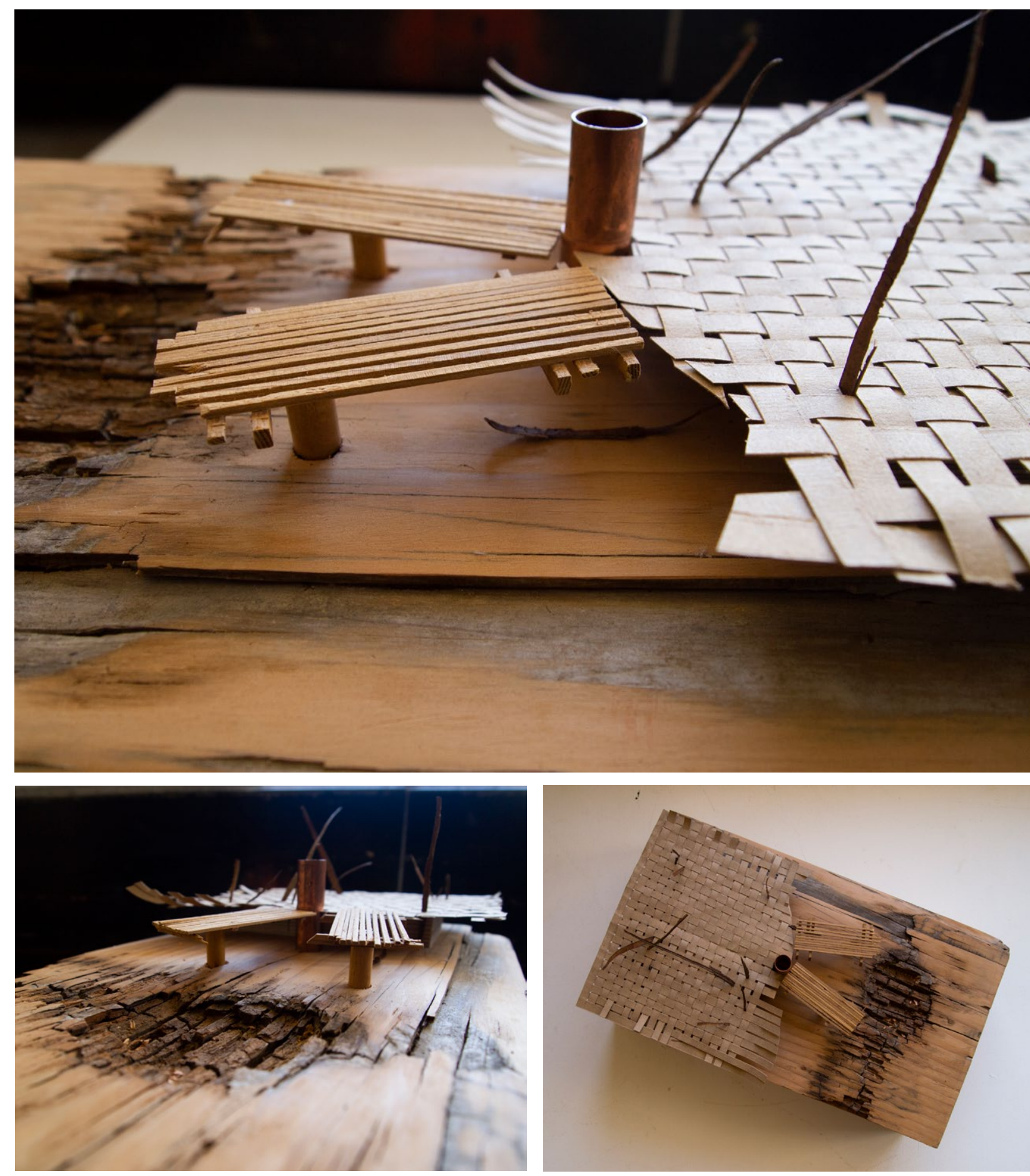

Figure 28: Conceptual Physical Model 


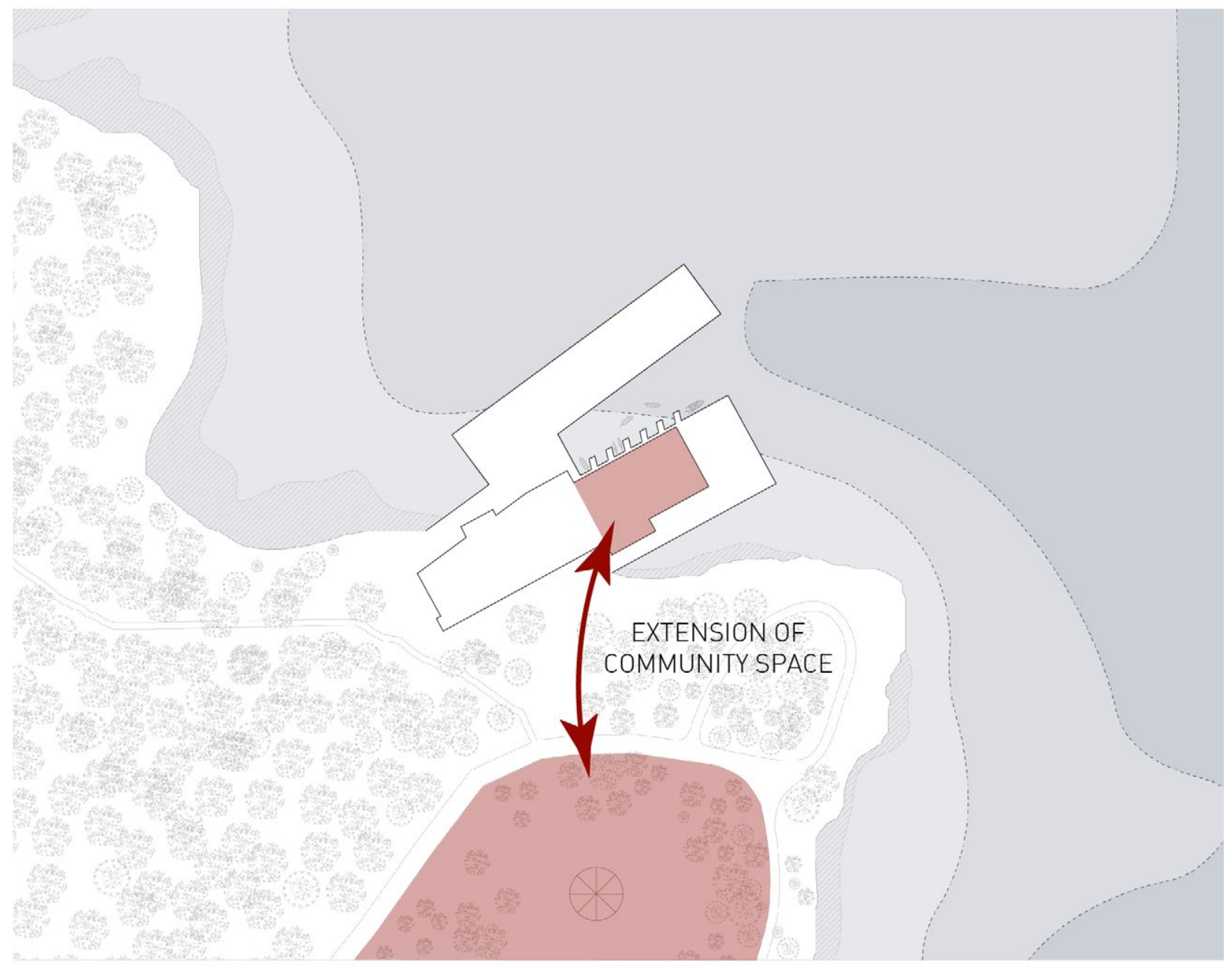

Figure 29: Connection to Community Space/Pow Wow Grounds 


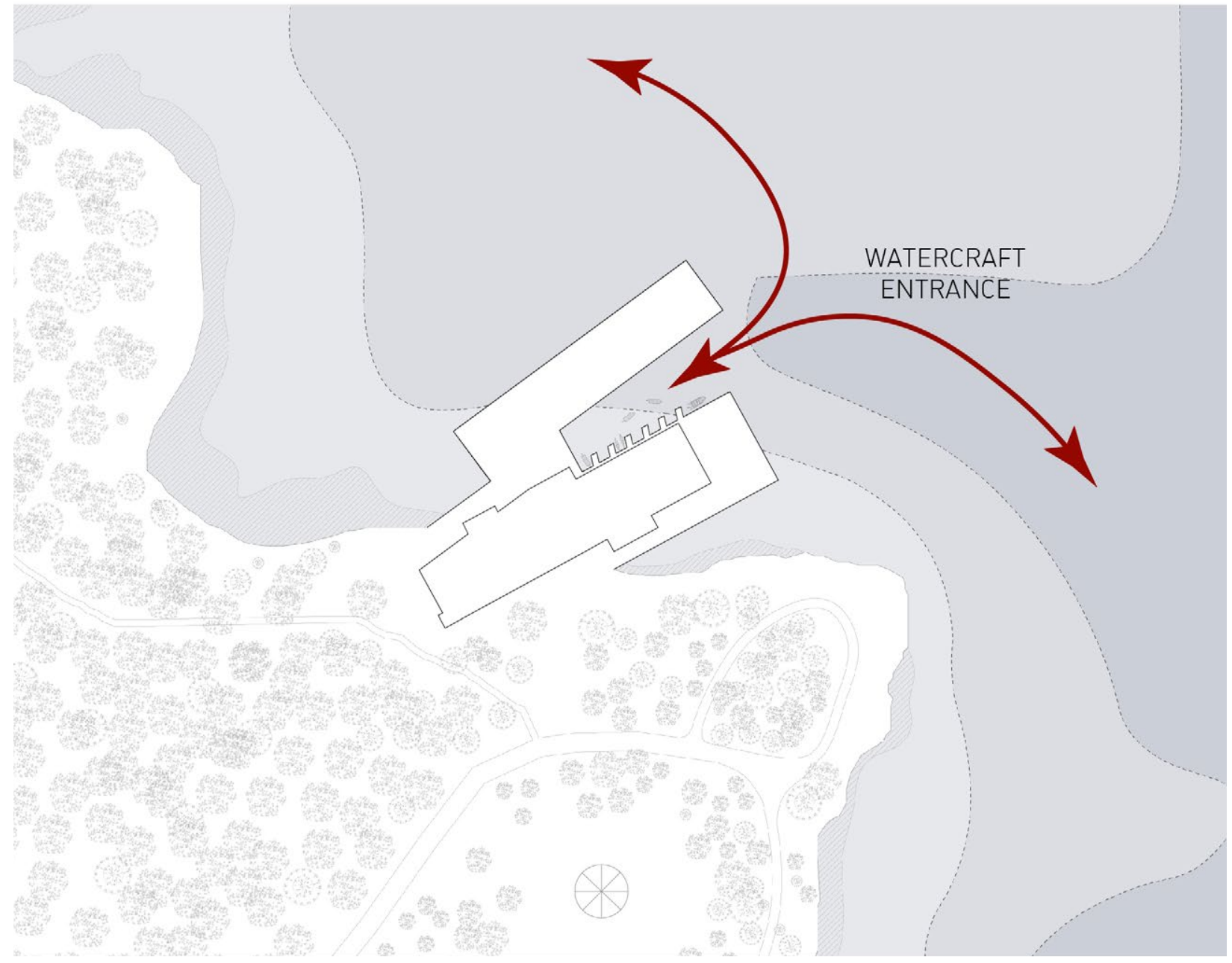

Figure 30: The building's connection to the water allows for community access by boat 


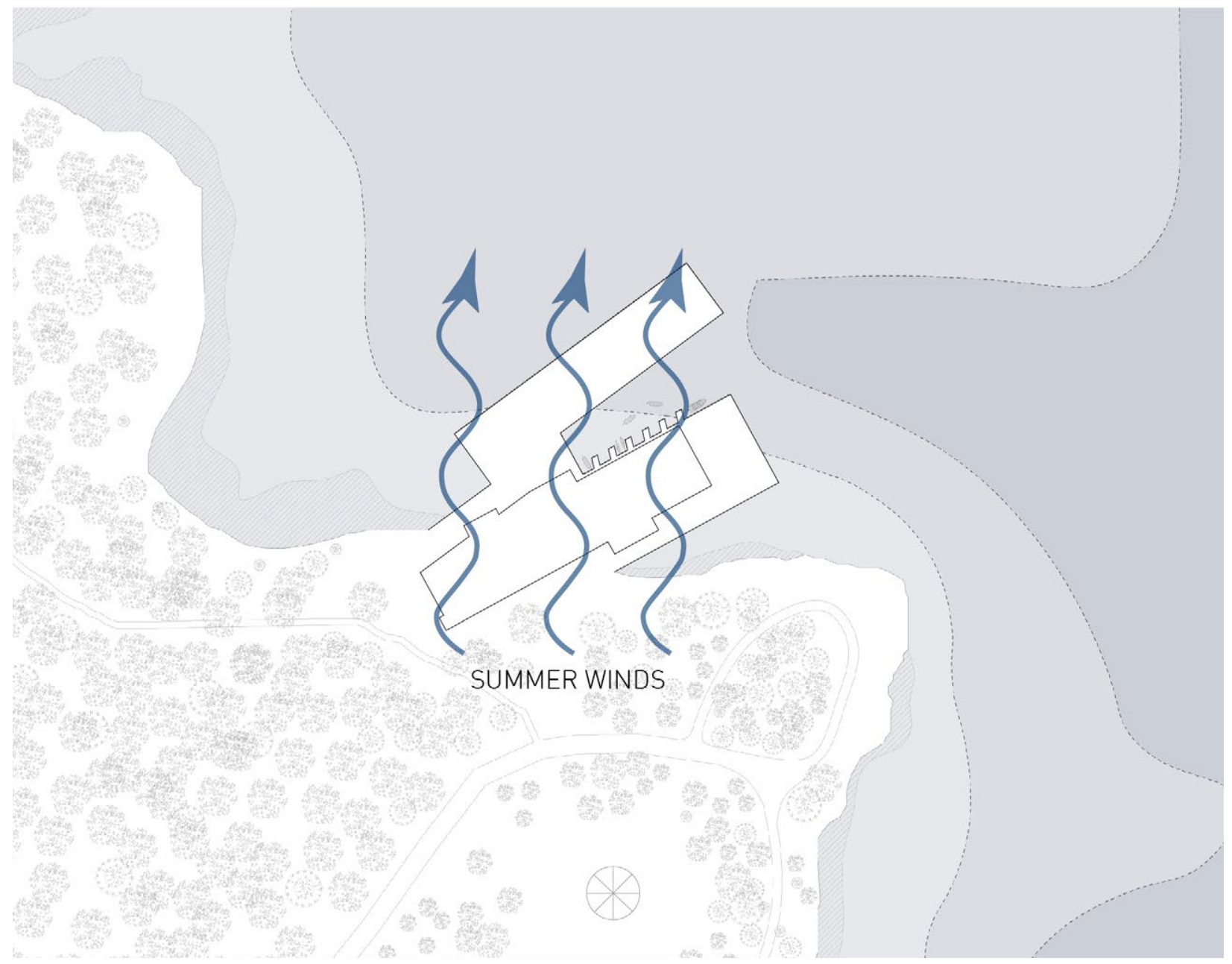

Figure 31: The buildings orientation takes advantage of the prevalent southern wind during the months of June to July, allowing for cross ventilation 


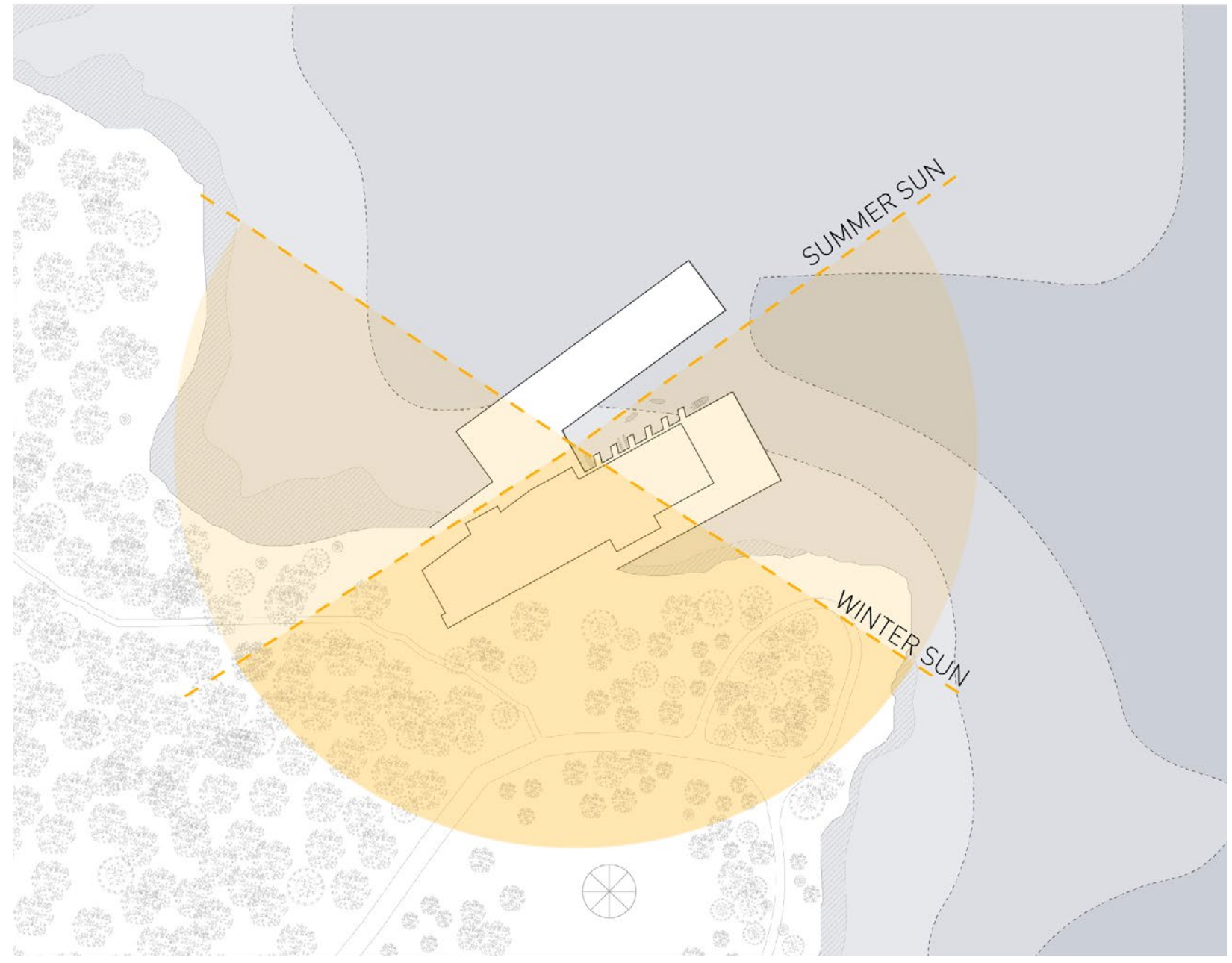

Figure 32: Orientation of the building takes advantage of natural daylighting strategies 


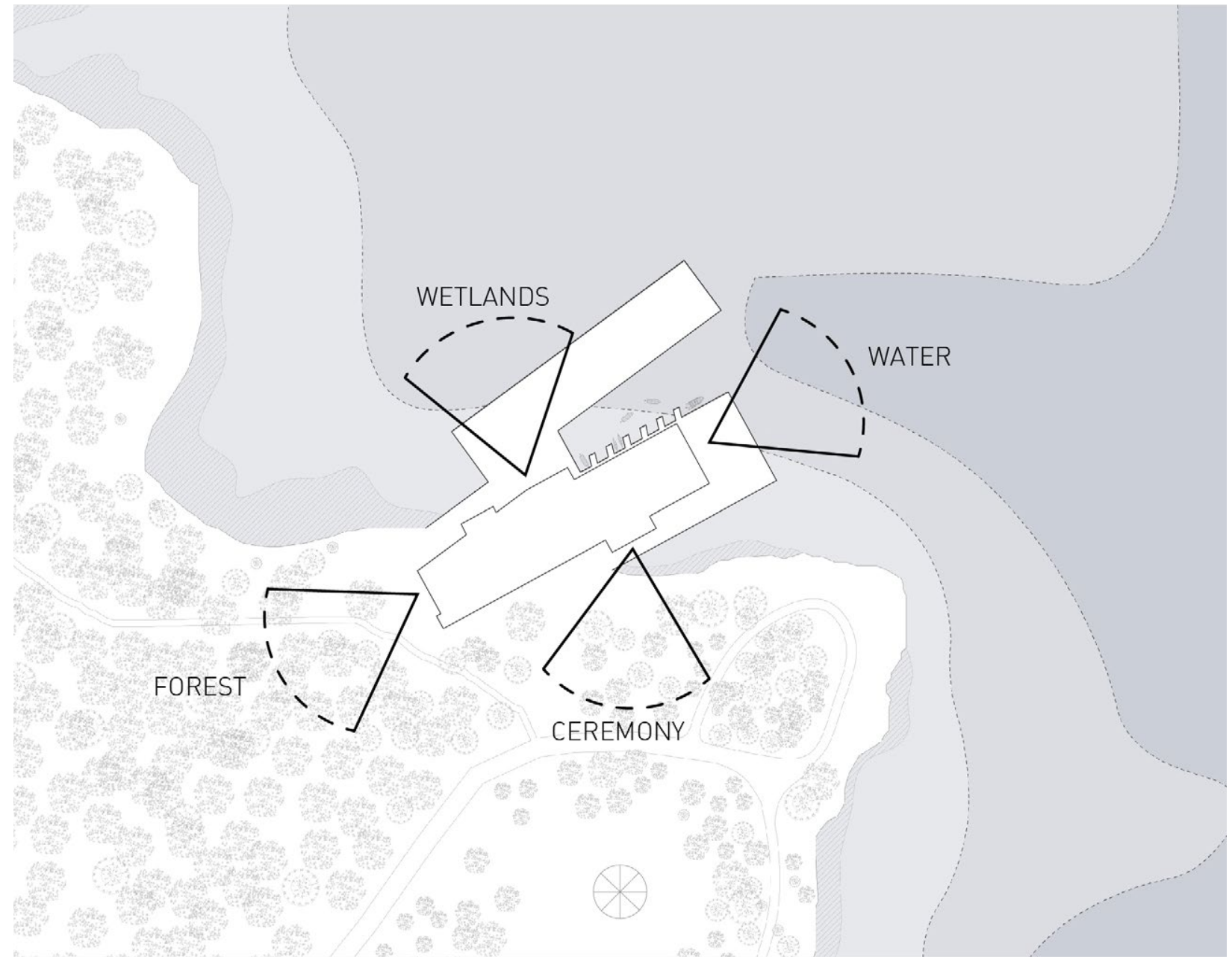

Figure 33: Views of surrounding landscape and community features 


\subsection{Spatial Relationships}

To encourage a stronger sense of community that facilitates the core values of Indigenous pedagogy and culture, the school, elder housing, and water treatment facility are integrated within one building. This allows various programs to better interrelate and flow through each other, both horizontally and vertically. This in turn permits the building to tell its own story as it creates a network of connections between various programs, people, and environmental conditions, which inspires a sense of community within the education process.

Generating a network of spaces that connect, intersect, and separate to facilitate both community and cultural integration into the programs was a crucial element to the design development. Versatile learning spaces, created through the inclusion of operable walls, allow the interaction between various age groups, encouraging a cumulative collective experience. Thus students can learn with each other and from each other, forming stronger connections with one another that span the various age groups. Generous circulation spaces also encourage small-scale gatherings and allow for classes to extend outside the classroom into a common space.

The programs are bound together by the life force that is water. The water storage tank extends through the programs and anchors the building to the land; it acts as a focal point with in the architecture. Water is present throughout the entirety of the structure via rainwater harvesting, radiant floor heating, the water treatment facility, and courses beneath the building. It is the spirit of the building, connecting the inhabitants back to the land and to the culture.

\subsection{Environmental Regeneration / Respect}

As a cultural representation, the associated architecture should embody the values of the community and its culture. Since the relative Indigenous culture is predominantly focused on a respect 
for the environment, this cultural manifestation is represented through both passive and active sustainable features, which allow for the regeneration of the land.

Passive features will include solar orientation, naturalventilation, use of local materials, and rainwater harvesting. The structure is south facing, allowing optimal daylighting strategies. Natural ventilation is achieved through both orientation, which takes advantage of the prevalent wind direction during the summer months, and the use of operable windows allowing for cross ventilation. The roof design strategy will allow for the collection of rainwater to be directed to the water treatment facility for reuse. Active features integrated within the design will include radiant floor heating through the use of roof mounted evacuated solar tubes.

The water treatment facility will use the process of slow sand filtration, a low maintenance and sustainable process that relies on biological processes rather than chemical, showing an innate respect for the water. The slow sand filtration procedure uses sedimentation, adsorption, and straining to remove fine particles, and microbiological processes to remove organic material and bacteria ${ }^{108}$. The biological process is the result of a combination of decomposing organic matter, iron, manganese, and silica ${ }^{109}$. Algae growing on the surface consume the oxidized organic material, releasing oxygen into the water ${ }^{110}$. Once the water has filtered through the sand bed it moves through the under drainage system, consisting of several layers of gravel, before it reaches the weir on its way to the storage tank.

108 "An Introduction to Slow Sand Filtration." Solutions for Water, Dec. 2005, www. solutionsforwater.org/wp-content/uploads/2011/12/Slow-Sand-Filtration-Introduction-7-MB-16Dec-2011.pdf.

109 Ibid.

110 lbid. 


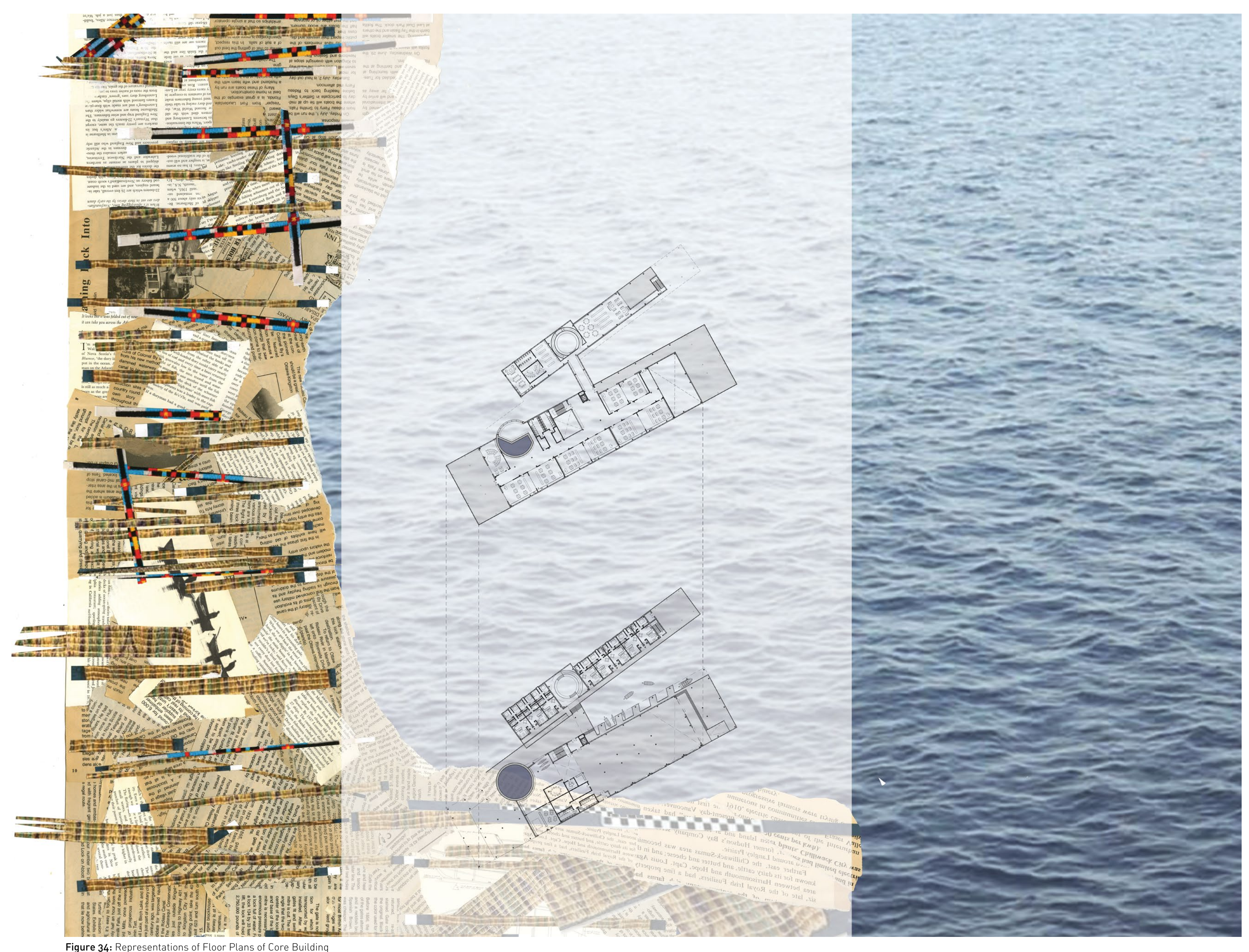





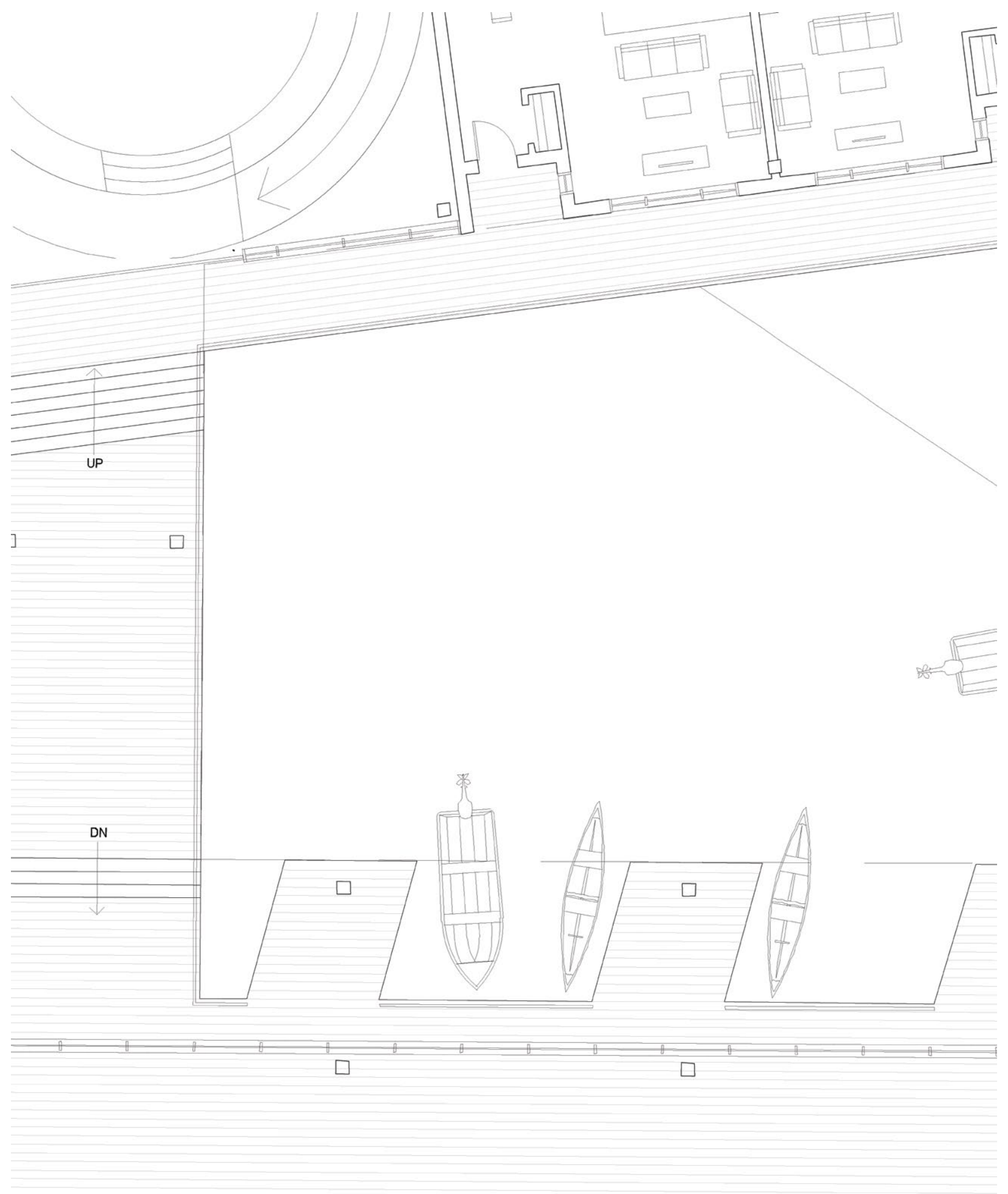

Figure 36: Detail of Floor Plan 


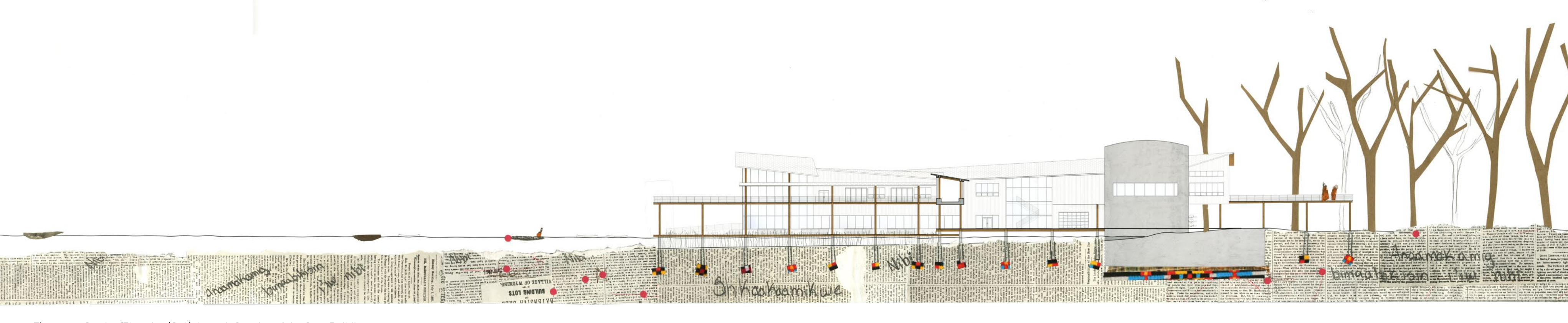
Figure 37: Section/Elevation (S-A) through Opening of the Core Building 


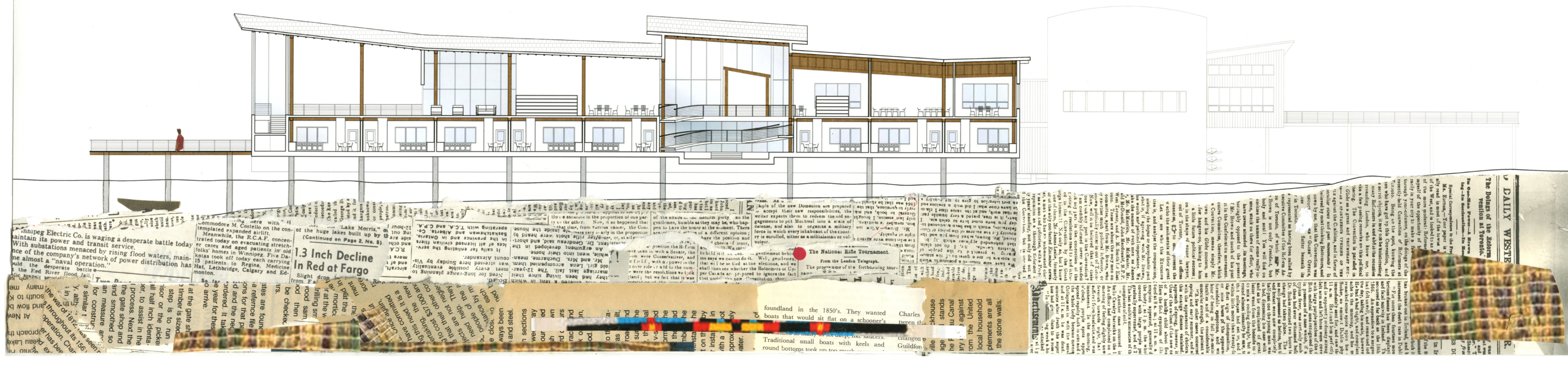

Figure 38: Section (S-B) through Library and Elder Housing of Core Building 


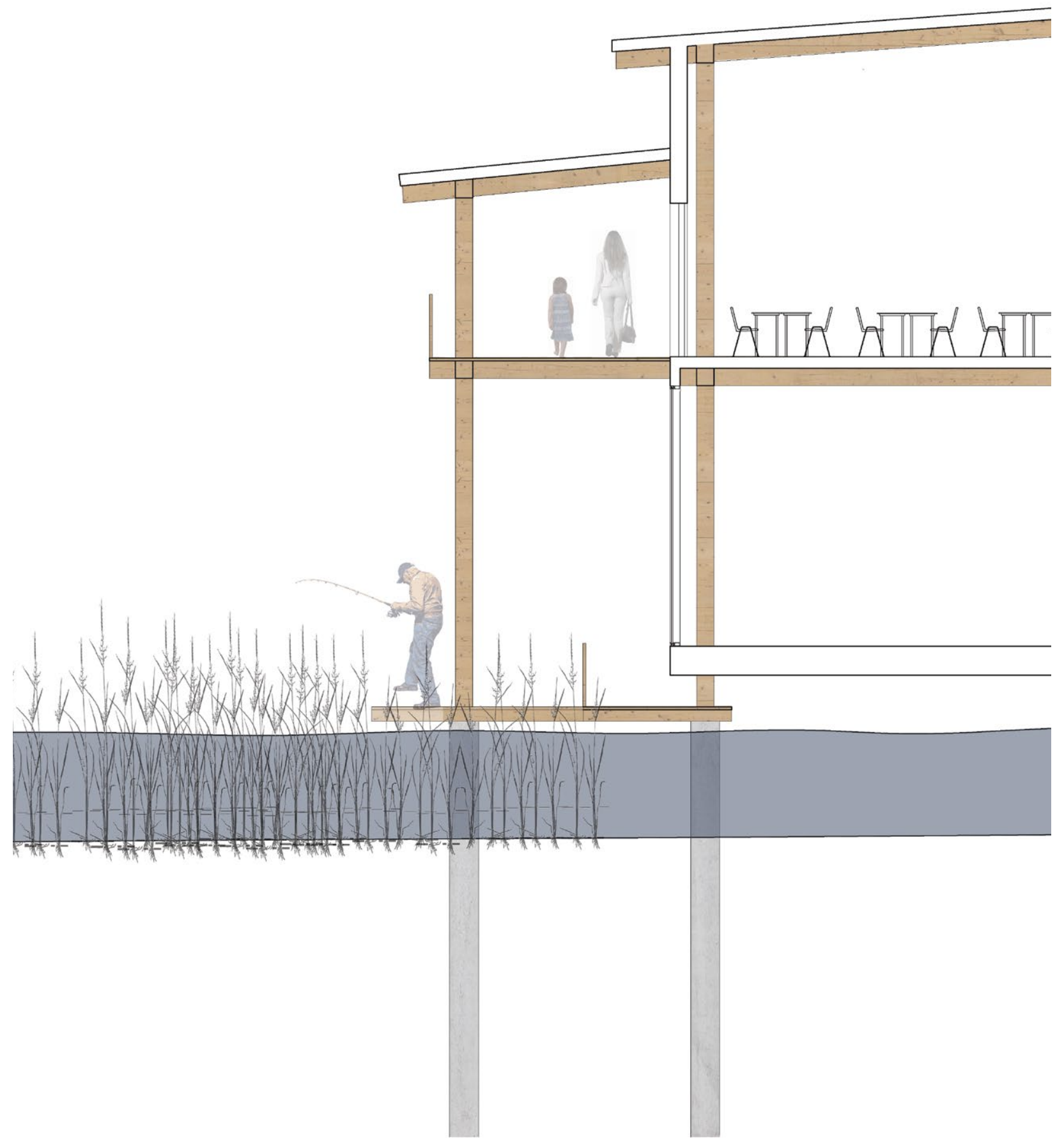

Figure 39: Detail section showing the Minoomin interact with the building 


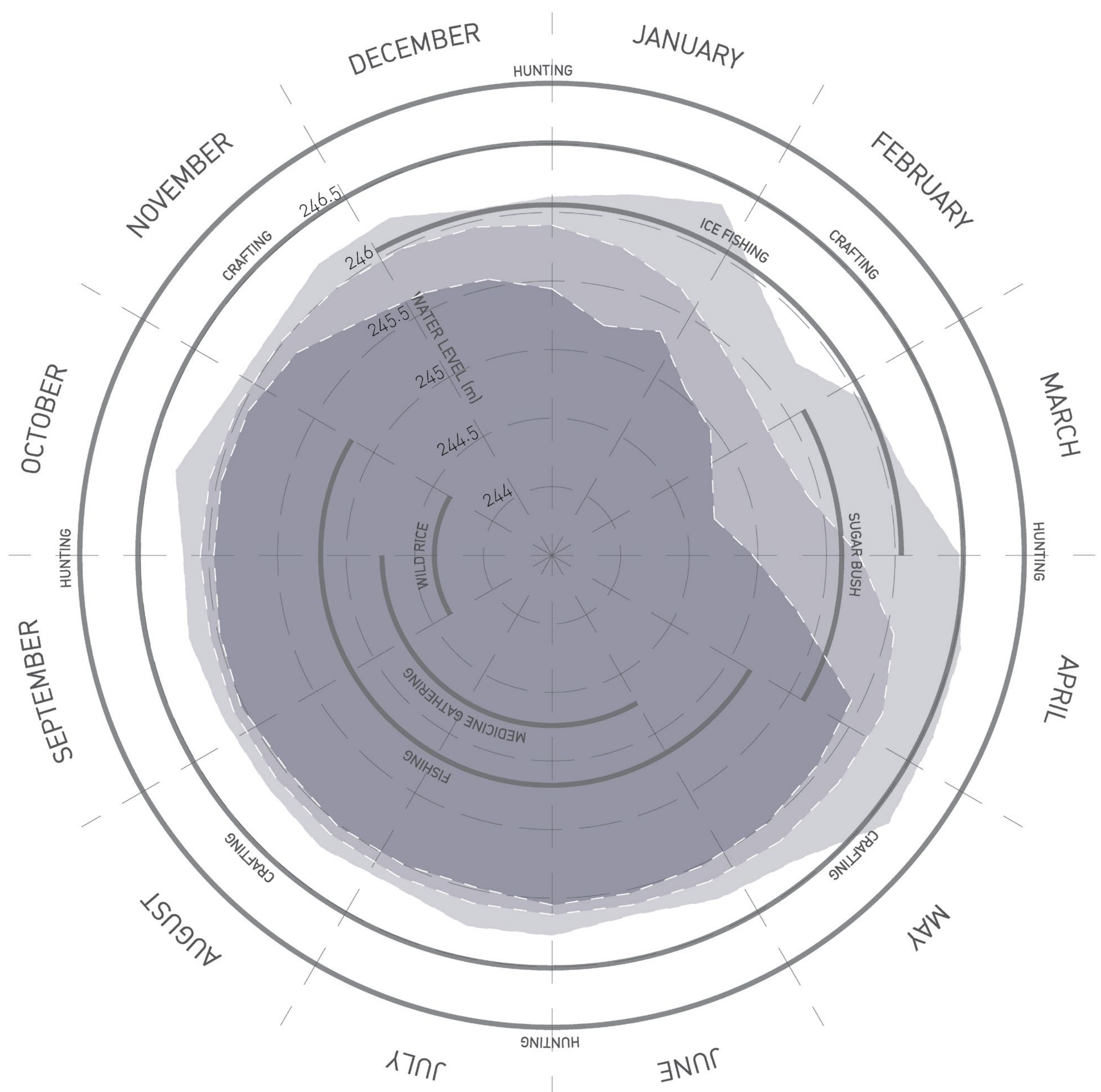

Figure 40: Traditional Activities Calendar in relation to Annual Water Levels 


\section{Chapter 5: Land-Based Markers}

The land-based markers act as an extension of the core building, branching off from the school as a way to facilitate Indigenous knowledge through experiential learning practices. Design development will be defined by the process behind each activity, as well as the natural elements that facilitate the action of each activity, as a way to highlight our connection to the land and our dependence on it. The proposed sites for the land guides are chosen based on environmental factors that help facilitate each activity, such as connection to water or proximity to landscape features.

\subsection{Minoomin (Wild Rice) Harvesting}

"The luxuriant grain grows to a height of about 4 feet with roots extending down six, eight, and even ten feet; so closely does it grow that many a time I have had to put the paddle in and grasp great handfuls of the standing straw and literally drag the canoe through. Imagine the pleasure of paddling all day in this field. The canoeist gets the craft along someway, slowly but surely all the while a deep wave of wild rice, heavily seeded, bends in behind him." "11

Program Requirements:

- Canoe docking

- Water Basin for Unprocessed Rice

- Drying Area

- Parching Area

- Hulling Area

- Winnowing Area

- Storage for Processed Rice

- Storage for tools and Equipment

Process of Harvesting:

The process of wild rice (minoomin) harvesting begins with the collection of the rice with either a canoe or an airboat. The use of

111 History of the Ojibwa of the Curve Lake Reserve and Surrounding Area Volume II: Social and Cultural History. Curve Lake Indian Band \#35, 1976, pp 42 
a canoe involves threshing (knocking) the stalks of rice from the plant and allowing it to fall into the bottom of the canoe. ${ }^{112}$ The more contemporary option is the airboat, which has a trough attached to the front that collects the rice as one moves through the rice beds. Once collected, the unprocessed rice can be stored for up to a week in a water basin. ${ }^{113}$

The first step in processing the rice is to dry the rice to prevent mildew from forming. This can either be done by drying the rice in the sun on a large canvas, or by laying the rice on canvas attached to scaffolding over small fires. ${ }^{114}$

Next the wild rice is parched by slow roasting it within large parching tubs where it is continuously stirred until the husk becomes loose ${ }^{115}$. This also preserves the rice kernels for storage.

Next step is hulling the rice, which is to remove the husk from the kernel, this means the rice is traditionally treaded on, thrashed with a flat stick, or churned ${ }^{116}$.

The final step before it is put into storage, is to winnow the rice; this is where the rice is placed on a large sheet and thrown in the air. During this process the chaff of the rice rises to the top of the pile where the wind carries it away. The rice is then traditionally stored underground in containers, where it will keep indefinitely if not exposed to moisture ${ }^{117}$.

Site:

The site, Fox Island, chosen for wild rice harvesting was based on its access to water, and also for its optimal growing conditions for the wild rice plant. A large area of shallow water surrounds the area chosen, which is ideal for the growth of wild rice beds.

112 "Wild Rice - the Harvesting, Processing and Cooking of This Ojibwa Food." Canadian Native Art - a Cultural Perspective by an Ojibwa Artist, www.native-art-in-canada.com/wildrice.html.

$113 \mathrm{lbid}$.

$114 \mathrm{Ibid}$

115 lbid.

$116 \mathrm{Ibid}$.

$117 \mathrm{Ibid}$. 
The Architecture:

- Take advantage of wind direction during harvesting period for winnowing

- Orientation of outdoor space to use Sun for drying of rice

- Highlight Sound and visuals of activities and direct back towards mainland

- Large docking areas to allow for boat access and rice drop off

- Take advantage of the water and the wind and highlight the natural connection to elements 


\section{wild rice harvesting ... begins with threshing of the stalks}
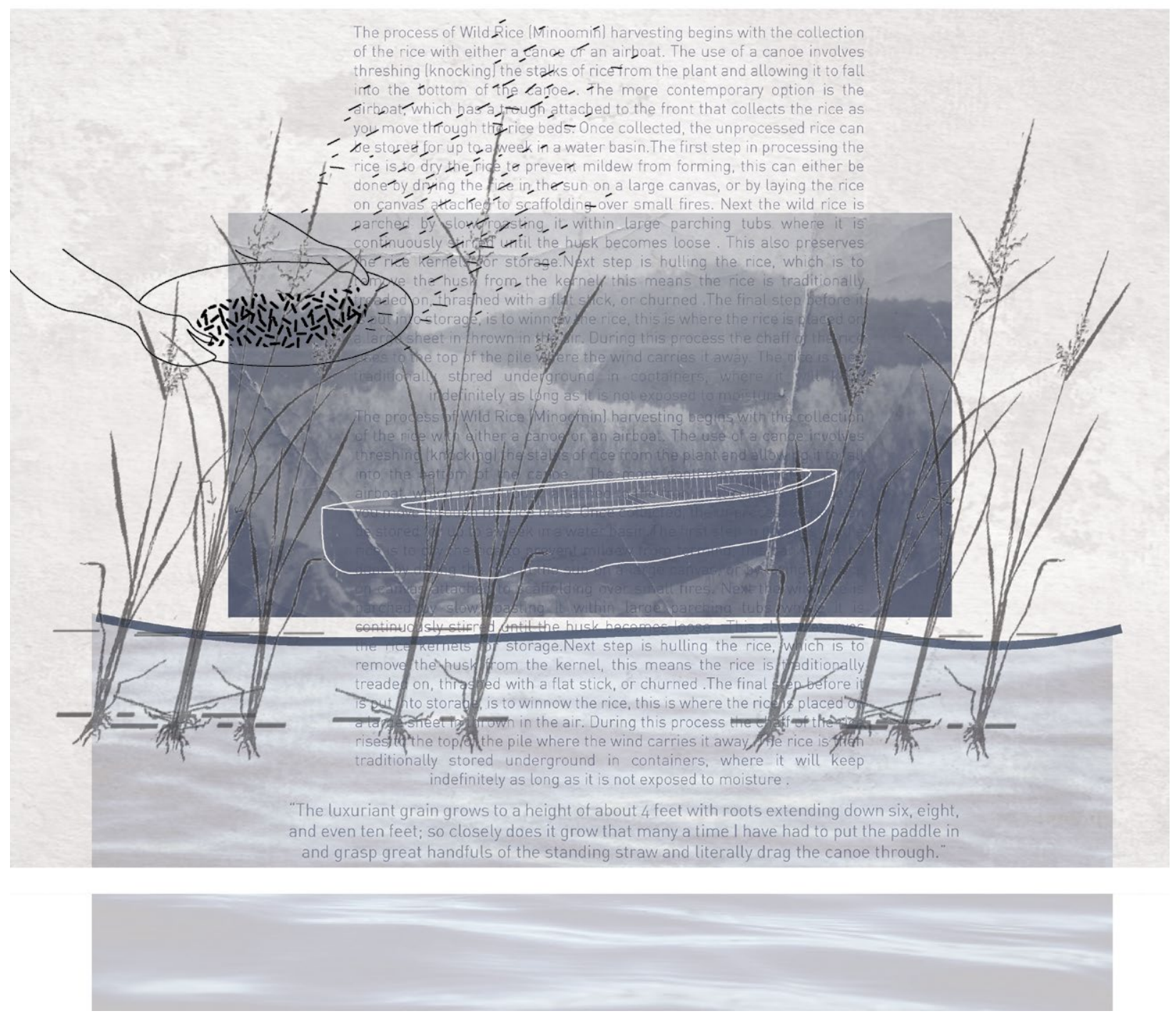

Figure 41: Representation of the Wild Rice Land Marker 


\subsection{Maple Syrup Harvesting}

"Mischievous Nanabozho tasted it and then diluted the sap until the sweet taste disappeared. Then he said, "Now my nephews will have to labor hard to make the sugar out of this sap and the sugar will be much more valuable to them in the future. "ns

Program Requirements:

- Storage for tools

- Collection tank to store sap

- Evaporation area

- Storage area for syrup

Process of Harvesting:

The process of harvesting maple sap begins with tapping maple trees. This begins as the weather starts to warm up during the day and goes below freezing temperatures at night causing the sap to begin to run ${ }^{119}$. This occurs because as the weather starts to warm during the day it creates pressure within the tree and pushes the absorbed water back down where it is collected as maple sap ${ }^{120}$.

Each tree can produce about 10 gallons of sap a season, and roughly 40 gallons of sap creates 1 gallon of syrup ${ }^{121}$. The sugar content of the sap varies though and can affect the amount of syrup produced ${ }^{122}$. Once the sap is collected it can be stored for a limited amount of time before evaporation, as the mixture allows easy bacteria growth ${ }^{123}$.

The evaporation process involves boiling down the sap over a fire until the syrup remains, thus producing large amounts of steam

118 History of the Ojibwa of the Curve Lake Reserve and Surrounding Area Volume II: Social and Cultural History. Curve Lake Indian Band \#35, 1976, pp.46-47

119 Corbiere, Alan. "Ninaatigwaaboo (Maple Tree Water): An Anishinaabe History of Maple Sugaring." GRASAC, Carleton University, 28 July 2015, carleton.ca/grasac/story/maple-exhibit/.

120 "How Maple Syrup Is Made." Pure Canadian Maple Syrup RSS, www.puremaplefromcanada.com/pure-maple-syrup/how-maple-syrup-is-made/.

121 "How Much Sap Does a Maple Tree Produce, and How Long Is the..." Old Farmer's Almanac, www.almanac.com/fact/how-much-sap-does-a-maple-tree\#.

122 "Maple Syrup Production for the Beginner." Penn State Extension, College of Agricultural Sciences of Pennsylvania State University, 17 Mar. 2019, extension.psu.edu/maple-syrup-production-for-the-beginner.

123 lbid. 
as the water is boiled off. The syrup is then filtered of any debris and stored in airtight containers indefinitely ${ }^{124}$. Before the use of metal pots, the Anishnaabe boiled down the sap using only bark and heated stones ${ }^{125}$.

There is also the option to continue to reduce the syrup down to sugar, producing maple sugar.

Site:

The site, Fox Island, was chosen for Maple syrup harvesting based on access to large areas of forest, and therefore maple trees. The inclusion of Fox Island for facilitating such activities as maple syrup and wild rice harvesting creates a stronger physical connection to the site than that which currently exists.

The Architecture:

- Highlight the trees and the land

- Extend upwards to highlight sky = smoke

- Highlight Smells

- Visual connection/orientation to wild rice post

- Building becomes hidden behind the trees as Maple Syrup season ends

124 Ibid.

125 Corbiere, Alan. “Ninaatigwaaboo (Maple Tree Water): An Anishinaabe History of Maple Sugaring." GRASAC, Carleton University, 28 July 2015, carleton.ca/grasac/story/maple-exhibit/. 


\section{the absorbed water ... is collected as maple sap}

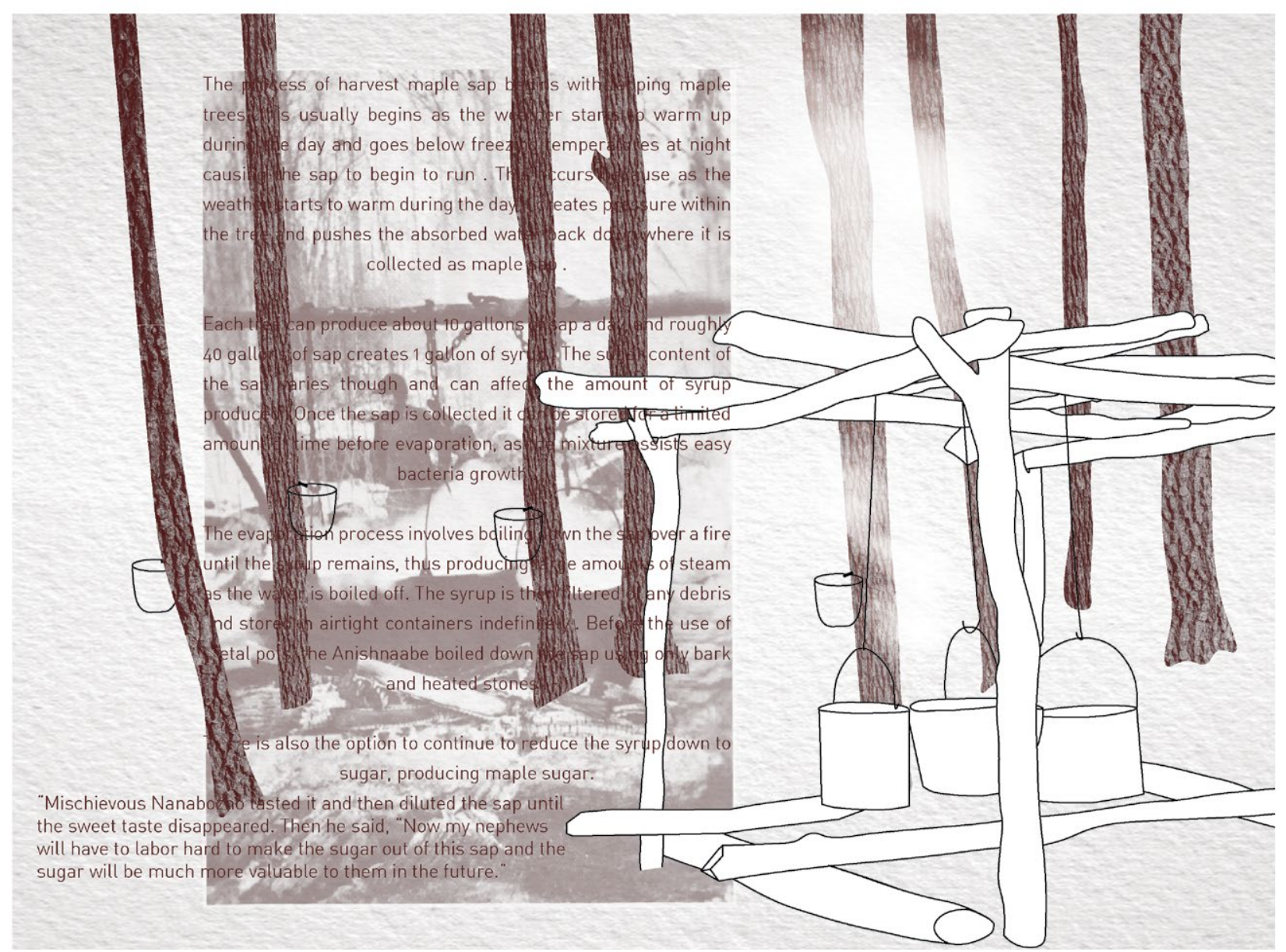

Figure 42: Representation of Maple Syrup Harvesting Land Marker 


\subsection{Ice Fishing / Fishing}

"Well - we used to fish through the ice, snow blowing, we just had little cedar boughs for shelter." 126

"This is the fishing season. Our lakes are famous for masquinonge, salmon-trout, whitefish, black bass, and many others. We often see the lighted canoes of the fishermen pass and repass of a dark night before our door." 127

Program Requirements:

- Boat Docking

- Storage for tools /canoes

- Ice fishing Huts with sleighs for transporting

- Area to clean fish

- Smoke house

- Kitchen for preparation of fish

Site:

The site chosen for fishing and ice fishing is based on current connections to the proposed site, Lance Wood Park has been used for fishing and boat launching for many years. Thus holding an existing importance to the community and the activity of fishing.

The Architecture:

- Connection to Water

- Adapt to changing conditions - water to ice

- Moving Parts - Ice Fishing Huts

126 History of the Ojibwa of the Curve Lake Reserve and Surrounding Area Volume II: Social and Cultural History. Curve Lake Indian Band \#35, 1976.pp. 34 127 Ibid. pp. 32 
"we often see the lighted canoes of the fishermen pass..."

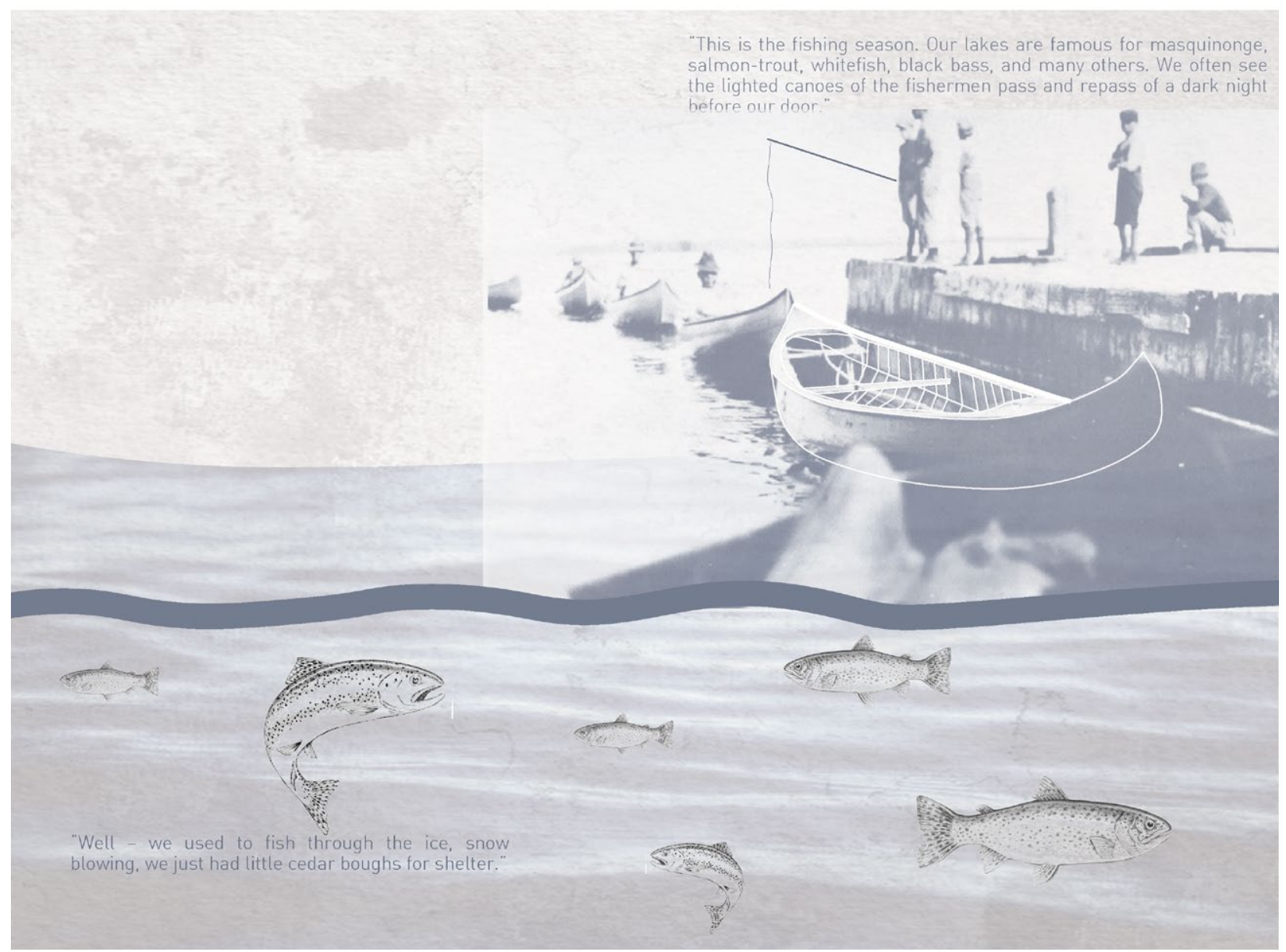

Figure 43: Representation of Fishing Land Marker 


\subsection{Hunting}

"My father had a trap line. He did lots of trapping, lots of fishing and everything in the hunting line. I went out with my father when I was young. He showed me how to hold a bamboo pole - fishing. We caught muskrat and mink, fox and the likes of that. Otter, beaver we trapped them out in the marsh... We caught most of the meat we ate. Deer and rats and the likes of that, fish, porcupines, groundhogs, everything like that. We would live on anything we could get hold of." 128

Program Requirements:

- Storage for equipment for hunting

- Drying Hide area

- Meat storage

- Kitchen to prepare meat

- Smoke house

- Cleaning area outside

Site:

The Site chosen for post hunting activities is located in the Northern section of the Community, for easy access from the main road into Curve Lake First Nation. Hunting would occur off the Reserve, as there are limited options for hunting on the small peninsula and therefore it would be ideal if the land-marker for hunting was accessed easily as one is first entering the community.

The Architecture:

- As hunting occurs year around, the land-based marker is geared towards the post handling of wild game

128 History of the Ojibwa of the Curve Lake Reserve and Surrounding Area Volume II: Social and Cultural History. Curve Lake Indian Band \#35, 1976, pp.32 


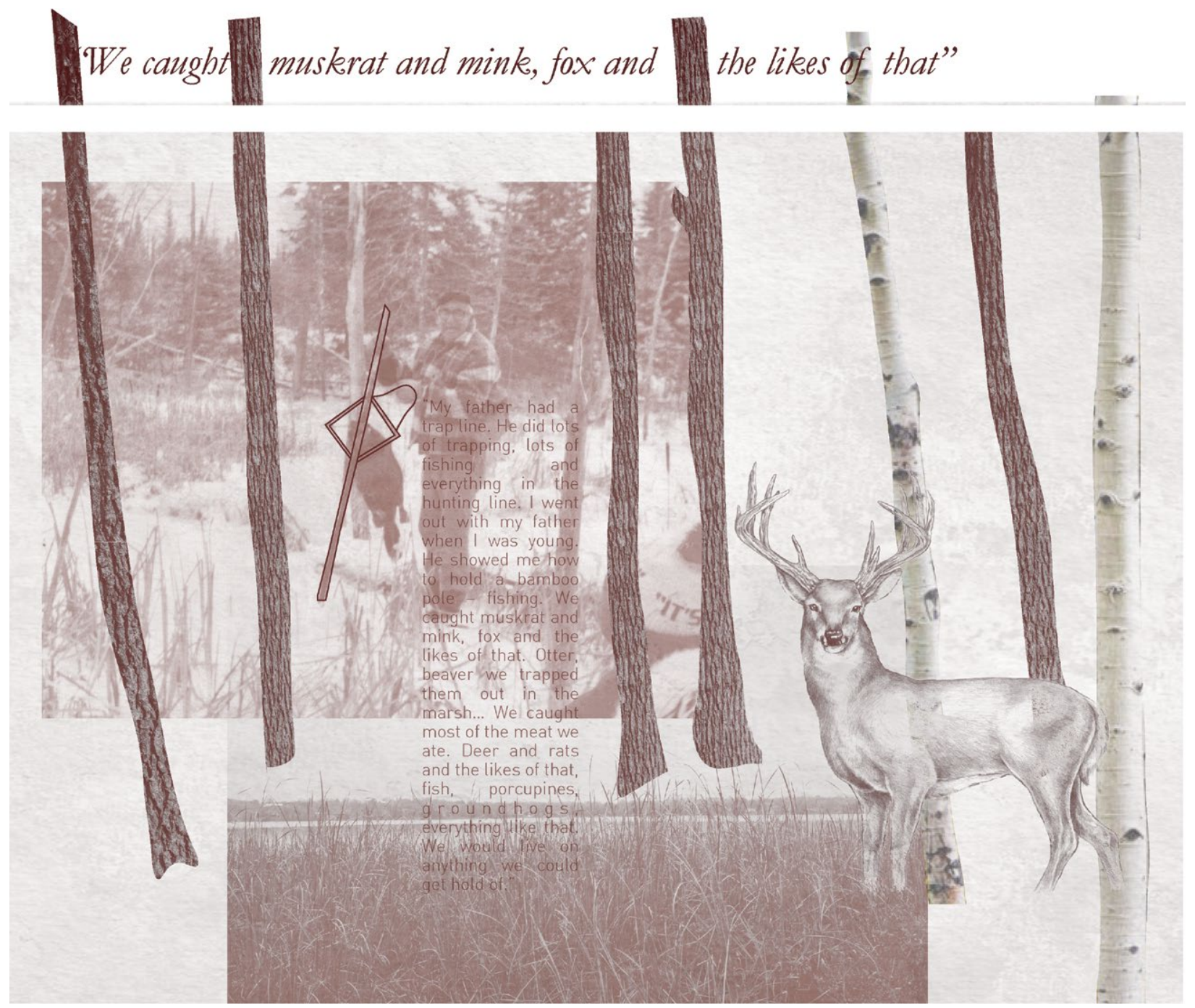

Figure 44: Representation of Hunting Land-Marker 


\subsection{Crafts}

"Nothing is done to the bark first. It is straight off the tree, and you have to dry it. If you just roll it up as you get it off the tree, it would be dark black. It won't be nice like this, you have to leave it out in the sun as you are pulling it off the trees. You stick your knife in and cut down, and all the bark will come off as far as you cut it. Then just put it to one side to dry. "2 29

Program Requirements:

- Material Storage

- Outdoor Work area

- Activities:

- Canoe building

- Cleaning area for Hide and Quills

- Indoor Work area

- Activities

- Quill work

- Beading

- Quilting

- Basket Making

- Drum Making

- Clothing

Site:

Henry's Gamiing was the site chosen for the production of crafts and was based on access to traditional materials such as reeds, which are abundant in that particular area due to the wetlands. The site also holds importance within the community for recreational purposes, making it a point of gathering ideal for the celebration of crafting, a shared activity that happens year around.

The Architecture:

- Connection to water and land

- Amongst the reeds

- Inside - outside blurred

- Community visibility

129 History of the Ojibwa of the Curve Lake Reserve and Surrounding Area Volume II: Social and Cultural History. Curve Lake Indian Band \#35, 1976, pp.93-94 


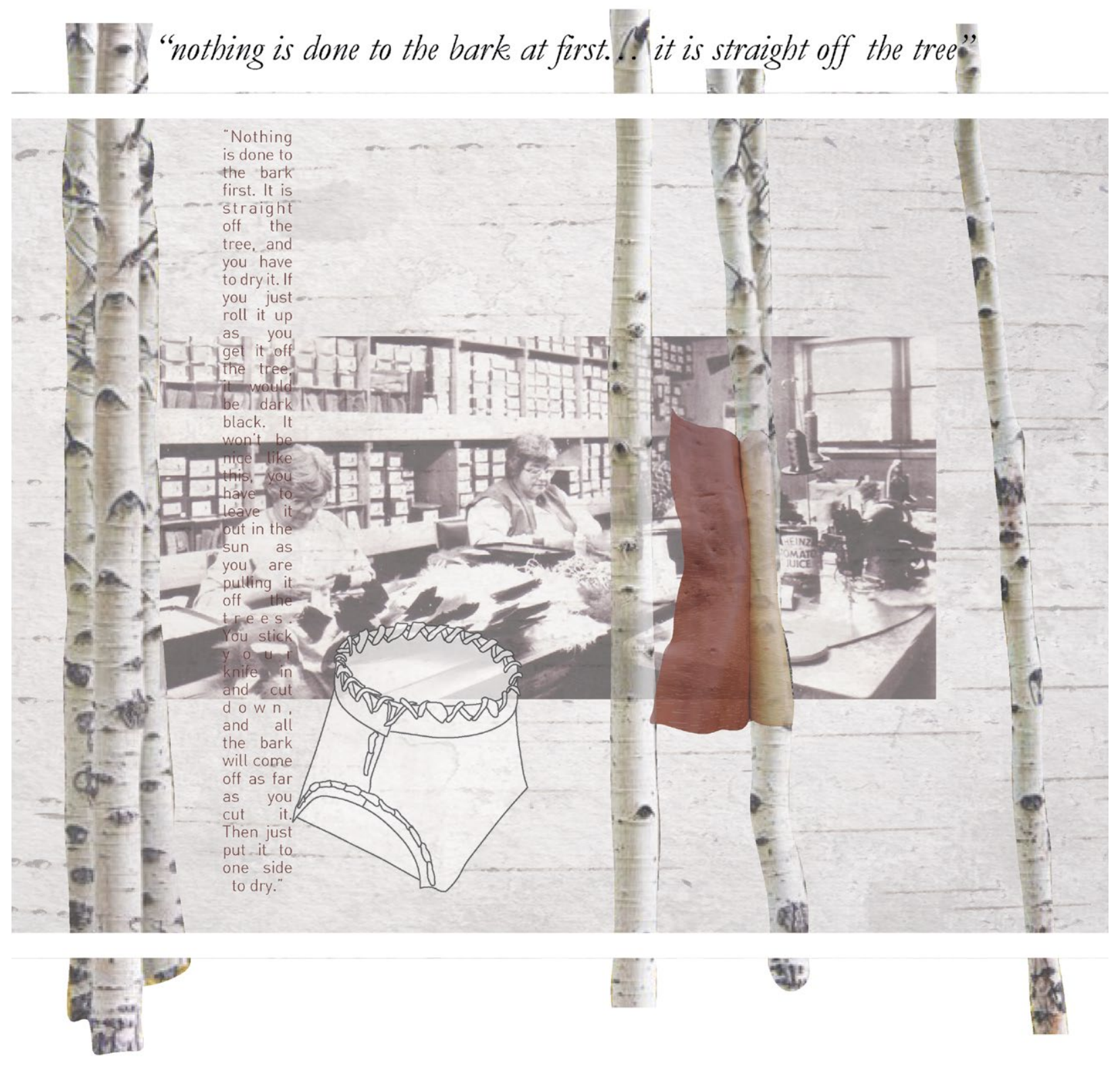

Figure 45: Representation of Crafts Land-Marker 


\subsection{Medicine Garden}

"It grows in with the other grass. It mixes right in there. You can tell the Sweetgrass. It shines, and you can smell it too. You pick it before it is ripe. June is the best time... Some dry it in the sun, but I just hang it up /roots to the top, in small bunches, about an inch or two across)." 130

"Our elders, the Nishnaabeg from the mist of time, would say a garden is more primal than humans themselves. They would point out that the first garden occurred at the time of creation and the earth itself, call the Great Mother, is our garden put on this Earth Plain for us to use." 131

Program Requirements:

- Drying Area outdoors

- Drying Area indoors

- Greenhouse for seedlings

- Storage

- Outdoor garden space

Process of Medicine Gathering

\begin{tabular}{|c|c|c|c|c|c|}
\hline Medicine & Sun & Soil & Plant & Harvest & How to Dry \\
\hline $\begin{array}{c}\text { Sage } \\
\text { (Perennial) }\end{array}$ & $\begin{array}{c}\text { Sun to } \\
\text { partial } \\
\text { shade } \\
\text { rich, well- } \\
\text { draining }\end{array}$ & N/A & $\begin{array}{c}\text { Tie cuttings } \\
\text { in small } \\
\text { to reach } \\
\text { maturity }\end{array}$ & $\begin{array}{c}\text { bunches and } \\
\text { hang upside } \\
\text { down in well } \\
\text { ventilated } \\
\text { room }\end{array}$ \\
\hline $\begin{array}{c}\text { Sweetgrass } \\
\text { (Perennial) }\end{array}$ & Full & Sich, Moist & $\begin{array}{c}5 \text {-6 weeks } \\
\text { before last } \\
\text { frost }\end{array}$ & $\begin{array}{c}\text { Late June } \\
\text { to Early } \\
\text { July }\end{array}$ & $\begin{array}{c}\text { Lay it in the } \\
\text { sun for 3 } \\
\text { days }\end{array}$ \\
\hline
\end{tabular}

130 History of the Ojibwa of the Curve Lake Reserve and Surrounding Area Volume III: Recreation and Arts. Curve Lake Indian Band \#35, 1976, pp.90

131 Williams, Doug. Michi Saagiig Nishnaabeg: This Is Our Territory. ARP Books, 2018, pp. 96 


\begin{tabular}{|c|c|c|c|c|c|}
\hline $\begin{array}{c}\text { Tobacco } \\
\text { (Perennial/ } \\
\text { but grown as } \\
\text { annual) }\end{array}$ & $\begin{array}{l}\text { Full } \\
\text { Sun }\end{array}$ & $\begin{array}{c}\text { Rich, Moist } \\
\text { Soil }\end{array}$ & $\begin{array}{l}\text { Spring: } \\
\text { when } \\
\text { thunders } \\
\text { arrive }\end{array}$ & $\begin{array}{c}\text { 5-7 weeks } \\
\text { after } \\
\text { flowering }\end{array}$ & $\begin{array}{c}\text { Hang } \\
\text { in well- } \\
\text { ventilated } \\
\text { area (dry } \\
\text { and warm). } \\
\text { No direct } \\
\text { sunlight. } \\
\text { Allow drying } \\
\text { for several } \\
\text { days or } \\
\text { weeks }\end{array}$ \\
\hline
\end{tabular}

Site:

The site chosen for the growth of traditional medicines such as Sweetgrass, Tobacco, and Sage is located on the western side of Curve Lake First Nation, facing towards Fox island. The site is the original location of the Curve Lake Pow Wow, and is positioned behind the Day care and Band Office, which allows the program to be integrated into the Day Care program where many of the children attend during the summer months between school years. This area is also receives optimal daylighting, which is necessary as the plants proposed for growth require full sun.

The Architecture:

- Connection to water and land

- Inside - outside blurred

- Visibility to Community

- Optimize orientation for sun 


\section{"the earth ... the Great mother, is our garden"}

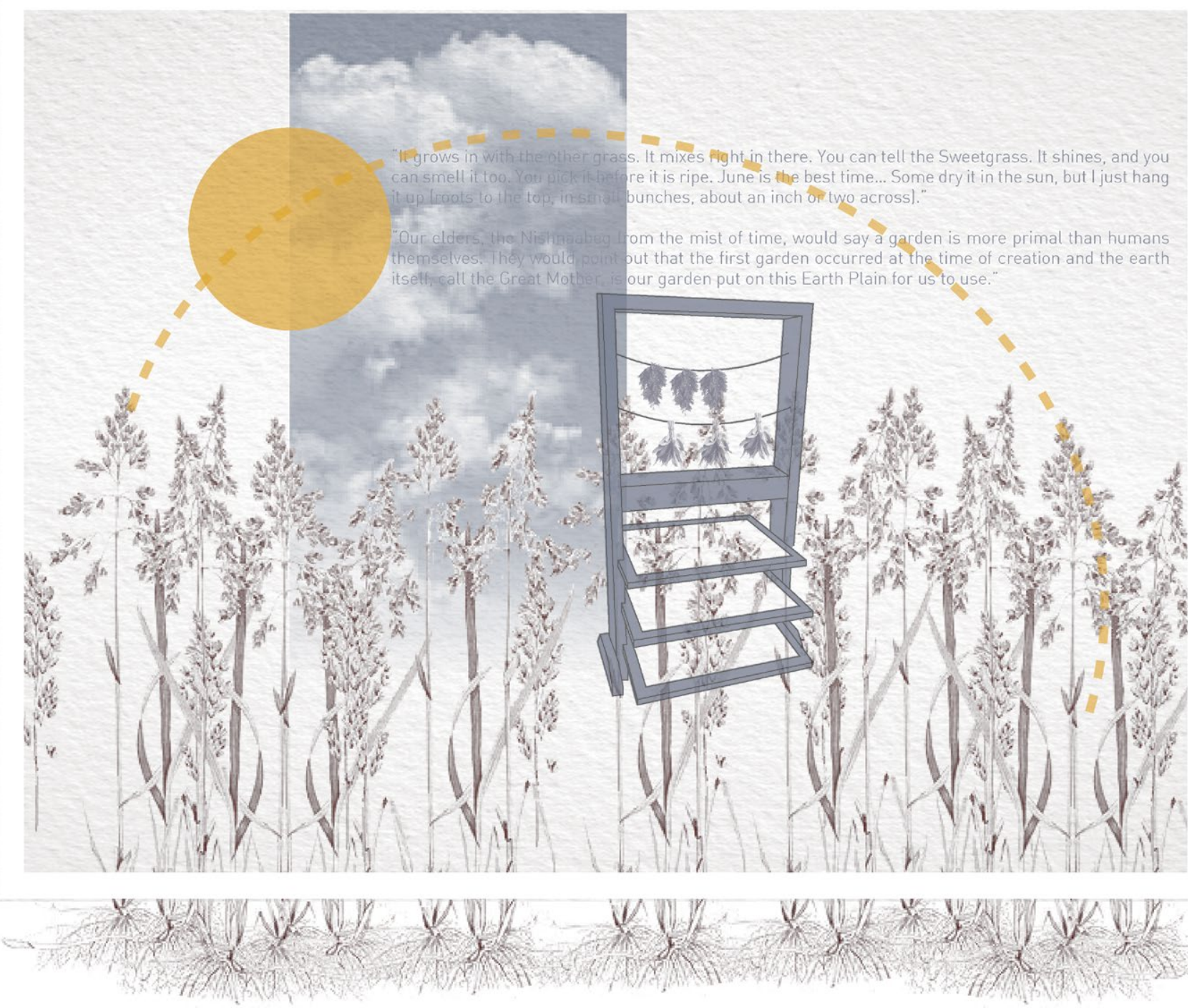

Figure 46: Representation of Medicine Garden Land-Marker 


\section{Conclusion:}

This design undertaken in Drowned Landscape is an exploration of architectural design that connects to the land and place of the Michi Saagiig Nishnaabeg, creating an architecture that speaks to the people of the place and their culture. As Indigenous communities across Canada strive to overcome generations of adversities, they have remained resilient, fighting to strengthen the connection to their culture and to keep traditions thriving. The core motivation of this thesis has been to inspire cultural sustainability and to encourage the longevity of the Michi Saagiig community of Curve Lake First Nation by developing the design of programs vital to growth and continuance.

The architectural design proposed within Drowned Landscape sought to enhance the connection that indigenous people have with their traditional lands, specifically within the community of Curve Lake First Nation. By straddling the drowned landscape of Curve Lake First Nation, the architecture physically reclaims lost territory and embeds the everyday movements of the people within the landscape. Through the facilitation of traditional land based teachings, the design intangibly tethers the users to their culture, their community, and the future generations - ensuring cultural longevity.

As Indigenous architecture and its social contribution becomes more prevalent within Canada, it provides an opportunity for Indigenous communities to give voice to how their identity is represented in the built environment. No longer should the built environment within 
Indigenous communities be developed without the active inclusion of its members. To overcome the inability to include community consultation within the design process for this thesis, research was purposely limited to include mainly writings and publications stemming from Indigenous authors whenever possible. A majority of the inspiration for exploration of a design for the community came from books written from within the CLFN community.

It was critical that the design proposed during this exploration be connected to not only the site and community in its current state, but that it also looked to the past and towards the future, following the Seven Generations methodology. The architectural design then responds to the history of the site, both cultural and physical, articulating the community's perseverance for future generations.

As evidenced through research, education is an essential component to cultural continuance. By engaging a cross-generational population, the project encourages storytelling, skill sharing and community building through a sense of connection to place. Thus allowing the building to tell its own story as it creates a network of connections between various programs, people, and environmental conditions. By designing structures, which respond to the land and environmental changes, the building becomes a barometer of the natural landscape.

Moving forward with this proposed design, I would explore the possibility of consultation with community members on how the project could develop further, so as to ensure the architecture not only met the needs of the community but also represents their identity. Given the opportunity to further explore architectural solutions that address the issues outlined in the Master Plan proposed by Curve Lake, I feel we could develop new ideas, which are more culturally relevant than those that were originally proposed. Especially given that I would be presenting another solution exploring how the issues outlined could be alternatively solved. As discussed in chapter 1 , the Master Plan originally proposed was a standard solution with no cultural significance, and I believe with further consultation a communal solution could be reached for the community. 
As environmental concerns are so important within the Indigenous culture, the design strived to include sustainable elements that practiced the respect for the land that is so prevalent in the culture. So, another concern with moving forward would be a more developed plan on how to include more passive features in a significant way.

The design explores an architecture that tangibly and intangibly connects the people of Curve Lake First Nation to one another and to their cultural practices. Encouraging a resiliency and well being among the Indigenous community. 


\section{References}

About Us." Curve Lake First Nation School, www.

curvelakefirstnation.ca/about-us/.

“Aboriginal Peoples in Canada: First Nations People, Métis and Inuit." Statistics Canada: Canada's National Statistical Agency /

Statistique Canada : Organisme Statistique National Du Canada, 25

July 2018, www12.statcan.gc.ca/nhs-enm/2011/as-sa/99-011-x/99-

011-x2011001-eng.cfm.

"An Introduction to Slow Sand Filtration." Solutions for Water, Dec.

2005, www.solutionsforwater.org/wp-content/uploads/2011/12/

Slow-Sand-Filtration-Introduction-7-MB-16-Dec-2011.pdf.

Angus, J. A Respectable Ditch: a History of the Trent-Severn

Waterway 1833-1920. McGill-Queens University Press, 2014.

“Bands." Indigenous Foundations, The University of British

Columbia, 2009, indigenousfoundations.arts.ubc.ca/bands/.

Banks, Tammy. "Curve Lake First Nation Capital Investment

Requirements." 19 Dec. 2011.

Battiste, M. “Indigenous Knowledge and Education: Site

of Struggle, Strength, and Survivance." The Struggle and

Renaissance of Indigenous Knowledge in Eurocentric Education,

Harvard Education Review., 2008, p. 87. 
Battiste, Marie. "Indigenous Knowledge and Pedagogy in First Nations Education: a Literature Review with Recommendations." Indigenous Knowledge and Pedagogy in First Nations Education: a Literature Review with Recommendations, National Working Group on Education, 2002.

Battiste, Marie. "The Struggle and Renaissance of Indigenous Knowledge in Eurocentric Education." Indigenous Knowledge and Education: Site of Struggle, Strength, and Survivance, Harvard Education Review, 2008

“Canada's Historic Treaties, Contemporary Agreements (Made after 1973l and Locations of Canada's Existing First Nations Communities." Canada by Treaty: Negotiating Histories, University Of Toronto, 2017

"Canada, Ontario and Williams Treaties First Nations Reach Negotiated Settlement Agreement for Alderville Litigation." Government of Canada, Canadian Environmental Assessment Agency, Northern Affairs Canada, 14 Sept. 2018, www.canada.ca/ en/crown-indigenous-relations-northern-affairs/news/2018/09/ canada-ontario-and-williams-treaties-first-nations-reachnegotiated-settlement-agreement-for-alderville-litigation.html.

Cardinal, Douglas. "Chapter 9: Cultural Identity and Architecture." Our Voices: Indigeneity and Architecture, ORO Editions, 2018, pp. 94-97.

Corbiere, Alan. “Ninaatigwaaboo (Maple Tree Water): An Anishinaabe History of Maple Sugaring." GRASAC, Carleton University, 28 July 2015, carleton.ca/grasac/story/maple-exhibit/.

“Curve Lake First Nation Land Tenure 2009." The Curve Lake Comprehensive Plan, Curve Lake First Nation, 2009, p. 19.

"Delivering on Truth and Reconciliation Commission Calls to Action." Government of Canada; Indigenous and Northern Affairs Canada, Government of Canada, 25 Oct. 2018, www.aadnc-aandc. 
gc.ca/eng/1524494530110/1524494579700.

Eagle Bull, Tammy. "Chapter 19: Designing to Express Community Values: A Community School in South Dakota." Our Voices:

Indigeneity and Architecture, ORO Editions, 2018,

“Economic Development Strategy: Curve Lake First Nation.” MNP: Consulting and Advisory Services, 2015.

"Elders." Deepening of Knowledge, University of Toronto, Apr. 26, 2018, www.oise.utoronto.ca/deepeningknowledge/Teacher_ Resources/Curriculum_Resources_(by_subjects)/Social_Sciences_ and_Humanities/Elders.html.

Faithful + Gould. "Curve Lake First Nation New Water Treatment Plant and Water Supply Project." 20 Jan. 2017.

Hare, Jan. "'They Tell a Story and Theres Meaning behind That Story': Indigenous Knowledge and Young Indigenous Childrens Literacy Learning." Journal of Early Childhood Literacy, vol. 12, no. 4, 2011, pp. 389-414., doi:10.1177/1468798411417378.

Hare, Jan. "To 'Know Papers': Aboriginal Perspectives on Literacy." Portraits of Literacy Across Families, Communities, and Schools: Intersections and Tensions, Routledge, 2005.

History of the Ojibwa of the Curve Lake Reserve and Surrounding Area Volume I: History of the Mississauga Band (Curve Lake). Curve Lake Indian Band \#35, 1976.

History of the Ojibwa of the Curve Lake Reserve and Surrounding Area Volume II: Social and Cultural History. Curve Lake Indian Band \#35, 1976.

History of the Ojibwa of the Curve Lake Reserve and Surrounding Area Volume III: Recreation and Arts. Curve Lake Indian Band \#35. 1976 
“How Maple Syrup Is Made." Pure Canadian Maple Syrup RSS, www.puremaplefromcanada.com/pure-maple-syrup/how-maplesyrup-is-made/.

“How Much Sap Does a Maple Tree Produce, and How Long Is the..." Old Farmer's Almanac, www.almanac.com/fact/how-muchsap-does-a-maple-tree\#.

Indian Community School, Antoine Predock Architects, www. predock.com/ICS/ics.html.

"Indian Status." Indigenous Foundations, The University of British Columbia, 2009, indigenousfoundations.arts.ubc.ca/bands/.

Jojola, Ted. “Indigenous Planning: Towards a Seven Generation Model." Reclaiming Indigenous Planning, McGill-Queens University Press, 2013

Kiddle, Rebecca, et al. Our Voices: Indigeneity and Architecture. ORO Editions, 2018.

Kovach, Joelle. “Cleaner Water Getting Closer for Curve Lake First Nation after Making Federal List." The Peterborough Examiner, 27 Jan. 2018, www.thepeterboroughexaminer.com/newsstory/8175152-cleaner-water-getting-closer-for-curve-lake-firstnation-after-making-federal-list/.

Malnar, Joy Monice., and Frank Vodvarka. New Architecture on Indigenous Lands. University of Minnesota, 2013.

"Maple Syrup Production for the Beginner." Penn State Extension, College of Agricultural Sciences of Pennsylvania State University, 17 Mar. 2019, extension.psu.edu/maple-syrup-production-for-thebeginner.

Natcher, David C., et al. Reclaiming Indigenous Planning. McGillQueens University Press, 2013. 
"Native American Facts for Kids." Anishinabe Indian Fact Sheet, 2015. www.bigorrin.org/anishinabe_kids.htm.

Parrott, Zach. “Indigenous Peoples in Canada”. The Canadian Encyclopedia, 07 September 2018, Historica Canada. https:// www.thecanadianencyclopedia.ca/en/article/aboriginal-people. Accessed 28 December 2018.

Peterson, Stagg. "Infusing Indigenous Knowledge And Epistemologies: Learning From Teachers In Northern Aboriginal Head Start Classrooms." McGill Journal of Education, vol. 53, no. 1, 2018, mje.mcgill.ca/article/view/9506/7326.

“Rental Applications - Housing Department." Curve Lake First Nation, www.curvelakefirstnation.ca/2018/07/03/rentalapplications-housing-department/.

"Reserves." Indigenous Foundations, The University of British Columbia, 2009, indigenousfoundations.arts.ubc.ca/bands/.

Restoule, Jean-Paul and Chaw-win-is. "Old ways are the new way forward: How Indigenous pedagogy can benefit everyone", the Canadian Commission for UNESCO's IdeaLab, Oct. 2017

Styres, Sandra D. "Land as First Teacher: a Philosophical Journeying." Reflective Practice, vol. 12, no. 6, 2011, pp. 717-731., doi :10.1080/14623943.2011.601083.

Switzer, Maurice. "Williams Treaty Crown Concedes Some Hunting Rights." Anishinabek News, Dec. 2012, anishinabeknews.ca/wpcontent/uploads/2013/04/2012-12.pdf.

Toulouse, Pamela. "What Matters in Indigenous Education: Implementing a Vision Committed to Holism, Diversity and Engagement." What Matters in Indigenous Education: Implementing a Vision Committed to Holism, Diversity and Engagement, People for Education, Mar. 2016, peopleforeducation. $\mathrm{ca} /$ report/what-matters-in-indigenous-education/. 
“Trent-Severn Waterway." The Canadian Encyclopedia, www. thecanadianencyclopedia.ca/en/article/trent-severn-waterway.

"Truth and Reconciliation Commission of Canada." Government of Canada; Indigenous and Northern Affairs Canada, Northern Affairs Canada, 19 Feb. 2019, www.rcaanc-cirnac.gc.ca/eng/1450124405592 $/ 1529106060525$.

“Upper Canada Land Surrenders and the Williams Treaties (1764-1862/1923)." Government of Canada; Indigenous and Northern Affairs Canada, 15 Feb. 2013, www.rcaanc-cirnac.gc.ca/ eng/1360941656761/1544619778887\#uc.

Wexler, Lisa. "The Importance of Identity, History, and Culture in the Wellbeing of Indigenous Youth." The Journal of the History of Childhood and Youth, vol. 2, no. 2, 2009, pp. 267-276., doi:10.1353/ hcy.0.0055.

"Wild Rice - the Harvesting, Processing and Cooking of This Ojibwa Food." Canadian Native Art - a Cultural Perspective by an Ojibwa Artist, www.native-art-in-canada.com/wildrice.html.

Williams, Doug. Michi Saagiig Nishnaabeg: This Is Our Territory. ARP Books, 2018. 


\section{Appendix A: Population Demographics}

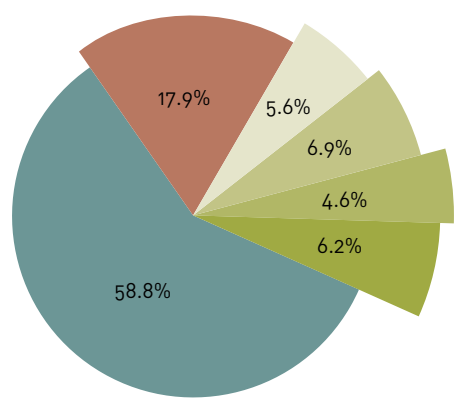

$$
\begin{aligned}
& \text { AGE GROUPS OF } \\
& \text { CURVE LAKE FIRST NATION } \\
& \text { On Reserve Population: 1,368 } \\
& \text { Age 0-4 } \\
& \text { Age 5-9 } \\
& \text { Age 10-14 } \\
& \text { Age 15-19 } \\
& \text { Age 20-64 } \\
& \text { Age 65-99 }
\end{aligned}
$$
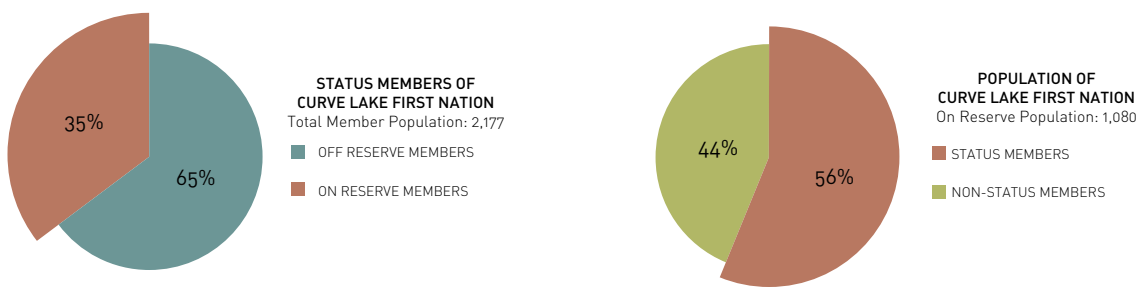